\title{
Why Invest in Emerging Markets? The Role of Conditional Return Asymmetry
}

\section{Eric Ghysels}

$\mathrm{UNC}$ and $\mathrm{CEPR}^{*}$
Alberto Plazzi

University of Lugano and SFI ${ }^{\dagger}$
Rossen Valkanov

$\mathrm{UCSD}^{\ddagger}$

\begin{abstract}
We propose a quantile-based measure of conditional asymmetry. We find that the asymmetry of international stock market returns varies significantly across countries, over time, and persists at long horizons. The asymmetry of emerging stock returns is positive and does not co-move with that of developed markets. In an international portfolio setting, conditioning on return asymmetry leads to sizeable certainty equivalent gains relative to the value-weighted benchmark. It also increases the weight on emerging indices from $9 \%$ to between $25 \%$ and $40 \%$. Investing in emerging markets seems to be about expectations of a higher upside than downside, consistent with recent theories.
\end{abstract}

JEL classification: G11, G15, C22

Keywords: return asymmetry, international equity markets, portfolio allocation, skewness

\footnotetext{
*Department of Finance, Kenan-Flagler Business School and Department of Economics, UNC, Gardner Hall CB 3305, Chapel Hill, NC 27599-3305, phone: (919) 966-5325, e-mail: eghysels@unc.edu.

${ }^{\dagger}$ Institute of Finance, USI, Via Buffi 13 Lugano, 6900, Switzerland, email: alberto.plazzi@usi.ch.

${ }^{\ddagger}$ Rady School of Management, Otterson Hall, 9500 Gilman Drive, La Jolla, CA 92093, phone: (858) 534-0898, e-mail: rvalkanov@ucsd.edu.

Some parts of this paper are similar to a now defunct manuscript, titled "Conditional Skewness of Stock Market Returns in Developed and Emerging Markets and its Economic Fundamentals". We thank Geert Bekaert, Robert Engle, René Garcia, Peter Hansen, Roger Koenker, Jun Liu, Eric Renault, Allan Timmermann, and Hal White for useful discussions. We have also benefitted from comments at the European Finance Association, NYU Volatility Institute, Saint Louis Federal Reserve Bank and Society for Financial Econometrics (SoFiE) conferences and seminars at the European Central Bank, University of Brussels, University of Houston, University of Lausanne, University of Luxembourg, and the University of Zurich. The authors gratefully acknowledge financial support from Inquire Europe. First draft: November 2010. All remaining errors are our own.
} 


\section{Introduction}

Emerging stock markets have grown significantly, in volume and in numbers, over the last twenty years. The Datastream database now lists 48 emerging stock market indices, in addition to the 25 developed ones. Now more than ever, investors seeking diversification are able to invest with relative ease in emerging economies. ${ }^{1}$ However, a larger number of liquid stock markets does not, in and of itself, implies that the prospects of international diversification have improved. The opposite seems to be true, in fact, if we consider the return correlation between emerging and developed markets: it has steadily increased over the years. ${ }^{2}$ Paradoxically, while interest and liquidity in emerging stock markets is peaking, the prospects of international diversification are waning. The question then arises whether reasons beyond diversification can justify investing in emerging economies?

In this paper, we ask whether it is profitable to invest in emerging stock markets in the quest for skewness. More specifically, we investigate the economic gains from exploiting asymmetries in the distribution of returns across international markets. In a broader context, is an investment in emerging economies, such as China or Kenya, as much about the prospect of larger gains than losses as it is about diversification? ${ }^{3}$ Skewness has a long history in finance. Early contributions focused on the co-skewness of returns with the market portfolio. ${ }^{4}$ More recent studies show that, in the U.S. stock market, the own skewness of returns (rather than the co-skewness) plays an important role in asset allocation. ${ }^{5}$ These empirical papers are motivated by novel theoretical work arguing that investors are willing to trade-off diversification benefits for skewness. ${ }^{6}$ However, the role of skewness in a cross-section of international markets has largely been unexplored.

\footnotetext{
${ }^{1}$ While not all these indices represent truly investable opportunities, the market capitalization and liquidity of many emerging stock markets exhibit an upward trend in absolute terms as well as relative to developed markets. For instance, at the end of 2011, the market capitalization of the BRIC countries (Brazil, Russia, India, and China) stood at an impressive $\$ 6.6$ trillion. As a comparison, the market capitalization of the four largest stock markets in developed economies-the U.S., Japan, the UK, and Hong Kong-were valued at approximated $\$ 24.7$ trillion.

${ }^{2}$ See, for instance Harvey (1995), Fama and French (1998), Henry (2000), Engle and Rangel (2008), Christoffersen, Errunza, Jacobs, and Jin (2012) among many others. This fact has often been explained by the increase in international market integration.

${ }^{3}$ Professional money managers often tout the large upside in emerging markets. For instance, a 2013 Blackrock document reports: "For investors who want to develop their portfolios, the developing world is an unmatched source of potential."

${ }^{4}$ Rubinstein (1973), Kraus and Litzenberger (1976), and Kraus and Litzenberger (1983).

${ }^{5}$ For instance, Chen, Hong, and Stein (2001), Boyer, Mitton, and Vorkink (2010), Conrad, Dittmar, and Ghysels (2013).

${ }^{6}$ Papers in the literature include Hong and Stein (2003), Brunnermeier, Gollier, and Parker (2007), and Barberis and Huang (2008).
} 
The difficulties of exploiting skewness in international portfolio allocation are twofold. First, the third moment is hard to estimate (Kim and White (2004), Neuberger (2012)). It is particularly sensitive to outliers, more so than are the first two moments. In the context of U.S. stock returns, the literature has addressed this issue by turning to options as a way of obtaining more precise skewness estimates (DeMiguel, Plyakha, Uppal, and Vilkov (2013), Conrad, Dittmar, and Ghysels (2013), Neuberger (2012), Chang, Christoffersen, and Jacobs (2013)). In an international setting, this approach is not feasible as the option markets in most countries are illiquid or simply non-existent. An investigation of skewness from an international portfolio perspective requires robust skewness estimates that rely on the underlying asset returns data alone. Second, incorporating conditional skewness in a portfolio choice problem that involves a large cross-section of countries is a challenging endeavor (Guidolin and Timmermann (2008), Brandt (2010), Harvey, Liechty, Liechty, and Muller (2010)).

We offer two contributions. First, we propose a robust method for estimating conditional asymmetry using potentially noisy emerging market returns. Our approach does not rely on estimating the conditional third moment (e.g., Harvey and Siddique (1999)). Rather, we use an asymmetry measure based on conditional quantiles, which by definition are not sensitive to outliers. The emphasis on conditional (rather than unconditional) asymmetry is driven by the conjecture that changes in economic conditions, financial regulations, and political climates are likely to be associated with changes in return skewness, given the overwhelming evidence that they lead to variations in expected returns (see e.g. Bekaert and Harvey (1995)).

Second, we incorporate our asymmetry measure in the parametric portfolio weights framework of Brandt, Santa-Clara, and Valkanov (2009). This portfolio approach allows us to introduce asymmetry in tractable fashion without having to specify the joint distribution of returns, as is usually done in the international portfolio allocation literature (Jondeau and Rockinger (2006), Guidolin and Timmermann (2008), Christoffersen, Errunza, Jacobs, and Jin (2012)). The formulation of the problem also allows us to isolate the role conditional asymmetry plays in international asset allocation. More importantly, we are able to trace out the effect of emerging economies' skewness in the optimal portfolio. 
As a starting point in our analysis, we document significant heterogeneity in unconditional skewness across developed and even more so across emerging markets (henceforth denoted EM). Specifically, across the 25 developed stock markets, the standard momentbased skewness is always negative and, on average, -1.154 for monthly returns. Of the 48 emerging economies, a quarter has large positive skewness (e.g., China at 0.446) whereas several display significantly negative skewness (India, -0.317), and the average is -0.222 . The heterogeneity is apparent even if we drop the largest outliers from the data, or use a robust measure of unconditional asymmetry (see Bowley (1920) and Hinkley (1975)). Similar patterns are present in longer-horizon, quarterly returns.

Then, inspired by Bowley (1920), Hinkley (1975), and Kim and White (2004), we propose a robust statistic of conditional asymmetry based on whether the interval between conditional return quantiles $1-\theta$ and $\theta$ is centered at the conditional median. For instance, let's consider the interquartile range, or $\theta=0.75$. If at time $t-1$ the interquartile range is not centered at the median, then the return distribution is asymmetric. We denote our measure by $C A_{\theta, t-1}$ (for conditional asymmetry between quantiles $1-\theta$ and $\theta$ at time $t-1$ ) and emphasize the fact that this statistic is different from estimating the third moment of returns. The $C A_{\theta, t-1}$ statistic is normalized to lie between -1 and 1 . The conditional distribution is asymmetric when $C A_{\theta, t-1} \neq 0$ for some $\theta$. We also offer a version of this statistic that obtains by integrating over all quantiles $0<\theta<.5$. This integrated statistic, called $C A_{I N T, t-1}$, does not necessitate choosing a particular quantile and preserves all the nice properties of $C A_{\theta, t-1}$.

The $C A_{\theta, t-1}$ and $C A_{I N T, t-1}$ statistics have three features of practical importance. They are (i) robust to outliers; (ii) do not involve the use of options data; (iii) can be computed at various horizons. While we have addressed the importance of the first two points, item (iii) is equally important as we focus our portfolio analysis on monthly and quarterly (rather than daily) holding-period returns. The recent asset allocation literature has placed emphasis on long-term investing strategies (Viceira (2001), Campbell and Viceira (2002)). Re-balancing is costly in emerging markets and a portfolio strategy that relies on frequent trading is unlikely to yield good after-transaction-costs performance. Given the length of the emerging markets data, the quarterly horizon strikes a balance between re-balancing frequency and estimation error. Skewness in long-horizon returns is also interesting from an econometric 
perspective. Even in the presence of skewness at short horizons, its role should decrease as the horizon increases, due to the Central Limit Theorem. Engle and Mistry (2007) and Neuberger (2012) recently document that, for U.S. data, skewness persists at monthly, quarterly, and even longer horizons. Moreover, Boyer, Mitton, and Vorkink (2010) show that 5-year idiosyncratic skewness is related to expected returns in the cross-section of U.S. equity. Given the short time span of many emerging economies, we rely on a novel mixeddata sampling (MIDAS) approach for the modeling of conditional quantiles that exploits the richness of daily returns to form long-horizon conditional skewness forecasts.

We estimate $C A_{I N T, t-1}$ and $C A_{\theta, t-1}$ for all 73 countries at monthly and quarterly horizons. The $C A$ statistics exhibit significant variation over time. For instance, the quarterly $C A_{I N T, t-1}$ for the U.S. portfolio fluctuates between -0.436 and 0.002 whereas in the case of China it ranges between -0.253 and 0.426 . Perhaps more surprising is the fact that the estimated $C A$ measures show little co-movement across countries. We quantify this finding by looking at pairwise correlations and by extracting the first two principal components at each point in time. For instance, across emerging economies, only about $23 \%$ of the comovement in quarterly returns asymmetry is explained by the first principal component. As a comparison, if we conduct the same exercise for conditional volatility, the first principal component explains $46 \%$ of the co-movement of the quarterly return volatility across these countries. We also show that estimated $C A$ statistics are negatively correlated with country volatility, consistent with the "leverage effect" literature (e.g., Campbell and Hentschel (1992), Glosten, Jagannathan, and Runkle (1993)). Finally, in the U.S., conditional asymmetry is worse (more negative) during recessions. There is little relation, however, between non-U.S. return asymmetry and U.S. recessions.

The presence of significant heterogeneity in the conditional asymmetry measures across countries lead us to ask whether these features of the data can be used by investors to improve their international portfolio allocation. To do that, we incorporate the estimated cross-sectional and time-series return asymmetries in an international portfolio choice setting. We side-step the difficult problem of modeling the joint conditional distribution of returns by using Brandt, Santa-Clara, and Valkanov's (2009) approach of directly modeling the portfolio weights as parametric functions of asset characteristics. The leading characteristic in our 
context is the conditional asymmetry of a country, but we also control for other variables such as country volatility and co-skewness with the market portfolio. The weights are specified as deviations from a benchmark portfolio which, in our case, is the World value-weighted index. We estimate the weights at monthly or quarterly horizons across all 73 countries by maximizing the sample analogue of the expected utility of a CRRA investor.

In the data, it is optimal for an investor to tilt her portfolio toward countries that are favorably skewed - either positively skewed, or less negatively skewed than the average in that period. As emerging stock markets feature more positive return asymmetry, the optimal portfolio ends up being much more heavily invested in these economies. In the value-weighted portfolio, only about $9 \%$ of the average portfolio weight is in EM. By comparison, the average optimal portfolio weight in EMs is about $27 \%$ at quarterly and more than $40 \%$ at monthly horizons. The optimal weight in EM markets is negligible in the earlier parts of the sample, increases monotonically, and rises to more than $50 \%$ in the latter part of the sample. The in-sample certainty equivalent gains from using conditional asymmetry are between $3 \%$ and $10 \%$ annualized.

In the estimated weight functions, the coefficient on the conditional asymmetry is positive and significant at monthly and quarterly horizons. This result is consistent with Engle and Mistry (2007) and Neuberger (2012) who document that, in U.S. market returns, skewness does not converge to zero at these holding-period horizons. We extend this finding using very different measures of skewness and a large cross-section of stock market indices. However, the significant impact of return asymmetry on the international portfolio allocation decision of investors at various holding-period horizons is, to our knowledge, a novel finding. The mixed-data sampling approach is key to obtaining asymmetry results at various horizons by conditioning on the same information set.

The significant tilt toward EM countries is due to the conditional asymmetry measures rather than the other variables in the portfolio weight function. We see that by isolating the marginal impact of the conditional asymmetries on the optimal weights. The portfolio gains can be traced to the low degree of co-movement in return asymmetry that characterizes emerging economies. Conditioning on the $C A$ measures leads to the expected result, that is, an optimal portfolio whose return is positively skewed (between 0.5 and 0.8 depending on the 
horizon and specification) whereas the skewness of the value-weighted benchmark is -1 . It is also an indirect validation of the $C A$ statistic which, despite being a quantile-based measure of asymmetry, leads to an increase in the more standard realized moment-based measure of skewness. Moreover, the most significant portfolio gains obtain for asymmetry measures defined with respect to quantiles that are in the tail or put a weight on the tail of the distribution. Indeed, we find the largest portfolio gains for $C A_{0.95, t-1}$ and $C A_{I N T, t-1}$. All these findings suggest that exploiting fluctuations in the asymmetry in returns across developed and emerging markets might be an important reason, one that goes beyond diversification arguments, for investing in emerging economies.

The paper is structured as follows. In section 2, we discuss various unconditional measures of asymmetry in a large cross-section of country index returns. Section 3 introduces the conditional robust measures of asymmetry and outlines their estimation. We discuss the properties, co-movement, and correlation with volatility and U.S. business cycles of the estimated asymmetry series in Section 4. Section 5 presents the portfolio results. Section 6 concludes.

\section{Measuring Unconditional Asymmetry in Stock Re- turns}

We are interested to quantify the asymmetry in the (conditional) distribution of $n$-period returns. The log continuously compounded $n$-period return of an asset is defined as $r_{t, n}=$ $\sum_{j=0}^{n-1} r_{t+j}$ for $n \geq 2$, where $r_{t}$ is the one-period log return. In this paper, $r_{t}$ corresponds to daily returns as most international indices are available at that frequency. For simplicity, we assume that the unconditional cumulative distribution function (CDF) of $r_{t, n}$, denoted by $F_{n}(r)=P\left(r_{t, n}<r\right)$, and its conditional CDF given information set $I_{t-1}$, denoted by $F_{n, t \mid t-1}(r)=P\left(r_{t, n}<r \mid I_{t-1}\right)$, are strictly increasing. The unconditional first and second moments of $r_{t, n}$ are denoted by $\mu_{n}=E\left(r_{t, n}\right)$ and $\sigma_{n}^{2}=E\left(\left(r_{t, n}-\mu_{n}\right)^{2}\right)$ and their conditional analogues by $\mu_{t-1, n}=E\left(r_{t, n} \mid I_{t-1}\right)$ and $\sigma_{t-1, n}^{2}=E\left(\left(r_{t, n}-\mu_{t-1, n}\right)^{2} \mid I_{t-1}\right)$, respectively. For the one-period returns, we simplify the notation by dropping the $n$ subscript. 
In the empirical and portfolio analysis, we focus on monthly $(n=22)$ and quarterly $(n=66)$ returns rather than on daily returns for several reasons. A portfolio strategy that assumes daily re-balancing is clearly not realistic, given the higher transaction costs in international markets. Moreover, the recent asset allocation literature emphasizes longhorizon investing strategies (Viceira (2001), Campbell and Viceira (2002)). While monthly and quarterly returns do not truly capture a long term perspective, the quarterly horizon is the longest we can work with, given the length of the international series. Finally, from an empirical perspective, little is known about the skewness properties of long-horizon returns. In the presence of skewness at short horizons, the Central Limit Theorem (CLT) implies that skewness should disappear as the holding period horizon increases. Contrary to the CLT prediction, Engle and Mistry (2007) and Neuberger (2012) recently document that, for U.S. data, skewness persists at monthly, quarterly, and longer horizons. However, it is not clear whether their finding holds more generally in other equity markets, or what this finding implies for portfolio allocation.

\subsection{Moment-Based and Quantile-Based Measures}

By far, the most popular measure of asymmetry is the unconditional skewness, or the third normalized moment of returns, $S\left(r_{t, n}\right)=E\left(r_{t, n}-\mu_{n}\right)^{3} / \sigma_{n}^{3}$. Conditional models of skewness based on autoregressive conditional third moments have been proposed by Harvey and Siddique (1999) and León, Rubio, and Serna (2005). A natural estimate of skewness is obtained by replacing expectations with sample averages. However, it is well-known that skewness estimates based on sample averages are sensitive to outliers, even more so than are estimates of the first two moments, because all observations are raised to the third power. The excessive sensitivity of skewness estimates to outliers compels researchers to truncate outliers before estimating the skewness (e.g., Chen, Hong, and Stein (2001)).

This lack of robustness has prompted researchers since Pearson (1895), Bowley (1920), and more recently Hinkley (1975) to look for measures of asymmetry that are not based on sample estimates of the third moment. Hinkley's (1975) robust coefficient of asymmetry 
(skewness) is defined as:

$$
R A_{\theta}\left(r_{t, n}\right)=\frac{\left[q_{\theta}\left(r_{t, n}\right)-q_{0.50}\left(r_{t, n}\right)\right]-\left[q_{0.50}\left(r_{t, n}\right)-q_{1-\theta}\left(r_{t, n}\right)\right]}{q_{\theta}\left(r_{t, n}\right)-q_{1-\theta}\left(r_{t, n}\right)}
$$

where $q_{1-\theta}\left(r_{t, n}\right), q_{0.50}\left(r_{t, n}\right)$ and $q_{\theta}\left(r_{t, n}\right)$ are the $1-\theta, 0.50$, and $\theta$ unconditional quantiles of $r_{t, n}$, and quantile $\theta$ is defined as $q_{\theta}\left(r_{t, n}\right)=F_{n}^{-1}\left(r_{t, n}\right)$, for $\theta \in(0,1]{ }^{7}$ This skewness measure captures asymmetry of quantiles $q_{1-\theta}\left(r_{t, n}\right)$ and $q_{\theta}\left(r_{t, n}\right)$ with respect to the median, $q_{0.50}\left(r_{t, n}\right)$. In the specific case of $\theta=0.75$, we are considering the inter-quartile range and (1) is known as Bowley's (1920) statistic. An alternative statistic, one that does not depend on a particular $\theta$, can be constructed by integrating over $0<\theta<0.5$ (Groeneveld and Meeden (1984)):

$$
R A_{I N T}\left(r_{t, n}\right)=\frac{\int_{0}^{0.5}\left\{\left[q_{\theta}\left(r_{t, n}\right)-q_{0.50}\left(r_{t, n}\right)\right]-\left[q_{0.50}\left(r_{t, n}\right)-q_{1-\theta}\left(r_{t, n}\right)\right]\right\} d \theta}{\int_{0}^{0.5}\left\{q_{\theta}\left(r_{t, n}\right)-q_{1-\theta}\left(r_{t, n}\right)\right\} d \theta}
$$

The normalization in the denominator of (1) and (2) ensures that the $R A_{\theta}\left(r_{t, n}\right)$ and $R A_{I N T}\left(r_{t, n}\right)$ statistics are unit independent with values between -1 and 1 . When the statistics are equal to zero, the distribution is symmetric, while values diverging to -1 (1) indicate skewness to the left (right).

The $R A_{\theta}\left(r_{t, n}\right)$ and $R A_{I N T}\left(r_{t, n}\right)$ are, unlike the moment-based skewness statistic $S\left(r_{t, n}\right)$, robust to outliers. At a technical level, the quantile-based skewness measures do not presume the existence of moments. This is particularly important for emerging market data, which are known to have fat tails. To our knowledge, $R A_{\theta}\left(r_{t, n}\right), R A_{I N T}\left(r_{t, n}\right)$ and their generalizations (see below), have received very limited attention in the empirical finance literature, the few notable exceptions being Kim and White (2004) and White, Kim, and Manganelli (2008). The reason is undoubtedly due to the fact that we need to estimate quantiles, which is not always straightforward. Fortunately, quantile regression methods have greatly improved in the last thirty years following the path-breaking work of Koenker and Bassett (1978) and we draw on results from that literature.

\footnotetext{
${ }^{7}$ The inverse of $F_{n}\left(r_{t, n}\right)$ is unique, since we assumed that $F_{n}\left(r_{t, n}\right)$ is strictly increasing. If $F\left(r_{t, n}\right)$ is not strictly increasing, then we can define the quantile as $q_{\theta_{k}}^{*}\left(r_{t, n}\right) \equiv \inf \left\{r: F_{n}\left(r_{t, n}\right)=\theta_{k}\right\}$. The measure in equation (1) also satisfies all conditions that Groeneveld and Meeden (1984) postulate any reasonable skewness measure should satisfy. Another widely-used skewness measure, the Pearson coefficient of skewness, defined as $\left(\mu-q_{0.5}\left(r_{t, n}\right)\right) / \sigma_{n}$, does not satisfy these properties.
} 


\subsection{How and How Much to Robustify?}

There are several ways of constructing statistics that are robust to outliers. While there is no best way of accomplishing this, it is helpful to discuss the alternatives. As mentioned above, one alternative is to modify the traditional skewness $S\left(r_{t, n}\right)$ such that extreme returns are trimmed from the sample. This truncated statistic will be denoted by $S^{T}\left(r_{t, n}\right)$ and the trimming threshold will be specified. The truncation approach eliminates outliers and hence the sensitivity of moment-based estimators of skewness. It also involves deciding what trimming threshold to use. A similar issue arises with the choice of $\theta$ in the robust statistic (1). For instance, while the $R A_{\theta}\left(r_{t}\right)$ statistic has historically been defined for $\theta=0.75$ (Bowley (1920)), there is no good reason to rule out other points of the distribution $F_{n, t \mid t-1}(r)$. The $R A_{I N T}\left(r_{t}\right)$ statistic partially addresses this concern by integrating over $\theta$.

In a portfolio setting, it is reasonable to ask whether any truncation should be applied at all. By eliminating extreme return outcomes from the sample, we might be mis-measuring rather than robustifying the statistics of interest. This is a profound question that has been extensively debated in the literature. From an economic perspective, since events in the tails of $F_{n}(r)$ enter into investors' assessment of risk, they should not be neglected. There is a voluminous literature that aims at estimating extreme events through the modeling of jumps, extreme value theory or other approaches (for references see inter alia Pukthuanthong and Roll (2010)). In the international context, Pukthuanthong and Roll (2010) look at several such measures to identify jumps and understand their temporal correlation. The papers in the jump literature have the common feature of focusing on extreme quantiles of the distribution.

The $R A_{\theta}\left(r_{t, n}\right)$ measure provides a complementary view to this literature in that it captures asymmetries between quantiles $1-\theta$ and $\theta$ of the distribution. If significant economic events fall outside of that interval but are important from an investor's perspective, then $\theta$ should be adjusted to reflect that fact. In practice, the selection of the quantile will be dictated by the application at hand. If the choice of $\theta$ is an issue, there are two ways of addressing it. One can either present results for various $\theta$ s as we do in the empirical part of the paper. Namely, we focus primarily on the 75th-25th and 95th-5th quantile pairs, as 
more extreme quantiles (e.g. 99th) are hard to estimate. There is a tradition in finance to look at the interquartile range, as the 25 th and the 75 th quantiles are the half-way point between the median and the extreme tails of the distribution. The 95th and 5th quantiles provide a measure of asymmetry that excludes only the most extreme returns. The second approach that we adopt below is to use the $R A_{I N T}\left(r_{t, n}\right)$ statistic.

\subsection{Data: Asymmetry in International Equity Markets}

We use daily U.S. dollar-denominated log returns, $r_{t}$, for a total of 73 country indices and the World (W) portfolio as proxied by the MCSI World Index. The country portfolios, obtained from Datastream, are divided into 25 developed markets (DM) and 48 emerging markets (EM) following recent papers by Bekaert and Harvey (1997) and Bekaert, Harvey, Lundblad, and Siegel (2011). ${ }^{8}$ We work with U.S. dollar-denominated (rather than local currency) returns because of the portfolio allocation perspective of an U.S. investor that we adopt later in the paper. ${ }^{9}$ We compute monthly and quarterly returns, $r_{t, 22}$ and $r_{t, 66}$, as the sum of 22 and 66 daily log returns, respectively. For most developed and a few emerging markets, the data span the full period from January 1, 1980 to December 31, 2011 (emerging markets data prior to 1980 is almost non-existent). For completeness, we include as many emerging countries as possible and economies with shorter data spans are introduced as soon as their series becomes available. Given the limited sample size for some markets, we construct returns in an overlapping fashion and account for the induced autocorrelation in our statistics.

Table 1 presents summary statistics for the return distributions for all countries in our sample, sorted within DM or EM category by their market capitalization at the end of 2011. The statistics that we consider are the mean, standard deviation, and three measures of skewness discussed above, namely, the sample skewness $(S)$, its robustified version computed by truncating the top and bottom $0.5 \%$ of daily returns $\left(S^{T}\right)$, and the robust coefficient of asymmetry $\left(R A_{I N T}\right)$ defined in expression 2$)$ using a range of $\theta=$

\footnotetext{
${ }^{8}$ Following Pukthuanthong and Roll (2009), we select value-weighted indices comprising the largest stocks by market capitalization in each exchange.

${ }^{9}$ It is worth mentioning, however, that skewness is also significantly present in long-horizon returns denominated in local currency.
} 
$[0.99 ; 0.975 ; 0.95 ; 0.90 ; 0.85 ; 0.80 ; 0.75]$. Since this is an initial summary statistics table, we do not display the $R A_{\theta}$ statistic for various quantiles as we do in the rest of the paper. However, the results for $R A_{I N T}$ also hold true for $R A_{0.95}$ and $R A_{0.75}$. Cross-sectional averages of all statistics across DM and EM markets are also shown in italics. The annualized means and standard deviations of daily log returns capture two known facts: the average returns of developed stock markets are comparable to those of emerging markets (8.6\% versus $8.2 \%$ ) but their average volatility is lower (23.0\% versus $28.1 \%$ ), consistent with evidence in Bekaert and Harvey (1997).

The three measures of unconditional skewness offer a first glimpse of the return asymmetry in our data. At monthly frequency, the $S\left(r_{t, 22}\right)$ is -1.095 for the World index and negative for all developed countries, averaging -1.154. Nearly half of DMs have significant $S\left(r_{t, 22}\right)$ below -1 , with Iceland peaking at -7.914 . The average skewness for emerging markets, in contrast, is much smaller $(-0.222)$ and there is more heterogeneity in the estimates. For instance, China, the largest emerging market has a skewness of 0.446, whereas the second largest market, India, has a skewness of -0.317 , both statistically significant. About one quarter of EMs exhibiting positive skewness. Hence, monthly emerging market returns are less negatively skewed and there is more heterogeneity in skewness across emerging economies.

Skewness is also present at quarterly horizons. The $S\left(r_{t, 66}\right)$ is about -1 for the World and U.S. returns, very similar to the monthly estimates. Even more striking is the fact that, for several markets, irrespective of their category, skewness increases in absolute value as the horizon lengthens. This result runs counter to CLT predictions and extends the findings of Engle and Mistry (2007) and Neuberger (2012) to DM and EM markets. For a lack of a better term, we refer to the skewness estimates at various horizons as the term structure of skewness.

To what extent are the above skewness estimates affected by outliers? A comparison of $S\left(r_{t, 22}\right), S^{T}\left(r_{t, 22}\right)$, and $R A_{I N T}\left(r_{t, 22}\right)$ offers an answer to this question, as the latter two statistics are by construction not influenced by extreme returns. The results in Table 1 demonstrate that some but not all of the skewness can be traced to the impact of extreme returns. For example, the monthly truncated skewness for the U.S. halves to -0.500 . 
However, it increases to -0.692 at quarterly horizons and is close to the estimates of the un-truncated series. The average $S^{T}\left(r_{t, 66}\right)$ across DMs remains large at about -0.315 . It increases in absolute value from -0.172 (monthly) to -0.232 (quarterly) for EMs.

Similar results obtain for the estimates of the coefficient of asymmetry, $R A_{I N T}\left(r_{t, 22}\right)$ and $R A_{I N T}\left(r_{t, 66}\right)$ in the last two columns of Table 1 . The asymmetry is negative for all but three DMs. The term structure of the asymmetry measure is downward sloping for the average DM, moving from -0.106 to -0.122 . The same pattern is observed for EMs, with smaller negative averages of -0.040 and -0.059 . Several EMs continue to display positive longhorizon asymmetry. Finally, we note that the estimates of $S, S^{T}$, and $R A_{I N T}$ are positively correlated. At quarterly frequency, the correlation between $S$ and $R A_{I N T}$ is 0.77 for DMs and 0.61 for EMs.

Table 1 reveals considerable heterogeneity in skewness estimates across markets. From that perspective, emerging markets seem to offer appealing benefits that extend beyond the first two moments. However, there is extensive evidence that the conditional mean and conditional variance of U.S. and international market returns are time varying (Bekaert and Harvey (1997)). Such fluctuations in the investment opportunity set give rise to portfolio choice dynamics that might be different from the static allocation (Brandt (2010)). If similar predictable fluctuations in conditional asymmetry exist, then it might be optimal for investors to exploit them when choosing their portfolio allocation.

To see whether this line of reasoning is worth pursuing, we display in Figure 1 rolling estimates of daily returns skewness, $S\left(r_{t}\right)$, based on 250-day rolling-windows, for the largest DM and EM countries, the U.S. and China. The top, middle, and lower panels display $S\left(r_{t}\right), S^{T}\left(r_{t}\right)$, and $R A_{I N T}\left(r_{t}\right)$, using the same statistics as in Table 1. In the top panel, the October 1987 crash has a dramatic impact on the rolling U.S. skewness estimates. As soon as October 19th, 1987 drops out of the estimation window, the skewness decreases. Other outliers in the U.S. and China returns also produce large sudden changes in the skewness estimates. The rolling $S^{T}\left(r_{t}\right)$ estimates are by construction not affected by extreme outliers. Nevertheless, they are characterized by distinct jumps in the time series for both countries. The rolling estimates of $R A_{I N T}\left(r_{t}\right)$ in the lower panel are smoother but continue to exhibit time-variation. These rolling estimates, while suggestive of predictable time-variation 
in the asymmetry of international returns, are however unsuitable for use in a portfolio allocation context. They capture skewness of daily returns but comparable estimates for even monthly (let alone quarterly) returns will be extremely poorly estimated, given the data span. Moreover, the 250-day rolling window length is quite arbitrary and was chosen only for illustrative purposes. To capture the dynamics of conditional asymmetry, we need a model of conditional robust asymmetry, which is the task we turn to next.

\section{Conditional Robust Measure of Asymmetry}

In this section, we define a conditional robust measure of asymmetry. If $q_{\theta, t-1}\left(r_{t, n}\right)=$ $F_{t, n \mid t-1}^{-1}(r)$ is the conditional quantile $\theta$ of return $r_{t, n}$, then we construct the asymmetry statistic, $C A_{\theta, t-1}$, given information $I_{t-1}$ as:

$$
C A_{\theta, t-1}\left(r_{t, n}\right)=\frac{\left[q_{\theta, t-1}\left(r_{t, n}\right)-q_{0.50, t-1}\left(r_{t, n}\right)\right]-\left[q_{0.50, t-1}\left(r_{t, n}\right)-q_{1-\theta, t-1}\left(r_{t, n}\right)\right]}{q_{\theta, t-1}\left(r_{t, n}\right)-q_{1-\theta, t-1}\left(r_{t, n}\right)} .
$$

Expression (3) is a conditional version of $R A_{\theta}\left(r_{t, n}\right)$ in that we use conditional quantiles in its construction. We are more explicit in our notation and denote the conditional quantiles by $q_{\theta, t-1}\left(r_{t, n} ; \delta_{\theta, n}\right)$ where the unknown model parameters are collected in vector $\delta_{\theta, n}$. The notation reflects the fact that the function $q$ will be estimated for each quantile $\theta$ and the parameters $\delta_{\theta, n}$ may differ across quantiles and horizons. ${ }^{10}$ Integrating over $0<\theta<0.50$, we obtain the conditional analogue to $R A_{I N T}\left(r_{t, n}\right)$ :

$$
C A_{I N T, t-1}\left(r_{t, n}\right)=\frac{\int_{0}^{0.5}\left\{\left[q_{\theta, t-1}\left(r_{t, n}\right)-q_{0.50, t-1}\left(r_{t, n}\right)\right]-\left[q_{0.50, t-1}\left(r_{t, n}\right)-q_{1-\theta, t-1}\left(r_{t, n}\right)\right]\right\} d \theta}{\int_{0}^{0.5}\left\{q_{\theta, t-1}\left(r_{t, n}\right)-q_{1-\theta, t-1}\left(r_{t, n}\right)\right\} d \theta}
$$

An appealing feature of $C A_{I N T, t-1}\left(r_{t, n}\right)$ is that we do not have to specify a particular quantile $\theta$. As before, $C A_{\theta, t-1}\left(r_{t, n}\right)$ and $C A_{I N T, t-1}\left(r_{t, n}\right)$ are bounded between -1 and 1 and are zero when the distribution is symmetric. Before modeling the quantiles $q_{\theta, t-1}\left(r_{t, n} ; \delta_{\theta, n}\right)$, we offer a few observations about $C A_{\theta, t-1}$ and $C A_{I N T, t-1}$.

Prior research has established that the conditional first and second moments of interna-

\footnotetext{
${ }^{10}$ We do not use additional notation to distinguish between population and sample analogues. The distinction will be clear
} from the context. 
tional market returns are time varying (e.g., Bekaert and Harvey (1997), Engle and Rangel (2008)). Therefore, we can write the $n$-period return of a given index as

$$
r_{t, n}=\mu_{t-1, n}+\sigma_{t-1, n} \varepsilon_{t, n}
$$

where $\varepsilon_{t, n}$ is a random variable with zero-mean and unit standard deviation. If the dynamics of the conditional distribution of $r_{t, n}$ are captured entirely by the first two conditional moments, then the distribution of $\varepsilon_{t, n}, F\left(\varepsilon_{t, n}\right)$, is time-invariant and so are its quantiles, $q_{\theta}\left(\varepsilon_{t, n}\right)=F^{-1}\left(\varepsilon_{t, n}\right)$. Under that assumption, the conditional quantile $\theta$ of returns in (5) is:

$$
q_{\theta, t-1}\left(r_{t, n}\right)=\mu_{t-1, n}+\sigma_{t-1, n} q_{\theta}\left(\varepsilon_{t, n}\right)
$$

The conditional variance $\sigma_{t-1, n}$ can include asymmetries, as in the Glosten, Jagannathan, and Runkle (1993) asymmetric GARCH model.

Expression (6) helps clarify a few important points. First, variations in the quantiles of returns may come from variations in the conditional mean and conditional variance. Second, the mean has the same impact on all quantiles and hence has no impact on $C A_{\theta, t-1}$. Third, if the asymmetry is successfully captured by the volatility dynamics (such as in asymmetric GARCH models) and $F\left(\varepsilon_{t, n}\right)$ is symmetric, then $C A_{\theta, t-1}$ will be zero, even though the conditional volatility is asymmetric. These first points can be summarized as follows: time variation in the first and second moment is not enough to generate fluctuations in the conditional asymmetry of returns. Finally, if the distribution of $\varepsilon_{t, n}$ is time-invariant, as the location-scale model assumes, then we do not expect time-series variation in $C A_{\theta, t-1}$. These arguments imply that we don't need to "de-mean" and "de-vol" the data to obtain estimates of $\varepsilon_{t, n}$, before computing the $C A_{\theta, t-1}$. Not having to specify a model for the first two moments reduces the possibility of mis-specifying the $C A_{\theta, t-1}$ measure itself. 


\subsection{Modeling the Conditional Quantiles}

We model $q_{\theta, t-1}\left(r_{t, n} ; \delta_{\theta, n}\right)$ as an affine function of predetermined variables, collected in a vector $Z_{\theta, t-1}$ :

$$
q_{\theta, t-1}\left(r_{t, n} ; \delta_{\theta, n}\right)=\alpha_{\theta, n}+\beta_{\theta, n} Z_{\theta, t-1}
$$

where $\delta_{\theta, n}=\left(\alpha_{\theta, n}, \beta_{\theta, n}\right)$ are unknown parameters to be estimated. In the above specification, we allow the conditioning variables $Z_{\theta, t-1}$ to differ across quantiles. The choice of functional form and conditioning variables in the estimation of quantile regressions is similar to that of any regression, whether we are estimating a conditional mean, conditional variance, or a conditional quantile. The parametrization of $q_{\theta, t-1}\left(r_{t, n} ; \delta_{\theta, n}\right)$ and the type of conditioning information are of primary importance. Below we consider a novel approach of modeling the quantiles that is particularly suitable for portfolio applications at various horizons.

To capture fluctuations in the quantiles of $n$-period returns, we use daily conditioning variables. Given that quantiles are hard to estimate precisely, this mixed-sampling approach allows us to use all the richness of the high-frequency (daily) data which is especially relevant in emerging markets with short histories. The alternative of aggregating the conditioning variables so that they match the frequency of the $n$-period returns would result in information loss and less precise quantile estimates. The horizon mismatch between the $n$-period returns and the daily observations is what compels us to use a mixed data sampling, or MIDAS, approach. While MIDAS models are not entirely new in finance, they are relatively recent and have never been used in the context of quantile regressions. ${ }^{11}$

We characterize a MIDAS quantile regression - where the conditional quantile pertains to $n$-period returns and the regressors are daily returns - as follows:

$$
\begin{aligned}
q_{\theta, t-1}\left(r_{t, n} ; \delta_{\theta, n}\right) & =\alpha_{\theta, n}+\beta_{\theta, n} Z_{t-1}\left(\kappa_{\theta, n}\right) \\
Z_{t-1}\left(\kappa_{\theta, n}\right) & =\sum_{d=0}^{D} \lambda_{d}\left(\kappa_{\theta, n}\right) x_{t-1-d}
\end{aligned}
$$

where $\delta_{\theta, n}=\left(\alpha_{\theta, n}, \beta_{\theta, n}, \kappa_{\theta, n}\right)$ are unknown parameters to estimate. The quantiles are an

\footnotetext{
${ }^{11}$ The original work on MIDAS focused on volatility predictions, see Ghysels, Santa-Clara, and Valkanov (2005) and Ghysels, Santa-Clara, and Valkanov (2006). For other contributions, see recent survey on MIDAS by Andreou, Ghysels, and Kourtellos (2011) and Armesto, Engenmann, and Owyang (2010) as well as the survey specifically on MIDAS and volatility prediction by Ghysels and Valkanov (2011).
} 
affine function of $Z_{t-1}\left(\kappa_{i, \theta, n}\right)$ which consists of linearly filtered $x_{t-1-d}$ representing daily conditioning information with lag of $d$ days. The weights $\lambda_{d}\left(\kappa_{\theta, n}\right)$ are parameterized as a lag polynomial function whose shape is captured by a low-dimensional parameter vector $\kappa_{\theta, n}$. Asymmetry is achieved when $\alpha_{\theta, n}$ and $\beta_{\theta, n}$ differ across quantiles, when the conditioning variables $Z_{t-1}\left(\kappa_{\theta, n}\right)$ are different across quantiles, or both. It is worth pointing out that $Z_{t-1}\left(\kappa_{\theta, n}\right)$ can differ across $\theta$ 's even when the daily data in $x_{t-1-d}$ is the same, because the estimated filtering weights $\lambda_{d}\left(\kappa_{\theta, n}\right)$ are not constrained to be the same across quantiles.

The parsimonious specification of the MIDAS weights $\lambda_{d}\left(\kappa_{\theta, n}\right)$ greatly reduces the number of lag coefficients to estimate from $D+1$ (which can be very large, given the frequency of the data), to only a few. The parameters $\kappa_{\theta, n}$ governing the filtering of the daily observations appearing in equation (9) and the parameters $\alpha_{\theta, n}$ and $\beta_{\theta, n}$ in the quantile regression equation (8) are estimated jointly as discussed below. The MIDAS regression framework allows us to use high-frequency data in the estimation of quantile forecasts at various horizons. The benefits and trade-offs of using high-frequency data in the context of quantile regression estimation or skewness forecasts is a topic that has not received much attention. While it is not the primary focus of this paper, we offer some first insights in that direction. ${ }^{12}$

To estimate the quantile function (8), we need to specify the functional form of $\lambda_{d}\left(\kappa_{\theta, n}\right)$ and the conditioning variables $x_{t-1-d}$ in the definition of $Z_{t-1}\left(\kappa_{\theta, n}\right)$. We address these model specifications briefly, as they are fairly standard in the literature. We follow Ghysels, SantaClara, and Valkanov (2006) and specify $\lambda_{d}\left(\kappa_{\theta, n}\right)$ as a "Beta" polynomial. ${ }^{13}$ A main advantage of this "Beta" function is its well-known flexibility using only two parameters $\kappa_{1}$ and $\kappa_{2}$. It can take many shapes, including flat weights, gradually declining weights as well as humpshaped patterns. In Appendix A we provide the technical details regarding estimation of MIDAS quantile regressions.

Regarding the choice of conditioning variables, we follow Engle and Manganelli (2004) who find that absolute returns successfully capture time variation in the conditional distribution of returns, and use $\left|r_{t-1-d}\right|$ as $x_{t-1-d}$ in (9). While we could have used any conditioning

\footnotetext{
${ }^{12}$ Arguably, an exception is the literature on tests for jumps in continuous time stochastic volatility jump diffusions. These tests typically apply to a decomposition of realized volatility into a continuous-path and discrete jump component. Such analysis requires intra-daily returns data which is not available for emerging markets.

${ }^{13}$ Ghysels, Sinko, and Valkanov (2006) and Ghysels (2013) discuss the properties of such polynomial lag and other specifications in detail. The expression for the polynomial appears in equation (A.1) of Appendix A.
} 
information, the $\left|r_{t-1-d}\right|$ specification provides the most robust results and also makes the comparison of our model with that of Engle and Manganelli (2004) straightforward. ${ }^{14}$ More generally, the problem of selecting the conditioning variables in the MIDAS quantile regression is exactly the same as in any other regression.

There are several benefits from using the MIDAS quantile specification (8) - (9) rather than other conditional quantile models. It is not a recursive quantile model: the conditioning information $x_{t-d-1}$ can be any variable that has the ability to capture time variation in the quantile of the return distribution. This allows us to handle the mismatch of sampling frequencies. Also, the MIDAS weights filter the potentially noisy daily data. This is particularly important while working with emerging markets returns. Another important feature of this specification is the possibility to forecast skewness at various horizons (in this case, monthly and quarterly) while keeping the information set fixed (i.e., daily frequency). Asymmetries in the quantiles can obtain because of differences in the $\kappa_{\theta, n}$, and differences in $\alpha_{\theta, n}$ and $\beta_{\theta, n}$. If the $\kappa_{\theta, n}$ are the same across quantiles, then so is the filtered conditioning variable $Z_{t-1}\left(\kappa_{\theta, n}\right)$ and the quantiles differ only through the $\alpha_{\theta, n}$ and $\beta_{\theta, n}$ parameters. However, differences in the $\kappa_{\theta, n}$ imply that the filtered predictors are also different across quantiles. ${ }^{15}$

\subsection{Quantile Estimates}

We estimate the conditional quantiles for $\theta$ of $0.99,0.975,0.95,0.90,0.85,0.80,0.75,0.50$, and for $1-\theta$ of the World portfolio and 73 country returns using the MIDAS models at monthly and quarterly frequency. A big advantage of the MIDAS framework is the ability to estimate quantiles at various horizons while conditioning on the same information set. We discuss the quantile estimates in some detail as they serve as inputs in the $C A$ measures. All quantiles are estimated separately. We impose the restrictions $\kappa_{1}=1$ and $\kappa_{2}>\kappa_{1}$ on the Beta polynomial weights, following Ghysels, Sinko, and Valkanov (2006), which in effect excludes shapes of the lag function that place increasingly more mass on distant observations.

\footnotetext{
${ }^{14}$ Alternative specifications based on transformations of daily returns yield similar, but slightly noisier estimates. Results from regressions using simple, squared, and cubed returns are available upon request.

${ }^{15}$ We do not explicitly consider the issue of quantile crossings, see e.g. Dette and Volgushev (2008) and Chernozhukov, FernándezVal, and Galichon (2010) for the recent literature. It turns out, however, that crossing of quantiles does not seem to be an issue in the applications at hand.
} 
Table 2 displays the $0.05,0.25,0.50,0.75$, and 0.95 , quantile estimates for the largest DM and EM countries, the U.S. and China, along with the World portfolio index as they enter in the construction of $C A_{I N T, t-1}, C A_{0.95, t-1}$ and $C A_{0.75, t-1}$. Panel A contains the monthly results whereas panel B displays the ones for the quarterly MIDAS. First, the estimated quantiles are time varying. The hypothesis of time invariant quantiles corresponds to $\beta_{\theta, n}=0$. The monthly MIDAS estimates of $\beta_{\theta, n}$ are negative for the 0.05 and 0.25 quantiles and positive for the 0.75 and 0.95 quantiles, always significant at conventional levels. This strong evidence of variability of the conditional quantiles is not surprising as a large part of that variation is undoubtedly due to fluctuations in the conditional volatility (or scale effect). In fact, our conditioning variable $Z_{t-1}\left(\kappa_{\theta, n}\right)$ is correlated with the volatility. Hence, the change in the sign of $\beta_{\theta, n}$ around the median captures the volatility effect on the quantiles. For conciseness, we don't display the estimates for the other 70 country indices as the results are similar to those in Table 2 (they are available upon request).

Second, the MIDAS quantile models provide a good unconditional coverage. To see that, in row "Coverage" we display the real unconditional coverage, the fraction of returns that fall beyond the estimated quantile over the entire series, and notice that it is very close to the nominal one. The Kupiec (1995) test of coverage indeed fails to reject the null that the estimated quantiles have the correct coverage for all portfolios at the monthly (Panel A) and quarterly (Panel B) frequency.

The skewness in the returns distribution can be gleaned from the MIDAS estimates even before computing the $C A$ statistics. For the U.S. and World portfolios, the absolute values of $\beta_{0.05,22}$ and $\beta_{0.25,22}$ are larger than $\beta_{0.95,22}$ and $\beta_{0.75,22}$, respectively, hinting at negative asymmetry in those markets. The same is true, even to a larger extent, at quarterly horizons, suggesting that asymmetry does not disappear as the holding period horizon increases. For China the asymmetry is less clear, as the betas and the kappas are quite different across quantiles. These results are suggestive of asymmetry, but a formal test would involve both the betas and the kappas. For brevity, we do not display the lag weights $w_{d}\left(\kappa_{\theta, n}\right)$ but they can be obtained, given the estimates of $\kappa_{\theta, n}$ in the Table.

To visualize the estimation results, Figure 2 graphs the monthly series of the $0.05,0.025$, 0.75, and 0.95 conditional quantiles of U.S. and China monthly returns (top plots) and 
quarterly returns (lower plots), based on the estimates in Table 2. For the U.S., the recent financial crisis and in general NBER recession periods are marked by a widening of the distribution which reflect countercyclical variation in volatility. For China, instead, quantiles vary in a wider range but the relation with NBER recession periods is not as strong as for the U.S. Also, we notice that lower quantiles of monthly returns appear somewhat smoother than the upper quantiles, similar to the evidence in White, Kim, and Manganelli (2008).

\subsection{Comparison to Other Conditional Quantile Models}

We investigate how do the MIDAS conditional quantiles estimates compare to those of other quantile models, such as the Conditional Autoregressive Value-at-Risk (CAViaR) proposed by Engle and Manganelli (2004). The CAViaR is a widely used conditional quantile model. To compare the MIDAS and CAViaR approaches, we use the asymmetric absolute value CAViaR which is the closest analogue to the MIDAS quantile specification in Table 2. Specifically, the conditional quantile is expressed as the sum of an autoregressive component and the absolute value of lagged one-period absolute return, $q_{\theta, t-1}\left(r_{t, n}\right)=\gamma_{0, \theta}+\gamma_{1, \theta} q_{\theta, t-2}\left(r_{t-1, n}\right)+\gamma_{2, \theta}\left|r_{t-1}\right|$, which is a specific version of expression (7), for $n=1$ (single-period horizon) and $Z_{\theta, t-1}=\left[q_{\theta, t-2}\left(r_{t-1}\right)\left|r_{t-1}\right|\right]^{\prime}$ for all $\theta$ s. ${ }^{16}$ A major difference with respect to the MIDAS specification is that the CAViaR has an autoregressive structure. As a result, we estimate the model using non-overlapping monthly data. ${ }^{17}$

We tabulate the CAViaR coefficient estimates for the World, U.S., and China in Appendix Table A.1. In addition to the CAViaR parameter estimates, row "Correl" displays the correlation between the fitted values of the MIDAS and CAViaR models for a given quantile. These correlations are high, in the range of 0.523 to 0.891 , across quantiles and portfolios. We interpret this as evidence that the two models capture a lot of the same dynamics. As a more visual representation of the results, Figure A.1 displays the 5th, 25th, 75th, and 95th fitted MIDAS (solid line) and CAViaR (dashed line) quantiles for the U.S. and China. For the U.S. in the top panel, the MIDAS and CAViaR estimates are indeed very close and

\footnotetext{
${ }^{16}$ Engle and Manganelli (2004) also consider other specifications but find no significant gains over this baseline model.

${ }^{17}$ We verify that using overlapping long-horizon returns significantly alters the CAViaR's performance. This is because the $n$-period return series is no longer a martingale difference sequence. This issue becomes more problematic as the horizon lengthens. The MIDAS estimation is instead not affected by the overlap as it always relates long-horizon quantiles to daily returns.
} 
capture similar dynamics. For instance, they produce very comparable estimates around the October 1987 crash. One noticeable difference is that the CAViaR estimates seem smoother that the MIDAS. This can be observed around the financial crisis of 2007-2009 and several episodes preceding it. During those volatile regimes, MIDAS fitted quantiles respond faster to the changing conditions, whereas the persistent autoregressive CAViaR model responds with somewhat of a lag. If we look at the correlation between corresponding fitted MIDAS and CAViaR quantiles before the financial crisis, it is higher that the numbers in Table 2 .

\subsection{Conditional Quantiles of Volatility-Filtered Returns}

Is it possible to capture the quantile dynamics in a parsimonious way by an asymmetric conditional volatility model? In other words, after filtering conditional volatility from the return series, do we still observe significant variation in their quantiles? To answer this question, we estimate the conditional volatility of monthly non-overlapping returns using the TARCH $(1,1,1)$ model of Glosten, Jagannathan, and Runkle (1993). We then divide the returns by the fitted values from the TARCH to obtain series that do not have significant volatility effects. We call these volatility-filtered series "de-TARCHed". We fit the deTARCHed returns to the MIDAS quantile models exactly as above and report the results in Table A.2 and Figure A.2 of the Appendix.

The extreme quantiles of the de-TARCHed monthly returns exhibit significant time variation. The $\beta$ estimates of the 0.05 and 0.95 quantiles for the U.S. are significant at conventional levels. For China and the World, $\beta$ is significant for the 0.95 quantile. All the quantiles of the de-TARCHed returns have the right coverage. Interestingly, the correlation between the quantiles of the simple and de-TARCHed returns, displayed in the last column of the table, is extremely high in all cases with the exception of the median for the U.S. In other words, the estimated quantiles of the simple and de-TARCHed returns exhibit similar variation, although the statistical significance in the latter is evident only in the tails. In Figure A.2 we plot the de-TARCHed quantiles and observe that their pattern is very similar to the quantiles of the simple returns in Figure 2 Panel A. These results suggest that while the TARCH $(1,1,1)$ is able to account for most of the quantile dynamics, the extreme quantiles are still better modeled by a MIDAS quantile model. 


\section{Estimates of Conditional Asymmetry and Their Prop- erties}

In this section, we present the estimates of the conditional asymmetry measures. We first discuss the statistical properties of $C A_{I N T, t-1}\left(r_{t, n}\right)$ and $C A_{\theta, t-1}\left(r_{t, n}\right)$ and provide a graphical overview of their pattern for the two largest countries in the sample, U.S. and China. Next, we investigate cross-sectional dependence in the $C A$ statistics using principal components analysis. Finally, we explore the link between conditional asymmetry, volatility, and U.S. recessions.

\subsection{Estimates of $C A_{I N T, t-1}\left(r_{t, n}\right)$ and $C A_{\theta, t-1}\left(r_{t, n}\right)$}

We construct the conditional asymmetry statistics $C A_{I N T, t-1}\left(r_{t, n}\right)$ and $C A_{\theta, t-1}\left(r_{t, n}\right)$ using the MIDAS quantile estimates. For $C A_{I N T, t-1}\left(r_{t, n}\right)$, we estimate the quantiles over the same grid of $\theta$ s as above and sum over the quantiles following expression (4). We report $C A_{\theta, t-1}\left(r_{t, n}\right)$ estimates at two points of the distribution, $\theta=0.95$ and $\theta=0.75$. All $C A$ statistics are estimated at monthly and quarterly horizons, and for all countries in our data.

Summary statistics for the $C A_{I N T, t-1}\left(r_{t, n}\right), C A_{0.95, t-1}\left(r_{t, n}\right)$, and $C A_{0.75, t-1}\left(r_{t, n}\right)$ series average, standard deviation, min and max - are displayed in Table 3 for the U.S., China, and the World portfolios. We also display averages for all DM countries except the U.S., and all EM countries except China. We note that the average $C A_{I N T, t-1}\left(r_{t, 22}\right)$ for the U.S. $(-0.159)$ is very close to the unconditional $R A_{I N T}\left(r_{t, 22}\right)$ statistic in Table $1(-0.157)$. The same is true for the World portfolio (-0.142 versus -0.159) and, to a lesser extent, for China (0.063 versus 0.095$)$. The average $C A_{I N T, t-1}\left(r_{t, 66}\right)$ and $C A_{I N T, t-1}\left(r_{t, 66}\right)$ statistics are also very close to their unconditional analogues. A $p$-value for the null that the mean of the $C A_{I N T, t-1}\left(r_{t, n}\right)$ is equal to the $R A_{I N T}\left(r_{t, n}\right)$ in Table 1 for a given $\theta$, horizon, and country is displayed in row 'pval' and is never significant. The fact that the average conditional asymmetry estimates are so close to the unconditional estimates is a validation of the conditional quantile models and that our $C A_{\theta, t-1}\left(r_{t, n}\right)$ estimates indeed measure conditional asymmetry.

Comparing the $C A_{I N T, t-1}\left(r_{t, n}\right), C A_{0.95, t-1}\left(r_{t, n}\right)$, and $C A_{0.75, t-1}\left(r_{t, n}\right)$ statistics for a given 
portfolio and horizon gives an interesting perspective of whether the asymmetry is driven exclusively by the tails (i.e., $\left.C A_{0.95, t-1}\left(r_{t, n}\right)\right)$ of the distribution. For instance, the monthly estimates of the $C A_{I N T, t-1}\left(r_{t, n}\right), C A_{0.95, t-1}\left(r_{t, n}\right)$, and $C A_{0.75, t-1}\left(r_{t, n}\right)$ statistics for the U.S. market return are $-0.159,-0.145$, and -0.124 , respectively, indicating that the asymmetry is likely observed along all quantiles. At quarterly horizons, however, the estimates for the same portfolio are $-0.168,-0.163$, and -0.013 , suggesting that the asymmetry is observed mainly at the tail quantiles.

The conditional asymmetry series for the U.S. and China are displayed in Figures 3.a (monthly returns) and 3.b (quarterly returns). The top, middle, and lower panel of the figures display the $C A_{I N T, t-1}\left(r_{t, n}\right), C A_{0.95, t-1}\left(r_{t, n}\right)$, and $C A_{0.75, t-1}\left(r_{t, n}\right)$ estimates. The bottom two plots in Figure 3.a obtain by plugging the corresponding MIDAS quantiles from Figure 2 in expression (3). The asymmetry of the U.S. stock market returns is almost always negative, whereas that of China is mostly positive. The $C A_{I N T, t-1}\left(r_{t, n}\right)$ estimates (top panel) are by far the smoothest, because averaging across quantiles reduces estimation error. The $C A_{0.95, t-1}\left(r_{t, n}\right)$ estimates (middle panel) are much noisier than $C A_{I N T, t-1}\left(r_{t, n}\right)$ and are also noisier than $C A_{0.75, t-1}\left(r_{t, n}\right)$ (middle panel) which is undoubtedly due to the less precise estimates of the 5th and 95th quantiles. The asymmetry estimates in all three panels of each figure are very similar in their overall dynamics. For the U.S., there is a pronounced low-frequency component and a volatile component during the 1987 crash and the recent financial crisis.

The U.S. and China conditional asymmetries are negatively correlated, as can be observed in Figures 3.a and 3.b. The correlation is largest in absolute value for the $C A_{I N T, t-1}\left(r_{t, n}\right)$ measure (top panels) at -0.30 . It is lowest toward the center of the distribution, for $C A_{0.75, t-1}\left(r_{t, n}\right)$ (bottom panels). For this pair of countries, the negative correlation is driven mostly by tail quantiles. The average correlation across all 2,701 index pairs of $C A_{I N T, t-1}\left(r_{t, 22}\right)$ estimates is only 0.06 . About $39 \%(1,052)$ of the correlations are negative and many of them are statistically significant. Similar results obtain for quarterly horizons, with average correlation across $C A_{I N T, t-1}\left(r_{t, 66}\right)$ pairs of 0.01 and about $49 \%$ negative $(1,316)$ correlations. The message that emerges from these correlations is that the conditional asymmetries do not exhibit a large positive correlation as do the returns themselves. It also 
seems that they do not have a significant common component, which is a result that we will demonstrate more directly below.

Comparing the $C A_{I N T, t-1}\left(r_{t, n}\right)$ estimates at monthly and quarterly horizons (Figures 3.a versus 3.b), we again notice similar time-series patterns. The quarterly series are somewhat smoother than the monthly ones, which is partly due to the overlap when estimating the quantiles. More interestingly, however, for the U.S., the asymmetries are larger for the longhorizon returns. A comparison of the top panels in the two figures reveals that the asymmetry is more pronounced at quarterly horizons during the October 1987 Crash and the recent financial crisis. More precisely, the lowest U.S. $C A_{I N T, t-1}\left(r_{t, n}\right)$ estimate is -0.320 at monthly horizon and -0.436 at quarterly horizon (Table 3). For China, the lowest monthly and quarterly estimates are -0.191 and -0.253 . The important message here is that asymmetry does not seem to vanish as the holding period increases. If anything, it is more pronounced at quarterly frequency for the U.S. and many other countries in our sample (Table 3).

\subsection{Co-Movements in Conditional Asymmetry}

We noted above that, on average, the correlation between countries' conditional asymmetry is small. The implication is that investor may exploit this fact by tilting their portfolios toward countries that offer positively (or less negatively) skewed returns and away from countries with negatively skewed returns (Barberis and Huang (2008) and Brunnermeier, Gollier, and Parker (2007)). To explore this further, we look for commonality in the $C A_{I N T, t-1}\left(r_{t, n}\right)$ and $C A_{\theta, t-1}\left(r_{t, n}\right)$ estimates across all 73 countries via principal components analysis. Namely, we extract the first two principal components for each $C A$ statistic and horizon. We present the quarterly result in Figure 4 and omit the monthly results, which are similar. In the figure, we display the fraction of the total variation that is explained by the first or first and second principal components. As a comparison, we also show the principal components results for the conditional volatility across countries, where volatility is estimated with a MIDAS regression as in Ghysels, Santa-Clara, and Valkanov (2006). ${ }^{18}$

Panel A of Figure 4 shows that $29.05 \%$ of the total variation in $C A_{I N T, t-1}\left(r_{t, 66}\right)$ is ex-

\footnotetext{
${ }^{18}$ We estimate the volatility with a MIDAS model (rather than with other volatility models) to preserve the use of the same information set of daily returns as in the $C A_{\theta, t-1}\left(r_{t, n}\right)$ estimation.
} 
plained by the first principal component and $46.44 \%$ is explained by the first two components. The results for $C A_{0.95, t-1}\left(r_{t, 66}\right)$ and $C A_{0.75, t-1}\left(r_{t, 66}\right)$ are similar. By contrast, $56.86 \%$ and $63.77 \%$ of the movement in return volatility is captured by the first and first two principal components, respectively. We notice that most of the co-movement in $C A$ is concentrated in developed countries. Panel B shows that in these markets, the first component explains $46.74 \%$ of the co-movement in $C A_{I N T, t-1}\left(r_{t, 66}\right)$. Again, the return volatility co-movement is much higher, with $84.85 \%$ of the variation captured by the first component. Notably, the commonality in $C A_{I N T, t-1}\left(r_{t, 66}\right)$ across emerging markets is dramatically lower. Panel C shows that only $22.98 \%$ of its variability across emerging economies is captured by the first component. For comparison, the co-movement of return volatility in these markets is significantly higher, with the first component explaining $43.66 \%$.

The principal component results confirm that the $C A_{I N T, t-1}\left(r_{t, n}\right), C A_{0.95, t-1}\left(r_{t, n}\right)$, and $C A_{0.75, t-1}\left(r_{t, n}\right)$ of emerging economies do not have a large common component, both in absolute terms and relative to the commonality that is observed in the volatility series. Developed economies exhibit more common movement in the asymmetry, which is consistent with increased market integration across these countries.

As a final remark, it might be tempting to ask whether the asymmetry co-movement might be addressed in the framework of a factor model. In other words, what fraction of the time variation in a country' $C A$ can be traced to a World factor. This question is particularly relevant because, as we saw in Table 3, the World portfolio returns exhibit significant conditional asymmetry. In the framework of an international factor model (e.g., Solnik (1974), Korajczyk and Viallet (1989), Cho, Eun, and Senbet (1986), Harvey (1991)), asymmetries in the distribution of returns may arise either because of shocks to systematic risk factors that affect the cross section of returns, or because of country-specific shocks. While it might be natural to think of decomposing the conditional asymmetry of a portfolio return into systematic and idiosyncratic risk components, the mechanics of such a decomposition are not straightforward and would likely involve distributional assumptions, which is what we have so far been trying to avoid. ${ }^{19}$

\footnotetext{
${ }^{19}$ Our asymmetry measure is a function of quantiles of returns $q_{\theta}\left(r_{i, t, n}\right)$ (conditional or unconditional). A general decomposition of the return quantiles into the quantiles of the systematic and idiosyncratic fluctuations is not possible without further assumptions about the joint distribution of the factors and the idiosyncratic shocks. Namely, modeling the systematic and idiosyncratic parts of return separately involves the marginal distributions. If we want to transition from the marginals to
} 


\subsection{Conditional Asymmetry, Volatility, and U.S. Recessions}

In this section, we address the following two questions. First, do we observe more negative skewness in periods of high volatility? This question is motivated by a large body of literature that has established a relation between higher volatility and negative returns in the U.S. stock market. The finding, known as the "leverage effect", has been documented using various statistical approaches. We revisit it here for a couple of reasons. Replicating this stylized fact with the $C A_{I N T, t-1}\left(r_{t, n}\right)$ and $C A_{\theta, t-1}\left(r_{t, n}\right)$ measures would lend further credence that we are capturing conditional asymmetry in returns. Moreover, while the leverage effect has been established for the U.S. and some DMs, whether it is present in EM returns is less clear. For instance, Bekaert and Harvey (1997) do not find support for the leverage effect in a limited sample of emerging economies.

Second, are the asymmetries more pronounced during U.S. recessions? From an U.S. investor's perspective, which we adopt in the next section, understanding whether $C A_{\theta, t-1}\left(r_{t, n}\right)$ and $C A_{I N T, t-1}\left(r_{t, n}\right)$ co-vary with U.S. investment opportunities is important for hedging. We expect the U.S. stock market return asymmetry to be more pronounced during U.S. recessions. Relative to the U.S. stock market, we also expect the $C A$ s in other markets to be less affected by downturns in the U.S. economy. It is this difference in markets' response to U.S. recessions that might provide hedging opportunities to investors. We use U.S. recessions dates provided by the National Bureau of Economic Research (NBER).

To tackle these questions, we estimate the model:

$$
C A_{t-1}\left(r_{t, n, i}\right)=a+b_{1} \sigma_{t-1, n, i}+b_{2} N B E R_{t-1}+\epsilon_{t, n, i}
$$

where $\sigma_{t-1, n, i}$ denotes the $n$-period return volatility of country $i$, estimated with a MIDAS regression as in the previous section. The index variable $N B E R_{t-1}$ is equal to one if month $t-1$ falls in a recession as defined by the NBER. The left-hand side variable is either $C A_{I N T, t-1}\left(r_{t, n, i}\right), C A_{0.95, t-1}\left(r_{t, n, i}\right)$, or $C A_{0.75, t-1}\left(r_{t, n, i}\right)$. The regression is estimated in the time-series for the U.S., China, and World portfolio. For the group of DM ex-U.S. and

the joint distribution of returns, we have to take a stand on the dependence between these two marginal distributions. One way of doing this would be through some parametric assumptions, such as a copula function. However, this would involve making distributional assumptions, and would critically depend on the choice of copula. 
EM ex-China, we pool the observations across countries and months, and compute clustered standard errors.

The monthly and quarterly results are presented in Table 4 . Consistent with the leverage effect literature, we observe a negative relation between the $C A_{I N T, t-1}\left(r_{n, i, t}\right)$ and volatility at monthly horizons (Panel A). The coefficient in front of volatility is significant at the $1 \%$ for the U.S. and China, and at the $10 \%$ for the World portfolio. The leverage effect seems to be present and quite pronounced in emerging economies in terms of magnitude and statistical significance. The volatility coefficient estimates for EM countries (China and EM ex-China) are larger in magnitude than in DM countries. The quarterly results in Panel B carry the same message as the leverage effect is present in DM and EM economies. The parameter estimates on volatility are larger in magnitude than in Panel A and significant at the $1 \%$ level in all columns but DM ex-U.S.. The same holds true for $C A_{I N T, t-1}\left(r_{t, n, i}\right), C A_{0.95, t-1}\left(r_{t, n, i}\right)$, as well as $C A_{0.75, t-1}\left(r_{t, n, i}\right)$.

U.S. stock market returns are generally more negatively skewed during U.S. downturns. In the monthly $C A_{I N T, t-1}\left(r_{t, 22, i}\right)$ regressions (Panel A of Table 4), the coefficient on the NBER dummy is negative and significant with a $p$-value of 0.03. At quarterly frequency (Panel B), the coefficient is negative, larger in magnitude, and significant at the $6 \%$ level. Given the low power of the $t$-test with these dummy variables (there are only 4 recessions in our sample) it is encouraging to detect statistical significance. The negative effect is still present in the $C A_{0.95, t-1}\left(r_{t, n, i}\right)$ and $C A_{0.75, t-1}\left(r_{t, n, i}\right)$ regressions, is not significant at monthly frequency, and is significant at quarterly horizons. Hence, for monthly returns, the effect must largely be due to the extreme quantiles that enter in the construction of $C A_{I N T, t-1}\left(r_{t, n, i}\right)$.

By contrast, U.S. recessions have little to no impact on the asymmetry regressions for China, DM ex-U.S., and EX ex-China. This is true for $C A_{I N T, t-1}\left(r_{t, n, i}\right), C A_{0.95, t-1}\left(r_{t, n, i}\right)$, and $C A_{0.75, t-1}\left(r_{t, n, i}\right)$ in Panels $\mathrm{A}$ and $\mathrm{B}$. The coefficients in World portfolio regressions are mostly negative and insignificant. These insignificant results might be somewhat surprising, given the financial markets integration especially among DM countries. To understand them, it is useful to recall that market integration has thus far been linked to the first and second moment of returns (e.g., Bekaert and Harvey (1995)). As discussed in section 3, however, the $C A$ measures ought not to be affected by variations in the conditional mean and variance. 
Moreover, regression (10) controls explicitly for country volatility. Hence, the findings in Table 4 suggest that, above and beyond mean-variance effects, U.S. recessions do not impact non-U.S. markets return asymmetry. This is again in line with the lack of commonality across country $C A$ s that we documented above.

\section{International Portfolio Allocation: Exploiting Con- ditional Return Asymmetry}

The benefits of international diversification and the related topic of global market integration have been mostly framed in the context of modeling the time varying means and covariance matrix of stock returns. ${ }^{20}$ To capture the gist of that literature - and at risk of over-simplifying a complex subject - in Panel A of Figure 5 we display the average rolling correlation of monthly returns among DM countries (dotted line), among EM countries (dash-dotted line), and between EM and DM countries (solid line). The plots illustrate why it is often argued that the benefits of international diversification are limited and decreasing (Christoffersen, Errunza, Jacobs, and Jin (2012)). The average correlation across DM returns increases over our sample to as high as 0.90, and even the average correlation between DM and EM countries is trending up over time and is currently about 0.50 .

The correlation in returns differs markedly from that of the asymmetry measure. Panel B of Figure 5 displays the average correlations of $C A_{I N T}\left(r_{t, 22}\right)$ across DM, across EM, and between DM and EM economies. The plot confirms the conclusions that already emerged from Figure 4 and section 4.2, namely, return asymmetries of emerging and developed markets exhibit little significant co-movement. In contrast with Panel A, there are virtually no trends in the $C A_{I N T}\left(r_{t, 22}\right)$ correlations throughout the sample. In an international portfolio context, Figure 5 suggests that investors can improve upon the standard mean-variance allocation by taking into account features of the return distribution, such as asymmetries, while making optimal portfolio decisions (Guidolin and Timmermann (2008) and Jondeau and Rockinger (2006)). However, incorporating return asymmetry in an optimal portfolio

\footnotetext{
${ }^{20}$ Among the many papers on the topic, see Solnik (1974), Stulz (1981, 1987), Korajczyk and Viallet (1989), King, Sentana, and Wadhwani (1994), Bekaert and Harvey (1995), Harvey (1995), Bekaert and Harvey (1997), Pukthuanthong and Roll (2009), Engle and Rangel (2008).
} 
setting and quantifying its benefits is not a simple task. The direct approach of modeling the joint conditional return distribution of 73 countries is practically speaking not possible, especially since we only have at most 30 years of data. One way of circumventing the problem of dimensionality is by modeling the non-linear dependence between pairs of countries as in Christoffersen, Errunza, Jacobs, and Jin (2012).

In this paper, we adopt the parametric portfolio approach of Brandt, Santa-Clara, and Valkanov (2009), which consists of specifying the portfolio weights as a function of assetspecific characteristics. Specifically, Brandt, Santa-Clara, and Valkanov (2009) investigate whether U.S. firm characteristics (such as size, value, and momentum) can lead to sizeable portfolio improvements relative to the benchmark value-weighted portfolio. In the current context, our main objective is to answer whether an investor can exploit the documented differences and variations in DM and EM return asymmetries by tilting her portfolio toward positively skewed (or less negatively skewed) country returns. And, if so, how large would the resulting portfolio gains be? Since the parametric portfolio approach is fairly novel and has to be modified for our application, we briefly describe it below.

\subsection{Methodology}

We investigate whether and to what extent the estimated conditional return asymmetry measures $C A_{I N T, t-1}\left(r_{t, n, i}\right)$ and $C A_{\theta, t-1}\left(r_{t, n, i}\right)$ could alter a representative investor's optimal asset allocation across 73 country returns relative to the natural benchmark-the value-weighted World portfolio return. As in the previous section, let the subscript $i$ denote a given country and $N_{t-1}$ be the number of countries in the sample at time (month or quarter) $t-1$. We simplify notation by dropping the horizon subscript $n$, while keeping in mind that the portfolio allocation results will be presented at monthly and quarterly frequencies.

An investor chooses portfolio weights $w_{t-1, i}$ to maximize the conditional expected utility of her portfolio return $r_{t, p}$,

$$
\max _{\left\{w_{t-1, i}\right\}_{i=1}^{N_{t-1}}} E_{t-1}\left[u\left(r_{t, p}\right)\right]
$$

where $r_{t, p}=\sum_{i=1}^{N_{t-1}} w_{t-1, i} r_{t, i}$. Following Brandt, Santa-Clara, and Valkanov (2009), we specify 
the portfolio weights of each country as a linear function of the CA measure:

$$
\begin{aligned}
w_{t-1, i} & =\widehat{w}_{t-1, i}+\phi \frac{1}{N_{t-1}} \widetilde{C A_{t-1}}\left(r_{t, i}\right) \\
& =\widehat{w}_{t-1, i}+w_{t-1, i}^{C A}
\end{aligned}
$$

where $\widehat{w}_{t-1, i}$ is the weight of country $i$ in the value-weighted (market) portfolio and $\widetilde{C A}_{t-1}\left(r_{t, i}\right)$ is the asymmetry measure of country $i$, standardized to have mean zero and unit standard deviation at each $t$. The normalization $1 / N_{t-1}$ allows the number of countries to vary across periods.

The weights in expression (12) are estimated by maximizing objective function (11) with respect to the parameter $\phi$. Standardizing $C A_{t-1}\left(r_{t, i}\right)$ ensures that $\sum_{i} w_{t-1, i}^{C A}=0$. This allows us to interpret the estimated $w_{t-1, i}^{C A}$ as the "actively managed" allocation in a longshort portfolio that tilts the optimal weight in country $i$ toward or away from $\widehat{w}_{t-1, i}$ depending on that country's $C A_{t-1}\left(r_{t, i}\right)$ relative to the cross-sectional mean. For instance, if the investor prefers positive skewed assets and the true value of the parameter $\phi$ is positive, then countries with higher (lower) $C A_{t-1}\left(r_{t, i}\right)$ will have a higher (lower) portfolio weight than in the valueweighted portfolio.

Solving for the optimal portfolio policy in (11) allows us to understand how do the performance and holdings change when conditional asymmetry is taken into account. We obtain this result by decomposing the portfolio return based on (12) as:

$$
r_{t, p}=\widehat{r}_{t, p}+r_{t, p}^{C A}
$$

Here, $\widehat{r}_{t, p}=\sum_{i=1}^{N_{t-1}} \widehat{w}_{t-1, i} r_{t, i}$ is the value-weighted market return while $r_{t, p}^{C A}=\sum_{i=1}^{N_{t-1}} w_{t-1, i}^{C A} r_{t, i}$ is the return of the actively-managed portfolio, which measures the economic impact of conditioning on $C A$.

The portfolio approach also enables us to keep track of whether the holdings are in developed versus emerging economies as:

$$
r_{t, p}=r_{t, D M}+r_{t, E M}
$$


In this expression, $r_{t, D M}=\sum_{i} 1_{i}^{D M} w_{t-1, i} r_{t, i}$ is the return attributable to developed markets and $r_{t, E M}$ is defined similarly. The decomposition is based on $\sum_{i} w_{t-1, i}=w_{t-1, D M}+w_{t-1, E M}$, where $w_{t-1, D M}=\sum_{i} 1_{i}^{D M} w_{t-1, i}, w_{t-1, E M}=\sum_{i} 1_{i}^{E M} w_{t-1, i}$ and $1_{i}^{D M}\left(1_{i}^{E M}\right)$ is a dummy variable that equals one if country $i$ is developed (emerging), and zero otherwise. ${ }^{21}$ Moreover, combining expressions (13) and (14), we obtain

$$
r_{t, p}=\widehat{r}_{t, p}+\left(r_{t, D M}^{C A}+r_{t, E M}^{C A}\right)
$$

The impact of $\widetilde{C A_{t-1}}\left(r_{t, i}\right)$ on the portfolio allocation is captured by the actively-managed weights $w_{t-1, D M}^{C A}$ and $w_{t-1, E M}^{C A}$. They reflect the net re-balancing between developed and emerging markets, as $w_{t-1, D M}^{C A}+w_{t-1, E M}^{C A}=0$ (because $\widetilde{C A_{t-1}}\left(r_{t, i}\right)$ is standardized crosssectionally). We report these weights, the returns associated with the re-balancing, $r_{t, D M}^{C A}$ and $r_{t, E M}^{C A}$, and also their correlation $\rho\left(r_{t, D M}^{C A}, r_{t, E M}^{C A}\right)$. The total correlation between the DM and EM returns, $\rho\left(r_{D M, t}, r_{E M, t}\right)$, which is affected by fluctuations in market weights, is also discussed.

The parametric weight function in (12) can be easily generalized to include other conditioning information by letting $w_{t-1, i}=\widehat{w}_{t-1, i}+\phi \frac{1}{N_{t-1}} \widetilde{C A_{t-1}}\left(r_{t, i}\right)+\xi^{\prime} \frac{1}{N_{t-1}} H_{t-1, i}=\widehat{w}_{t-1, i}+$ $w_{t-1, i}^{C A}+w_{t-1, i}^{H}$, where $H_{t-1, i}$ is a vector of country-specific characteristics, and $\xi$ is a vector of coefficients to be estimated. We are interested in $w_{t-1, i}^{C A}$ which is the part of the weights due solely to fluctuations in $\widetilde{C A}_{t-1, i}$.

\subsection{International Portfolio Results}

We estimate the parametric portfolio weights (12) by maximizing the sample analogue of the expected utility (11) with respect to the parameters of interest. In Tables 5 and 6 we present the results for a power utility investor with a coefficient of relative risk aversion $\gamma=5$ who re-balances her portfolio over the entire panel of 73 countries monthly (Panel A) or quarterly (Panel B). Our main conclusions hold for a range of risk aversion parameters and we present those results in a robustness section. The benchmark value-weighted weights are computed based on countries' stock market capitalizations at the end of the previous year.

\footnotetext{
${ }^{21}$ Note that $r_{t, D M}$ and $r_{t, E M}$ are not proper portfolio returns as their weights do not sum up to one. Rather, they are components of $r_{t, p}$ that are attributable to developed versus emerging countries.
} 
Table 5 displays the estimation results for eight specifications of the portfolio weights (12) or its generalization. In columns (1)-(3), we include the measures $C A_{I N T, t-1}\left(r_{t, n}\right)$, $C A_{0.95, t-1}\left(r_{t, n}\right)$, and $C A_{0.75, t-1}\left(r_{t, n}\right)$, separately. The conditional asymmetry has a significant impact on the portfolio allocation at monthly and quarterly horizons. Namely, $C A_{I N T, t-1}\left(r_{t, n}\right)$ enters with the expected positive sign and is significant at the $1 \%$ level. In the quarterly results, a country with a $C A_{I N T, t-1}\left(r_{t, n}\right) 1$ standard deviation higher than the cross-sectional mean ought to have a $2.391 \%$ higher weight in the optimal portfolio than in the value-weighted portfolio. The results are even stronger for the monthly horizons, because the $C A_{I N T, t-1}\left(r_{t, 22}\right)$ estimates are more variable than the $C A_{I N T, t-1}\left(r_{t, 66}\right)$.

We observe that most of the significance comes from the tails of the distribution. Comparing the $C A_{0.95, t-1}\left(r_{t, n}\right)$ and $C A_{0.75, t-1}\left(r_{t, n}\right)$ results, the estimates are larger in magnitude and statistically significant for the 0.95 quantile. The coefficient on $C A_{0.75, t}\left(r_{t, n}\right)$, while positive, is insignificant at monthly and quarterly frequencies. These results suggest that, from an international portfolio perspective, asymmetries in the tail of the distribution of returns can be used to improve upon the benchmark value-weighted portfolio.

In specifications (4)-(8), we include conditional volatility, expected moment-based skewness, co-skewness, and interaction with NBER recessions as additional controls in the parametric portfolio weights. The last column includes both $C A_{0.95, t}\left(r_{t, n}\right)$ and $C A_{0.75, t}\left(r_{t, n}\right)$ in addition to all controls. Expected skewness is computed as the fitted value from regressing the future realized skewness of $n$-day returns on conditional volatility and lagged 250-day skewness, similarly to Boyer, Mitton, and Vorkink (2010). Co-skewness obtains from regressing (lagged) 250-day country returns on the contemporaneous squared returns to the World portfolio. Note that all our conditioning variables are based on the same information set of lagged, 250 daily returns thus allowing proper comparisons. While the value-weighted benchmark should already account for the risk captured in the volatility of country returns (i.e., the value-weighted portfolio should be close to mean-variance efficient), we control for volatility because time-variations in the second moment might give rise to short-term re-balancing opportunities. By including country volatility in the parametric portfolio function, we also rule out the possibility that the $C A$ measures might simply be proxying for volatility given the above-documented negative volatility-conditional asymmetry correlation 
(leverage effect).

The inclusion of additional controls does not significantly alter the coefficients of $C A_{I N T, t-1}\left(r_{t, n}\right)$ and $C A_{0.95, t-1}\left(r_{t, n}\right)$ nor their significance. The estimates in front of volatility have the expected negative sign, but are insignificant at the monthly horizon. Volatility is significant at quarterly horizons only in the $C A_{0.75, t-1}\left(r_{t, n}\right)$ specification. The interaction with NBER recessions does not seem to play a significant role in the optimal allocation at any horizon. This implies that the portfolio gains of conditioning on $C A$ are not purely concentrated around recession times. Expected skewness has the expected positive sign in all specifications in Panels A and B. At monthly frequency, it is insignificant in the specification with $C A_{I N T, t-1}\left(r_{t, n}\right)$ and $C A_{0.95, t-1}\left(r_{t, n}\right)$, but the magnitude of its coefficients are about twothirds smaller. However, it is significant at quarterly horizons for most of the specifications. Co-skewness, on the other hand, is not significant at any horizon in any of the specifications.

Table 6 presents the allocation and performance of the same eight specifications at monthly and quarterly frequencies. In each panel, we first report time-series averages of the weights $w_{t-1, i}$ and their decompositions, then of returns and their decompositions, and finally risk and portfolio performance statistics. All returns are annualized to facilitate comparison across horizons. As a benchmark, the first column "VW" displays the properties of the value-weighted portfolio. In it, the average weight placed on emerging markets $w_{E M}$ is $9.290 \%$ and the average total return $\bar{r}_{p}$ of $7.7 \%$ is mostly due to the performance of developed markets $\left(\bar{r}_{D M}\right) .{ }^{22}$ The annualized volatility of the value-weighted portfolio is $16.3 \%$ and its skewness is -1.038 .

Exploiting $C A_{I N T, t-1}\left(r_{t, 22}\right)$ shifts the monthly portfolio allocation significantly toward emerging markets. In specification (1), the average EM weight is $47 \%$, which is about five times higher that in the value-weighted allocation. The average portfolio return increases to 14.6\%, with all the gains coming from EM markets (7.2\%). The correlation between the EM and DM components is close to zero (-0.072). Since specification (1) has only one conditioning variable, $C A_{I N T, t-1}\left(r_{t, n}\right)$, the average EM returns attributable to $C A_{I N T, t-1}\left(r_{t, n}\right)$ fluctuations $\left(\bar{r}_{E M}^{C A}\right)$ is $7.2 \%$ whereas for DM indices it is negligible $(-0.003)$. In other words, the

\footnotetext{
${ }^{22}$ This finding can be explained as follows. EM have positive average returns in our sample (see Table 1), but their weight in the VW portfolio increases in significance just in the latter part of the sample, when realized returns happen to be low.
} 
optimal portfolio weights successfully exploit the favorable asymmetry in emerging markets. The volatility of the optimal portfolio $(16 \%)$ is actually lower than that of the value-weighted benchmark and its certainty equivalent return is $8.4 \%$. Importantly, the optimal portfolio moment-based skewness is now positive at 0.501 whereas it is -1.038 in the value-weighted portfolio. The increased skewness of the optimal portfolio is a good check that conditioning on $C A_{I N T, t-1}\left(r_{t, 22}\right)$ has the expected effect and is further confirmation that $C A_{I N T, t-1}\left(r_{t, 22}\right)$ is a proper measure of return asymmetry.

The results for $C A_{0.95, t-1}\left(r_{t, n}\right)$ in column (2) are similar to those in column (1). The resultant optimal portfolio allocates about $40 \%$ of the portfolio weight into EM countries, and its return and volatility are $16.5 \%$ and $17.0 \%$, respectively. Most of the gains are again attributable to EM countries $\left(\bar{r}_{E M}\right.$ is 0.082$)$ and the correlation between the EM and DM components of the return is -0.152 . The $C A_{0.75, t-1}\left(r_{t, n}\right)$ results in column 3 are markedly different, mirroring the low and statistically insignificant coefficient in front of $C A_{0.75, t-1}\left(r_{t, n}\right)$ in Table 5.

The properties of the optimal portfolio are not significantly altered by the inclusion of country volatility, expected skewness, and co-skewness. In specifications (4), (5), (7), and (8) the portfolio weight in EM is between $41.621 \%$ and $48.335 \%$. The portfolio returns in those specifications are in the $15 \%$ to $21 \%$ range, the volatility is between $16 \%$ and $19.6 \%$, and the certainty equivalent return is between $9 \%$ and $10 \%$. Interestingly, the gains in these portfolios can mostly be traced to the $C A$ measures rather than to the other controls. To see that in specification (4), we compare the average active returns from EM countries $\bar{r}_{E M}$ of $8.6 \%$ to the average $\bar{r}_{E M}^{C A}$ of $7.0 \%$. The first return captures the joint impact of all controls whereas the second one isolates the contribution of the CA measure in the return decomposition. Similar results hold for specifications (5), (7), and (8).

The use of $C A_{0.75, t-1}\left(r_{t, n}\right)$ in columns (3) and (6) does not lead to important portfolio improvements. The performance gains are lower than for the other two measures, the weight on $\mathrm{EM}$ is lower, and so is the certainty equivalent return. By contrast, including $C A_{0.95, t-1}\left(r_{t, n}\right)$ and $C A_{0.75, t-1}\left(r_{t, n}\right)$ jointly (specification $\left.(8)\right)$ raises the optimal portfolio performance, the weights on EM, and the certainty equivalent return. This is perhaps the most convincing evidence that asymmetries are exploitable in an international portfolio context as long as 
they are in the tails of the distribution.

The quarterly results in Panel B of Table 6 are similar with a few qualifications. The use of $C A_{I N T, t-1}\left(r_{t, 66}\right)$ and $C A_{0.95, t-1}\left(r_{t, 66}\right)$ increases the average weight in emerging markets from $9.161 \%$ to between $23 \%$ and $39 \%$. The somewhat lower weight on EM is attributable to the lower volatility of the quarterly CA statistics. While the portfolio returns and certainty equivalent return are somewhat lower than in the monthly case, they are still economically meaningful. For instance, the certainty equivalent return in all specifications excluding (3) and (6) are between $3.1 \%$ to $8.8 \%$ higher than that of the value-weighted benchmark, which is practically zero $(-0.009)$.

In Figure 6, we display the time-series of the quarterly optimal portfolio weights $w_{t-1, E M}$ and $w_{t-1, E M}^{C A}$ in specification (6). In Panel A, we see a clear upward drift in $w_{t-1, E M}$ which implies that the optimal portfolio allocates a larger fraction of the overall holdings to emerging markets. Part of that increase is due to the fact that emerging stock markets are growing faster than some developed markets and are getting a larger share in the value-weighted portfolio. Another part is due to the pure conditional asymmetry effect, which is captured in $w_{t-1, E M}^{C A}$ and displayed in Panel B. The positive albeit not as pronounced trend in $w_{t-1, E M}^{C A}$ implies that the gains from exploiting conditional asymmetry in emerging markets are quite stable and persistent over time. Finally, we include in the plot the minimum and maximum weights across EM on a given quarter. For the optimal $C A$ weights, these vary in the -0.10 to 0.10 range implying that short and long positions in any given country do not exceed $10 \%$ of the value of the portfolio. This evidence is rather reassuring that the gains we document in Table 6 do not emerge from the investor taking disproportionately large positions in a small number of countries.

Overall, the evidence in Tables 5, 6 and Figure 6 convey a uniform message: conditioning on $C A_{I N T, t-1}\left(r_{t, n}\right)$ and $C A_{0.95, t-1}\left(r_{t, n}\right)$ improves the portfolio allocation by tilting the portfolio toward emerging economies, because their returns tend to be less negatively skewed. Asymmetries that are not in the tail of the return distribution have little effect on portfolio allocation decisions. 


\subsection{Additional Analysis and Robustness}

We perform a series of checks to verify that the portfolio results are robust to the choice of the risk aversion parameter, to de-TARCHing the returns, and to an alternative dataset. The results are presented in Table 7 for monthly returns following the format of Tables 5 and 6. For conciseness, we display only the loading on $C A_{I N T, t-1}\left(r_{t, n}\right)$ corresponding to specification (7) of Table 5.

Different degree of relative risk aversion: We estimate the optimal portfolio policy for $\gamma$ of 3, 10, and 20. The results are displayed in columns (1), (3), and (4) respectively. The benchmark $\gamma=5$ from Table 5 is also reported in column (2) to facilitate the comparison. The $C A_{I N T, t-1}\left(r_{t, n}\right)$ measure is always significant, more so when the investor is less risk averse. This is expected as low $\gamma$ investors are able to better exploit fluctuations in conditional asymmetry. Investors with a $\gamma$ of 20 and 10 hold on average between $29 \%$ and $36 \%$ of their portfolio in emerging economies, which is significantly larger than the value-weighted weight of about $9 \%$. In all specifications, the correlations between the EM and DM returns is close to zero. The certainty equivalent return and alpha of the optimal portfolio decrease as the risk aversion increases.

Volatility-Filtered Returns: We saw in section 3.4 that there are significant dynamics in the quantiles of de-TARCHed returns. However, the question remains whether the conditional asymmetry in the de-TARCHed returns is substantial enough to matter in an international portfolio context. To this end, we compute the optimal portfolio weights conditioning on $C A_{I N T, t-1}\left(r_{t, n}\right)$ estimated from the quantiles of de-TARCHed returns in section 3.4. The results are reported for $\gamma=5$ in column (5) of Table 7 . The coefficient of $C A_{I N T, t-1}\left(r_{t, n}\right)$ is statistically significant and very similar to that of the unfiltered series (column (2)). This result is not unexpected if we recall that the quantiles of the filtered and unfiltered returns are highly correlated.

Investable indices: Is the predicted optimal portfolio a truly achievable investment strategy? This issue is relevant for international portfolio allocation as foreigners cannot invest in country indices in an unrestricted fashion. To address this concern, following Christoffersen, Errunza, Jacobs, and Jin (2012), we rely on Emerging Markets S\&P IFCI indices, which 
track the return a foreign investor is legally able to achieve through investment in a country domestic equity. For Developed Markets, we use FTSE indices. The use of this series reduces considerably our time span as the data start on July 3, 1995. We also have a smaller cross section. All developed markets but Iceland are in this sample, but we only have a subset of 19 out of the 48 emerging countries. ${ }^{23}$

We estimate the conditional asymmetry and the dynamic portfolio policy problem at the monthly horizon for this new dataset and report the results in column (5). The role of conditional asymmetry remains significant and economically strong. In particular, the loading on $C A_{I N T}$ is now 4.050 (compared to 2.988 in column (2)) with a certainty equivalent return of 0.099 (versus 0.091). The fraction invested in emerging markets due to conditional asymmetry remains substantially larger than in the value-weighted portfolio figure (which is about $5 \%$ ). This evidence clarifies that our results are not driven by positions in very small countries that may be in practice out-of-reach.

\section{Conclusions}

We use a new approach to estimate the conditional asymmetry in portfolio returns at different points of the distribution and study a large cross-section of developed and emerging markets. Estimates of $C A$ reveal several novel results such as significant dynamics over time, heterogeneity across countries, a low correlation between asymmetries of DM and EM portfolio returns, and negative correlation with the conditional volatility. These findings have significant implications for international asset allocation and risk sharing, some of which are explored in this paper. Namely, employing a parametric portfolio approach to study the impact of return asymmetry on the asset allocation across 73 countries, we find that the optimal portfolio is tilted toward countries that are less negatively skewed, which in our sample are the emerging economies. In other words, the introduction of conditional asymmetry results in the optimal portfolio placing a significantly larger weight on emerging economies than does the value-weighted portfolio.

Our empirical findings suggest a rich agenda for future research. First, the low correlation

\footnotetext{
${ }^{23}$ These countries tend to have mature and liquid markets. They are: Brazil, Chile, China, Czech Republic, Egypt, Hungary, India, Indonesia, Malaysia, Mexico, Morocco, Peru, Philippines, Poland, Russia, South Africa, Taiwan, Thailand, and Turkey.
} 
in $C A$ s prompts questions about its economic provenance and significance. Exploring the role of global and country-specific macroeconomic shocks in driving the conditional asymmetry in returns might prove particularly insightful. Moreover, while we do not directly link expected returns and conditional asymmetry, an explicit investigation of this relation, following Boyer, Mitton, and Vorkink's (2010) work on U.S. data, would be of great importance for international asset pricing. Finally, our investigation focuses primarily on monthly and quarterly returns, but it also suggests that the term structure of conditional skewness may provide new insights into the measures of risk at different horizons. While we know remarkably little about this topic, the current mixed-data approach offers a tractable framework for further explorations. 


\section{References}

Andreou, Elena, Eric Ghysels, and Andros Kourtellos, 2011, Forecasting with MixedFrequency Data, in M. P. Clements, and D. F. Hendry, ed.: Oxford Handbook of Economic Forecasting. Oxford University Press.

Armesto, Michelle T., Kristie M. Engenmann, and Michael T. Owyang, 2010, Forecasting with mixed frequencies, Federal Reserve Bank of St. Louis Review 92, 521-536.

Barberis, Nicholas, and Ming Huang, 2008, Stocks as Lotteries: The Implications of Probability Weighting for Security Prices, American Economic Review 98, 2066-2100.

Bekaert, Geert, and Campbell R. Harvey, 1995, Time-Varying World Market Integration, Journal of Finance 50, 403-444. 77.

, 1997, Emerging Equity Market Volatility, Journal of Financial Economics 43, 29-

Christian Lundblad, and Stephan Siegel, 2011, What Segments Equity Markets?, Review of Financial Studies 24, 3847-3890.

Bowley, Arthur, 1920, Elements of Statistics (Charles Scribner's Sons: New York).

Boyer, Brian, Todd Mitton, and Keith Vorkink, 2010, Expected Idiosyncratic Skewness, Review of Financial Studies 23, 169-202.

Brandt, Michael, 2010, Portfolio choice problems, in Y. Ait-Sahalia, and L.P. Hansen, ed.: Handbook of Financial Econometrics, Volume 1: Tools and Techniques pp. 269-336. North Holland.

, Pedro Santa-Clara, and Rossen Valkanov, 2009, Parametric Portfolio Policies: Exploiting Characteristics in the Cross Section of Equity Returns, Review of Financial Studies $22,3411-3447$.

Brunnermeier, Markus, Christian Gollier, and Jonathan Parker, 2007, Optimal Beliefs, Asset Prices and the Preference for Skewed Returns, American Economics Review (Papers and Proceedings) 97, 159-165.

Campbell, John, and Luis Viceira, 2002, Strategic Asset Allocation: Portfolio Choice for Long-Term Investors (Oxford University Press).

Campbell, John Y., and Ludger Hentschel, 1992, No News is Good News: An Asymmetric Model of Changing Volatility in Stock Returns, Journal of Financial Economics 31, 281318.

Chang, B., Peter Christoffersen, and Kris Jacobs, 2013, Market Skewness Risk and the Cross-Section of Stock Returns. , 107, 46-68., Journal of Financial Economics 107, 46-68.

Chen, Joseph, Harrison Hong, and Jeremy Stein, 2001, Forecasting Crashes: Trading Volume, Past Returns, and Conditional Skewness in Stock Prices, Journal of Financial Economics 61, 345-381.

Chernozhukov, Victor, Iván Fernández-Val, and A. Galichon, 2010, Quantile and Probability Curves without Crossing, Econometrica 78, 1093-1125.

Cho, D. Chinhyung, Cheol S. Eun, and Lemma W. Senbet, 1986, International Arbitrage Pricing Theory: An Empirical Investigation, Journal of Finance 41, 313-329. 
Christoffersen, Peter, Vihang R. Errunza, Kris Jacobs, and Xisong Jin, 2012, Is the Potential for International Diversification Disappearing?, Review of Financial Studies 25, 3711-3751 Discussion Paper, University of Toronto.

Conrad, Jennifer, Robert Dittmar, and Eric Ghysels, 2013, Ex Ante Skewness and Expected Stock Returns, Journal of Finance 68, 85-124.

DeMiguel, Victor, Yuliya Plyakha, Raman Uppal, and Grigory Vilkov, 2013, Improving Portfolio Selection using Option-implied Volatility and Skewness, Journal of Financial and Quantitative Analysis, forthcoming.

Dette, Holger, and Stanislav Volgushev, 2008, Non-crossing Non-parametric Estimates of Quantile Curves, Journal of the Royal Statistical Society: Series B (Statistical Methodology) $70,609-627$.

Engle, Robert, and Simone Manganelli, 2004, CAViaR: COnditional Autoregressive Value at Risk by Regression Quantiles, Journal of Business and Economic Statistics 22, 367-381.

Engle, Robert, and Abhishek Mistry, 2007, Priced Risk and Asymmetric Volatility in the Cross-Section of Skewness, Working Paper, NYU Stern School of Business.

Engle, Robert, and Jose Gonzalo Rangel, 2008, The Spline-GARCH Model for LowFrequency Volatility and Its Global Macroeconomic Causes, Review of Financial Studies 21, 1187-1222.

Fama, Eugene F., and Kenneth R. French, 1998, Value versus Growth: The International Evidence, Journal of Finance 53, 1975-1999.

Ghysels, Eric, 2013, Matlab Toolbox for Mixed Sampling Frequency Data Analysis using MIDAS Regression Models - Version 8, Available at http://www. unc. edu/ eghysels.

, Pedro Santa-Clara, and Rossen Valkanov, 2005, There is a Risk-Return Tradeoff After All, Journal of Financial Economics 76, 509-548.

— 2006, Predicting Volatility: Getting the Most out of Return Data Sampled at Different Frequencies, Journal of Econometrics 131, 59-95.

Ghysels, Eric, Arthur Sinko, and Rossen Valkanov, 2006, MIDAS Regressions: Further Results and New Directions, Econometric Reviews 26, 53-90.

Ghysels, Eric, and Rossen Valkanov, 2011, Volatility Prediction with MIDAS, in L. Bauwens, C. Hafner, and S. Laurent, ed.: Wiley Handbook Volatility Models and Their Applications. Wiley (forthcoming).

Glosten, Larry R., Ravi Jagannathan, and David E. Runkle, 1993, On the Relation Between the Expected Value and the Volatility of the Nominal Excess Return on Stocks, Journal of Finance 48, 1779-1801.

Groeneveld, Richard, and Glen Meeden, 1984, Measuring Skewness and Kurtosis, The Statistician 33, 391-399.

Guidolin, Massimo, and Allan Timmermann, 2008, International Asset Allocation under Regime Switching, Skew, and Kurtosis Preferences, Review of Financial Studies 21, 889935.

Harvey, Campbell R., 1991, The World Price of Covariance Risk, Journal of Finance 46, $111-157$. 
, 1995, Predictable Risk and Returns in Emerging Markets, Review of Financial Studies 8, 773-816.

, John C. Liechty, Merrill W. Liechty, and Peter Muller, 2010, Portfolio selection with higher moments, Quantitative Finance 10, 469-485.

Harvey, Campbell R., and Akhtar Siddique, 1999, Autoregressive Conditional Skewness, Journal of Financial and Quantitative Analysis 34, 465-487.

Henry, Peter B., 2000, Stock Market Liberalization, Economic Reform, and Emerging Market Equity Prices, Journal of Finance 55, 529-564.

Hinkley, David V., 1975, On Power Transformations to Symmetry, Biometrika 62, 101-111.

Hong, Harrison, and Jeremy C. Stein, 2003, Differences of Opinion, Short Sales Constraints, and Market Crashes, Review of Financial Studies 16, 487-525.

Jondeau, E., and M. Rockinger, 2006, Optimal Portfolio Allocation under Higher Moments, European Financial Management 12, 29-55.

Kim, Tae-Hwan, and Halbert White, 2004, On More Robust Estimation of Skewness and Kurtosis, Finance Research Letters 1, 56-70.

King, Mervyn, Enrique Sentana, and Sushi Wadhwani, 1994, Volatility and Links between National Stock Markets, Econometrica 62, 901-933.

Koenker, Roger, and George Bassett, 1978, Regression Quantiles, Econometrica 46, 33-50.

Koenker, Roger, and Zhijie Xiao, 2006, Quantile Autoregression, Journal of the American Statistical Association 101, 980-990.

Korajczyk, Robert, and Claude Viallet, 1989, An Empirical Investigation of International Asset Pricing, Review of Financial Studies 2, 553-585.

Kraus, Alan, and Robert Litzenberger, 1976, Skewness Preference and the Valuation of Risk Assets, Journal of Finance 31, 1085-1100.

— 1983 , On the distributional conditions for a consumption-oriented three moment capm, The Journal of Finance 38, pp. 1381-1391.

Kupiec, Paul, 1995, Techniques for Verifying the Accuracy of Risk Measurement Models, Journal of Derivatives 2, 73-84.

León, Ángel, Gonzalo Rubio, and Gregorio Serna, 2005, Autoregressive Conditional Volatility, Skewness and Kurtosis, Quarterly Review of Economics and Finance 45, 599-618.

Neuberger, Anthony, 2012, Realized skewness, Review of Financial Studies 25, 3423-3455.

Newey, Whitney K., and Kenneth D. West, 1987, A simple positive semi-definite, heteroskedasticity and autocorrelation consistent covariance matrix, Econometrica 55, 703708.

Pearson, Karl, 1895, Contributions to the Mathematical Theory of Evolution. II. Skew Variation in Homogeneous Material, Philosophical Transactions of the Royal Society of London. A $186,343-414$.

Pukthuanthong, Kuntara, and Richard Roll, 2009, Global Market Integration: An Alternative Measure and its Application, Journal of Financial Economics 94, 214-232. 
— , 2010, Internationally Correlated Jumps, UCLA Anderson School Working Paper.

Rubinstein, Mark E., 1973, The fundamental theorem of parameter-preference security valuation, Journal of Financial and Quantitative Analysis 8, 61-69.

Solnik, Bruno, 1974, The International Pricing of Risk: An Empirical Investigation of the World Capital Market Structure, Journal of Finance 29, 48-54.

Stulz, Rene, 1987, An equilibrium model of exchange rate determination and asset pricing with nontraded goods and imperfect information, Journal of Political Economy 95, 10241040 .

Viceira, Luis, 2001, Optimal Portfolio Choice for Long-Horizon Investors with Nontradable Labor Income, Journal of Finance 56, 433-470.

Weiss, Andrew A., 1991, Estimating Nonlinear Dynamic Models using Least Absolute Error Estimation, Econometric Theory 7, 46-68.

White, Halbert, 1996, Estimation, Inference and Specification Analysis (Cambridge University Press: Cambridge).

Tae-Hwan Kim, and Simone Manganelli, 2008, Modeling Autoregressive Conditional Skewness and Kurtosis with Multi-Quantile CAViaR, in Robert F. Engle, and Halbert White, ed.: A Festschrift in Honor of Clive W.J. Granger. Oxford University Press. 


\section{Table 1: Unconditional Statistics of International Equity Markets}

The table reports Initial date, total number of observations $(N)$, annualized mean (Mean), annualized standard deviation (Std), and unconditional measures of asymmetry at the monthly (subscript ' $t, 22$ ') and quarterly (subscript ' $t, 66$ ') horizon of returns to the MSCI World portfolio and 73 individual country stock markets. $S$ denotes the moment-based skewness estimator. $S^{T}$ denotes the moment-based skewness estimator, when the top $0.5 \%$ and bottom $0.5 \%$ of the distribution of daily returns have been truncated. $R A_{I N T}$ is the integrated quantile-based robust measure of asymmetry from expression (2), using $\theta=[0.99 ; 0.975 ; 0.95 ; 0.90 ; 0.85 ; 0.80 ; 0.75]$. Superscripts $a, b$, and $c$ denote statistical significance at the $1 \%, 5 \%$, and $10 \%$ confidence level, respectively, based on Monte Carlo simulation assuming daily returns are normal with sample mean and standard deviation. In italics, we report averages for the group of Developed Markets (DM) and Emerging Markets (EM).

\begin{tabular}{|c|c|c|c|c|c|c|c|c|c|c|}
\hline Country & Initial date & $N$ & Mean & Std & $S\left(r_{t, 22}\right)$ & $S\left(r_{t, 66}\right)$ & $S^{T}\left(r_{t, 22}\right)$ & $S^{T}\left(r_{t, 66}\right)$ & $R A_{I N T}\left(r_{t, 22}\right)$ & $R A_{I N T}\left(r_{t, 66}\right)$ \\
\hline World & $01 / 02 / 1980$ & 8348 & 0.066 & 0.144 & $-1.095^{a}$ & $-0.990^{a}$ & $-0.541^{a}$ & $-0.297^{b}$ & $-0.159^{a}$ & $-0.132^{a}$ \\
\hline \multicolumn{11}{|c|}{ Developed Markets (DM) } \\
\hline U.S. & $01 / 02 / 1980$ & 8348 & 0.105 & 0.177 & $-1.140^{a}$ & $-1.102^{a}$ & $-0.500^{a}$ & $-0.692^{a}$ & $-0.157^{a}$ & $-0.179^{a}$ \\
\hline Japan & $01 / 02 / 1980$ & 8348 & 0.059 & 0.215 & -0.014 & -0.023 & -0.099 & 0.028 & 0.011 & -0.023 \\
\hline U.K. & $01 / 02 / 1980$ & 8348 & 0.106 & 0.195 & $-0.897^{a}$ & $-0.849^{a}$ & $-0.190^{b}$ & -0.067 & $-0.065^{b}$ & $-0.078^{c}$ \\
\hline Hong Kong & $01 / 02 / 1980$ & 8348 & 0.111 & 0.275 & $-1.374^{a}$ & $-0.918^{a}$ & $-0.577^{a}$ & $-0.744^{a}$ & $-0.164^{a}$ & $-0.217^{a}$ \\
\hline Canada & $01 / 02 / 1980$ & 8348 & 0.087 & 0.193 & $-1.326^{a}$ & $-1.224^{a}$ & $-0.214^{a}$ & -0.106 & $-0.123^{a}$ & $-0.187^{a}$ \\
\hline France & $01 / 02 / 1980$ & 8348 & 0.097 & 0.213 & $-1.010^{a}$ & $-0.711^{a}$ & $-0.562^{a}$ & $-0.331^{a}$ & $-0.156^{a}$ & $-0.146^{a}$ \\
\hline Australia & $01 / 02 / 1980$ & 8348 & 0.102 & 0.226 & $-1.572^{a}$ & $-1.169^{a}$ & $-0.417^{a}$ & $-0.488^{a}$ & $-0.087^{a}$ & $-0.178^{b}$ \\
\hline Germany & $01 / 02 / 1980$ & 8348 & 0.078 & 0.236 & $-0.838^{a}$ & $-0.613^{a}$ & $-0.574^{a}$ & $-0.327^{b}$ & $-0.134^{a}$ & $-0.082^{c}$ \\
\hline Switzerland & $01 / 02 / 1980$ & 8348 & 0.105 & 0.175 & $-0.744^{a}$ & $-0.350^{b}$ & $-0.440^{a}$ & -0.097 & $-0.123^{a}$ & -0.063 \\
\hline Spain & $01 / 02 / 1980$ & 8348 & 0.071 & 0.219 & $-0.354^{a}$ & 0.184 & $-0.225^{a}$ & $0.322^{b}$ & -0.041 & 0.018 \\
\hline South Korea & $01 / 02 / 1980$ & 8348 & 0.056 & 0.327 & $-0.855^{a}$ & $-1.021^{a}$ & -0.064 & $-0.470^{a}$ & $0.023^{c}$ & -0.047 \\
\hline Sweden & $01 / 02 / 1980$ & 8348 & 0.104 & 0.247 & $-0.753^{a}$ & $-0.754^{a}$ & $-0.375^{a}$ & $-0.378^{a}$ & $-0.135^{a}$ & $-0.136^{a}$ \\
\hline Italy & $01 / 02 / 1980$ & 8348 & 0.086 & 0.243 & $-0.378^{a}$ & 0.171 & $-0.242^{a}$ & $0.318^{b}$ & -0.036 & $0.070^{b}$ \\
\hline Netherlands & $01 / 02 / 1980$ & 8348 & 0.106 & 0.200 & $-1.863^{a}$ & $-2.065^{a}$ & $-0.865^{a}$ & $-0.751^{a}$ & $-0.206^{a}$ & $-0.254^{a}$ \\
\hline Singapore & $01 / 02 / 1980$ & 8348 & 0.105 & 0.220 & $-0.818^{a}$ & $-0.610^{a}$ & $-0.332^{a}$ & $-0.561^{a}$ & $-0.097^{a}$ & $-0.125^{a}$ \\
\hline Norway & $01 / 03 / 1980$ & 8347 & 0.102 & 0.267 & $-1.135^{a}$ & $-1.294^{a}$ & $-0.552^{a}$ & $-0.419^{a}$ & $-0.159^{a}$ & $-0.164^{a}$ \\
\hline Belgium & $01 / 02 / 1980$ & 8348 & 0.096 & 0.188 & $-1.360^{a}$ & $-1.198^{a}$ & $-0.457^{a}$ & $-0.386^{a}$ & $-0.100^{a}$ & $-0.098^{b}$ \\
\hline Denmark & $01 / 02 / 1980$ & 8348 & 0.118 & 0.222 & $-0.907^{a}$ & $-1.311^{a}$ & $-0.434^{a}$ & $-0.379^{a}$ & $-0.080^{a}$ & $-0.172^{a}$ \\
\hline Israel & $04 / 24 / 1987$ & 6441 & 0.090 & 0.274 & $-0.620^{a}$ & $-0.537^{a}$ & $-0.560^{a}$ & $-0.836^{a}$ & $-0.160^{a}$ & $-0.107^{b}$ \\
\hline Finland & $01 / 03 / 1991$ & 5477 & 0.094 & 0.297 & $-0.500^{a}$ & $-0.476^{a}$ & $-0.460^{a}$ & $-0.379^{b}$ & $-0.126^{a}$ & $-0.156^{a}$ \\
\hline Austria & $01 / 02 / 1980$ & 8348 & 0.090 & 0.201 & $-0.437^{a}$ & 0.134 & $0.196^{b}$ & $1.119^{a}$ & 0.052 & $0.132^{a}$ \\
\hline Portugal & $01 / 06 / 1988$ & 6258 & 0.025 & 0.194 & $-0.649^{a}$ & $-0.325^{b}$ & $-0.397^{a}$ & -0.119 & $-0.081^{a}$ & $-0.071^{b}$ \\
\hline Ireland & $01 / 02 / 1980$ & 8348 & 0.095 & 0.217 & $-1.059^{a}$ & $-1.012^{a}$ & $-0.458^{a}$ & $-0.498^{a}$ & $-0.117^{a}$ & $-0.128^{a}$ \\
\hline New Zealand & $01 / 05 / 1988$ & 6259 & 0.080 & 0.203 & $-0.335^{a}$ & $-0.566^{a}$ & $-0.422^{a}$ & $-0.290^{b}$ & $-0.119^{a}$ & $-0.094^{b}$ \\
\hline Iceland & $01 / 01 / 1993$ & 4956 & -0.013 & 0.333 & $-7.914^{a}$ & $-4.979^{a}$ & $-0.860^{a}$ & $-1.332^{a}$ & $-0.264^{a}$ & $-0.555^{a}$ \\
\hline Average & & & 0.086 & 0.230 & -1.154 & -0.905 & -0.403 & -0.315 & -0.106 & -0.122 \\
\hline \multicolumn{11}{|c|}{ Emerging Markets (EM) } \\
\hline China & $04 / 04 / 1991$ & 5412 & 0.091 & 0.375 & $0.446^{a}$ & $0.496^{a}$ & $0.449^{a}$ & $0.503^{a}$ & $0.095^{b}$ & $0.136^{c}$ \\
\hline India & $01 / 05 / 1987$ & 6520 & 0.078 & 0.284 & $-0.317^{a}$ & -0.061 & $-0.282^{a}$ & -0.212 & $-0.062^{a}$ & -0.008 \\
\hline Brazil & $04 / 13 / 1983$ & 7493 & 0.128 & 0.635 & $-0.662^{a}$ & $-0.392^{a}$ & -0.055 & -0.060 & $-0.062^{c}$ & $-0.118^{b}$ \\
\hline South Africa & $01 / 02 / 1980$ & 8348 & 0.102 & 0.269 & $-0.853^{a}$ & $-0.564^{a}$ & $-0.321^{a}$ & $-0.323^{b}$ & $-0.115^{a}$ & $-0.113^{b}$ \\
\hline Russia & $09 / 04 / 1995$ & 4260 & 0.154 & 0.431 & $-1.061^{a}$ & $-1.220^{a}$ & $-0.977^{a}$ & $-1.304^{a}$ & $-0.185^{a}$ & $-0.200^{a}$ \\
\hline Taiwan & $01 / 01 / 1985$ & 7044 & 0.085 & 0.305 & $-0.157^{b}$ & $-0.230^{c}$ & $-0.341^{a}$ & -0.091 & -0.021 & -0.070 \\
\hline Mexico & $01 / 05 / 1988$ & 6259 & 0.162 & 0.310 & $-0.880^{a}$ & $-1.423^{a}$ & $-0.444^{a}$ & $-0.406^{b}$ & $-0.165^{a}$ & $-0.193^{a}$ \\
\hline Malaysia & $01 / 03 / 1980$ & 8347 & 0.049 & 0.256 & $-0.476^{a}$ & $-1.001^{a}$ & $-0.623^{a}$ & $-1.095^{a}$ & $-0.132^{a}$ & $-0.255^{a}$ \\
\hline Indonesia & $04 / 03 / 1990$ & 5674 & 0.019 & 0.395 & $-0.696^{a}$ & $-0.716^{a}$ & $-0.377^{a}$ & $-0.366^{b}$ & $-0.108^{a}$ & $-0.188^{a}$ \\
\hline
\end{tabular}


Table 1 (Cont'd): Unconditional Statistics of International Equity Markets

\begin{tabular}{|c|c|c|c|c|c|c|c|c|c|c|}
\hline Country & Initial date & $N$ & Mean & Std & $S\left(r_{t, 22}\right)$ & $S\left(r_{t, 66}\right)$ & $S^{T}\left(r_{t, 22}\right)$ & $S^{T}\left(r_{t, 66}\right)$ & $R A_{I N T}\left(r_{t, 22}\right)$ & $R A_{I N T}\left(r_{t, 66}\right)$ \\
\hline Saudi Arabia & $01 / 02 / 1998$ & 3651 & 0.106 & 0.237 & $-0.867^{a}$ & $-1.020^{a}$ & $-0.429^{a}$ & -0.120 & $-0.100^{b}$ & $-0.151^{a}$ \\
\hline Chile & 07/04/1989 & 5869 & 0.154 & 0.194 & $-0.303^{a}$ & -0.025 & -0.030 & 0.149 & -0.027 & 0.017 \\
\hline Turkey & $01 / 05 / 1988$ & 6259 & 0.054 & 0.497 & -0.106 & -0.203 & -0.085 & -0.124 & -0.005 & $-0.090^{c}$ \\
\hline Thailand & $01 / 05 / 1987$ & 6520 & 0.107 & 0.312 & -0.129 & $-0.394^{b}$ & $-0.489^{a}$ & $-0.707^{a}$ & $-0.112^{a}$ & $-0.097^{b}$ \\
\hline Colombia & 03/11/1992 & 5168 & 0.113 & 0.215 & $-0.635^{a}$ & -0.192 & -0.110 & -0.015 & -0.091 & -0.003 \\
\hline Poland & 04/17/1991 & 5403 & 0.108 & 0.346 & -0.103 & $0.310^{b}$ & $0.162^{c}$ & $0.417^{b}$ & -0.027 & -0.026 \\
\hline Kuwait & $12 / 29 / 1994$ & 4437 & 0.077 & 0.150 & $-1.594^{a}$ & $-1.437^{a}$ & $-0.990^{a}$ & $-1.175^{a}$ & $-0.119^{a}$ & $-0.234^{b}$ \\
\hline Philippines & 01/03/1986 & 6781 & 0.097 & 0.304 & 0.091 & -0.043 & 0.100 & 0.055 & $-0.016^{b}$ & -0.069 \\
\hline Peru & $01 / 03 / 1991$ & 5477 & 0.227 & 0.274 & 0.000 & -0.100 & $0.303^{a}$ & 0.029 & $0.052^{b}$ & 0.026 \\
\hline Nigeria & 07/03/1995 & 4305 & 0.090 & 0.194 & $-0.236^{b}$ & $-1.106^{a}$ & 0.003 & $-0.673^{a}$ & 0.003 & -0.145 \\
\hline Egypt & $01 / 03 / 1995$ & 4434 & 0.047 & 0.243 & $-0.196^{b}$ & -0.104 & 0.142 & 0.251 & 0.047 & 0.045 \\
\hline Greece & $10 / 03 / 1988$ & 6065 & 0.013 & 0.301 & -0.120 & 0.040 & $-0.257^{a}$ & $-0.257^{c}$ & 0.006 & 0.004 \\
\hline Argentina & $10 / 20 / 1989$ & 5791 & 0.027 & 0.508 & $-0.581^{a}$ & $-0.289^{c}$ & $-0.273^{a}$ & $-0.412^{b}$ & $-0.083^{a}$ & $-0.116^{a}$ \\
\hline Ukraine & $02 / 02 / 1998$ & 3630 & 0.029 & 0.422 & $0.168^{c}$ & $-0.824^{a}$ & $-1.038^{a}$ & $-1.766^{a}$ & $-0.119^{a}$ & $-0.115^{a}$ \\
\hline Bangladesh & $01 / 02 / 1990$ & 5739 & 0.056 & 0.307 & $0.351^{a}$ & $0.454^{a}$ & -0.050 & 0.202 & 0.041 & 0.078 \\
\hline Pakistan & $01 / 02 / 1989$ & 6000 & 0.058 & 0.262 & $-0.357^{a}$ & $-0.258^{c}$ & $-0.435^{a}$ & $-0.400^{b}$ & -0.011 & -0.005 \\
\hline CzechRepublic & $11 / 10 / 1993$ & 4733 & 0.123 & 0.273 & $-0.284^{a}$ & $-0.574^{a}$ & $-0.664^{a}$ & $-0.297^{c}$ & $-0.114^{a}$ & $-0.154^{c}$ \\
\hline Romania & $09 / 22 / 1997$ & 3725 & -0.001 & 0.332 & $-0.798^{a}$ & $-0.882^{a}$ & $-0.782^{a}$ & $-0.944^{a}$ & $-0.162^{a}$ & $-0.253^{a}$ \\
\hline Jordan & $11 / 22 / 1988$ & 6029 & 0.055 & 0.181 & 0.019 & 0.110 & $0.271^{a}$ & $0.614^{a}$ & $0.085^{a}$ & $0.158^{a}$ \\
\hline Oman & $10 / 23 / 1996$ & 3963 & 0.071 & 0.184 & $-0.256^{b}$ & $-0.650^{a}$ & 0.116 & 0.050 & -0.009 & $-0.179^{b}$ \\
\hline Hungary & 01/03/1991 & 5477 & 0.066 & 0.323 & $-0.838^{a}$ & $-0.700^{a}$ & $-0.410^{a}$ & $-0.607^{a}$ & $-0.069^{a}$ & -0.105 \\
\hline Croatia & $01 / 03 / 1997$ & 3911 & 0.052 & 0.295 & $-0.865^{a}$ & $-0.956^{a}$ & $-0.439^{a}$ & $-0.673^{a}$ & $-0.121^{a}$ & -0.138 \\
\hline Trin. and Tob. & $01 / 01 / 1996$ & 4175 & 0.115 & 0.163 & $0.789^{a}$ & 0.249 & $0.597^{a}$ & 0.073 & $0.165^{a}$ & $-0.002^{b}$ \\
\hline Sri Lanka & $01 / 03 / 1985$ & 7042 & 0.095 & 0.204 & $0.366^{a}$ & 0.196 & $0.161^{b}$ & 0.094 & $0.052^{a}$ & $0.050^{c}$ \\
\hline Kenya & $01 / 12 / 1990$ & 5731 & -0.001 & 0.218 & $0.887^{a}$ & $0.945^{a}$ & 0.088 & $-0.336^{b}$ & $0.053^{b}$ & 0.059 \\
\hline Morocco & 01/01/1988 & 6261 & 0.120 & 0.181 & $-0.135^{c}$ & -0.204 & -0.106 & -0.221 & -0.003 & 0.017 \\
\hline Tunisia & $01 / 01 / 1998$ & 3652 & 0.088 & 0.112 & -0.081 & -0.167 & $0.209^{c}$ & 0.125 & $0.075^{a}$ & $0.045^{c}$ \\
\hline Slovenia & $01 / 01 / 1999$ & 3391 & 0.025 & 0.190 & $-0.758^{a}$ & $-0.984^{a}$ & $-0.363^{a}$ & $-0.289^{c}$ & -0.099 & -0.165 \\
\hline Slovakia & $09 / 15 / 1993$ & 4773 & 0.038 & 0.261 & $3.258^{a}$ & $2.312^{a}$ & -0.085 & $-0.505^{a}$ & 0.012 & 0.176 \\
\hline Bulgaria & $10 / 03 / 2000$ & 2934 & 0.225 & 0.324 & $-0.370^{a}$ & $-0.399^{b}$ & -0.046 & $-0.308^{c}$ & -0.031 & -0.132 \\
\hline Ghana & $01 / 01 / 1996$ & 4175 & -0.023 & 0.190 & -0.138 & $-0.291^{c}$ & $0.206^{b}$ & -0.046 & $-0.045^{c}$ & $-0.108^{c}$ \\
\hline Lithuania & $01 / 03 / 2000$ & 3130 & 0.108 & 0.225 & $-1.008^{a}$ & $-1.235^{a}$ & $-0.486^{a}$ & $-0.311^{c}$ & -0.109 & $-0.087^{c}$ \\
\hline Ecuador & $08 / 03 / 1993$ & 4804 & -0.004 & 0.262 & 0.113 & $1.164^{a}$ & $0.641^{a}$ & $1.688^{a}$ & $0.078^{b}$ & $0.114^{c}$ \\
\hline Malta & $12 / 28 / 1995$ & 4177 & 0.066 & 0.157 & $0.418^{a}$ & $0.682^{a}$ & $-0.185^{c}$ & -0.097 & 0.033 & 0.081 \\
\hline Botswana & $01 / 01 / 1996$ & 4175 & 0.131 & 0.216 & $0.803^{a}$ & $0.409^{b}$ & $-0.513^{a}$ & -0.225 & $-0.043^{c}$ & $0.114^{c}$ \\
\hline Venezuela & $01 / 03 / 1990$ & 5738 & 0.066 & 0.432 & $-0.504^{a}$ & $0.317^{b}$ & $0.173^{c}$ & 0.210 & $-0.017^{b}$ & 0.044 \\
\hline Latvia & $01 / 04 / 2000$ & 3129 & 0.108 & 0.268 & $-0.197^{c}$ & $-1.122^{a}$ & $0.245^{b}$ & $-0.646^{a}$ & $-0.152^{a}$ & $-0.184^{a}$ \\
\hline Namibia & $02 / 01 / 2000$ & 3109 & 0.071 & 0.201 & $-0.600^{a}$ & $-0.518^{b}$ & $-0.250^{b}$ & $-0.352^{c}$ & -0.083 & $-0.187^{a}$ \\
\hline Estonia & $06 / 04 / 1996$ & 4064 & 0.104 & 0.285 & $-1.191^{a}$ & $-0.809^{a}$ & $-0.180^{c}$ & -0.218 & $-0.114^{b}$ & $-0.095^{b}$ \\
\hline Average & & & 0.082 & 0.281 & -0.222 & -0.279 & -0.172 & -0.232 & -0.040 & -0.059 \\
\hline
\end{tabular}

Table continued from previous page. 
Table 2: MIDAS Conditional Quantile Estimates of U.S., China, and the World Portfolio Returns

Estimates of the MIDAS model (equations (8) - (9)) for the 5th, 25th, 50th, 75th, and 95th conditional quantiles of stock returns to the U.S., China, and World index. Results are reported at the monthly (22-day) horizon in Panel A, and at the quarterly (66-day) horizon in Panel B. $p$-values based on HAC standard errors appear in parenthesis below the estimates. For $\kappa_{2}$, the null hypothesis is $\kappa_{2}=1$. The row 'Coverage' reports the unconditional coverage associated to each quantile, with underneath the $p$-value of the Kupiec (1995) test of the null that Coverage equals $\theta$.

\begin{tabular}{|c|c|c|c|c|c|c|c|c|c|c|c|c|c|c|c|}
\hline \multirow[b]{2}{*}{$\theta$} & \multicolumn{15}{|c|}{ Panel A: Monthly horizon $(n=22)$} \\
\hline & 0.05 & 0.25 & $\begin{array}{c}\text { U.S. } \\
0.50\end{array}$ & 0.75 & 0.95 & 0.05 & 0.25 & $\begin{array}{c}\text { China } \\
0.50\end{array}$ & 0.75 & 0.95 & 0.05 & 0.25 & $\begin{array}{c}\text { World } \\
0.50\end{array}$ & 0.75 & 0.95 \\
\hline$\alpha$ & $\begin{array}{c}-0.008 \\
(0.54)\end{array}$ & $\begin{array}{l}0.003 \\
(0.73)\end{array}$ & $\begin{array}{l}0.010 \\
(0.04)\end{array}$ & $\begin{array}{l}0.021 \\
(0.00)\end{array}$ & $\begin{array}{l}0.037 \\
(0.00)\end{array}$ & $\begin{array}{l}-0.021 \\
(0.38)\end{array}$ & $\begin{array}{l}-0.012 \\
(0.42)\end{array}$ & $\begin{array}{c}-0.011 \\
(0.34)\end{array}$ & $\begin{array}{l}0.013 \\
(0.53)\end{array}$ & $\begin{array}{l}0.066 \\
(0.00)\end{array}$ & $\begin{array}{c}-0.003 \\
(0.87)\end{array}$ & $\begin{array}{l}0.000 \\
(0.95)\end{array}$ & $\begin{array}{c}0.007 \\
(0.29)\end{array}$ & $\begin{array}{l}0.015 \\
(0.04)\end{array}$ & $\begin{array}{l}0.033 \\
(0.00)\end{array}$ \\
\hline$\beta$ & $\begin{array}{r}-8.195 \\
(0.00)\end{array}$ & $\begin{array}{c}-2.656 \\
(0.03)\end{array}$ & $\begin{array}{l}0.484 \\
(0.52)\end{array}$ & $\begin{array}{l}2.188 \\
(0.02)\end{array}$ & $\begin{array}{l}5.000 \\
(0.00)\end{array}$ & $\begin{array}{c}-10.125 \\
(0.00)\end{array}$ & $\begin{array}{c}-3.758 \\
(0.00)\end{array}$ & $\begin{array}{l}1.048 \\
(0.22)\end{array}$ & $\begin{array}{l}4.500 \\
(0.00)\end{array}$ & $\begin{array}{l}8.250 \\
(0.00)\end{array}$ & $\begin{array}{c}-10.742 \\
(0.00)\end{array}$ & $\begin{array}{c}-3.148 \\
(0.02)\end{array}$ & $\begin{array}{l}0.539 \\
(0.63)\end{array}$ & $\begin{array}{l}3.219 \\
(0.01)\end{array}$ & $\begin{array}{l}5.875 \\
(0.00)\end{array}$ \\
\hline$\kappa_{2}$ & $\begin{array}{l}6.230 \\
(0.12)\end{array}$ & $\begin{array}{l}3.316 \\
(0.54)\end{array}$ & $\begin{array}{l}1.003 \\
(1.00)\end{array}$ & $\begin{array}{l}8.094 \\
(0.50)\end{array}$ & $\begin{array}{c}29.094 \\
(0.01)\end{array}$ & $\begin{array}{l}3.016 \\
(0.32)\end{array}$ & $\begin{array}{l}1.814 \\
(0.70)\end{array}$ & $\begin{array}{c}75.000 \\
(0.33)\end{array}$ & $\begin{array}{c}17.172 \\
(0.14)\end{array}$ & $\begin{array}{c}20.266 \\
(0.00)\end{array}$ & $\begin{array}{l}2.128 \\
(0.54)\end{array}$ & $\begin{array}{l}5.050 \\
(0.46)\end{array}$ & $\begin{array}{l}1.000 \\
(1.00)\end{array}$ & $\begin{array}{l}3.453 \\
(0.40)\end{array}$ & $\begin{array}{l}5.863 \\
(0.12)\end{array}$ \\
\hline Coverage & $\begin{array}{l}0.050 \\
(0.99)\end{array}$ & $\begin{array}{l}0.248 \\
(0.66)\end{array}$ & $\begin{array}{l}0.500 \\
(0.96)\end{array}$ & $\begin{array}{l}0.746 \\
(0.42)\end{array}$ & $\begin{array}{l}0.950 \\
(0.99)\end{array}$ & $\begin{array}{l}0.050 \\
(0.95)\end{array}$ & $\begin{array}{l}0.250 \\
(0.98)\end{array}$ & $\begin{array}{c}0.500 \\
(0.94)\end{array}$ & $\begin{array}{c}0.751 \\
(0.92)\end{array}$ & $\begin{array}{l}0.948 \\
(0.57)\end{array}$ & $\begin{array}{l}0.050 \\
(0.91)\end{array}$ & $\begin{array}{l}0.250 \\
(0.96)\end{array}$ & $\begin{array}{c}0.500 \\
(0.97)\end{array}$ & $\begin{array}{l}0.747 \\
(0.58)\end{array}$ & $\begin{array}{l}0.949 \\
(0.83)\end{array}$ \\
\hline
\end{tabular}

Panel B: Quarterly horizon $(n=66)$

\begin{tabular}{|c|c|c|c|c|c|c|c|c|c|c|c|c|c|c|c|}
\hline$\theta$ & 0.05 & 0.25 & $\begin{array}{l}\text { U.S. } \\
0.50 \\
\end{array}$ & 0.75 & 0.95 & 0.05 & 0.25 & $\begin{array}{c}\text { China } \\
0.50 \\
\end{array}$ & 0.75 & 0.95 & 0.05 & 0.25 & $\begin{array}{c}\text { World } \\
0.50 \\
\end{array}$ & 0.75 & 0.95 \\
\hline$\alpha$ & $\begin{array}{c}-0.027 \\
(0.49)\end{array}$ & $\begin{array}{c}0.019 \\
(0.06)\end{array}$ & $\begin{array}{c}0.029 \\
(0.00)\end{array}$ & $\begin{array}{l}0.059 \\
(0.00)\end{array}$ & $\begin{array}{c}0.082 \\
(0.00)\end{array}$ & $\begin{array}{r}-0.039 \\
(0.23)\end{array}$ & $\begin{array}{c}-0.035 \\
(0.20)\end{array}$ & $\begin{array}{l}0.000 \\
(0.98)\end{array}$ & $\begin{array}{l}0.038 \\
(0.34)\end{array}$ & $\begin{array}{l}0.301 \\
(0.00)\end{array}$ & $\begin{array}{l}0.016 \\
(0.84)\end{array}$ & $\begin{array}{c}0.014 \\
(0.36)\end{array}$ & $\begin{array}{c}0.017 \\
(0.17)\end{array}$ & $\begin{array}{l}0.031 \\
(0.01)\end{array}$ & $\begin{array}{l}0.088 \\
(0.00)\end{array}$ \\
\hline$\beta$ & $\begin{array}{c}-12.188 \\
(0.05)\end{array}$ & $\begin{array}{c}-4.219 \\
(0.01)\end{array}$ & $\begin{array}{c}0.758 \\
(0.60)\end{array}$ & $\begin{array}{l}2.594 \\
(0.08)\end{array}$ & $\begin{array}{l}7.750 \\
(0.00)\end{array}$ & $\begin{array}{c}-18.530 \\
(0.00)\end{array}$ & $\begin{array}{r}-5.250 \\
(0.01)\end{array}$ & $\begin{array}{c}0.012 \\
(0.99)\end{array}$ & $\begin{array}{l}7.500 \\
(0.01)\end{array}$ & $\begin{array}{l}6.844 \\
(0.00)\end{array}$ & $\begin{array}{c}-22.930 \\
(0.08)\end{array}$ & $\begin{array}{c}-6.000 \\
(0.03)\end{array}$ & $\begin{array}{l}1.188 \\
(0.61)\end{array}$ & $\begin{array}{l}6.063 \\
(0.00)\end{array}$ & $\begin{array}{l}7.000 \\
(0.00)\end{array}$ \\
\hline$\kappa_{2}$ & $\begin{array}{c}40.797 \\
(0.18)\end{array}$ & $\begin{array}{l}7.018 \\
(0.40)\end{array}$ & $\begin{array}{l}1.493 \\
(0.92)\end{array}$ & $\begin{array}{c}3.971 \\
(0.61)\end{array}$ & $\begin{array}{l}9.836 \\
(0.10)\end{array}$ & $\begin{array}{l}2.438 \\
(0.40)\end{array}$ & $\begin{array}{l}4.035 \\
(0.57)\end{array}$ & $\begin{array}{c}75.000 \\
(0.00)\end{array}$ & $\begin{array}{c}23.383 \\
(0.14)\end{array}$ & $\begin{array}{c}56.508 \\
(0.01)\end{array}$ & $\begin{array}{l}1.283 \\
(0.88)\end{array}$ & $\begin{array}{l}4.484 \\
(0.43)\end{array}$ & $\begin{array}{l}1.277 \\
(0.95)\end{array}$ & $\begin{array}{l}3.311 \\
(0.44)\end{array}$ & $\begin{array}{l}3.781 \\
(0.37)\end{array}$ \\
\hline Coverage & $\begin{array}{l}0.051 \\
(0.78)\end{array}$ & $\begin{array}{l}0.250 \\
(0.98)\end{array}$ & $\begin{array}{c}0.501 \\
(0.92)\end{array}$ & $\begin{array}{c}0.751 \\
(0.83)\end{array}$ & $\begin{array}{c}0.948 \\
(0.43)\end{array}$ & $\begin{array}{l}0.050 \\
(0.91)\end{array}$ & $\begin{array}{c}0.250 \\
(0.98)\end{array}$ & $\begin{array}{l}0.500 \\
(0.97)\end{array}$ & $\begin{array}{l}0.749 \\
(0.85)\end{array}$ & $\begin{array}{l}0.950 \\
(0.99)\end{array}$ & $\begin{array}{l}0.050 \\
(0.89)\end{array}$ & $\begin{array}{l}0.247 \\
(0.55)\end{array}$ & $\begin{array}{l}0.498 \\
(0.73)\end{array}$ & $\begin{array}{l}0.751 \\
(0.77)\end{array}$ & $\begin{array}{l}0.949 \\
(0.75)\end{array}$ \\
\hline
\end{tabular}


Table 3: Summary Statistics of Conditional Asymmetry Estimates $\left(C A_{\theta, t}\right)$

Summary statistics of the estimated conditional asymmetry at the monthly horizon $\left(C A_{\theta, t-1}\left(r_{t, 22}\right)\right.$, Panel A) and quarterly horizon $\left(C A_{\theta, t-1}\left(r_{t, 66}\right)\right.$, Panel B) for integrated $\theta$ (left block), $\theta=0.95$ (middle block), and $\theta=0.75$ (right block) for stock returns to the U.S., China, World index, Developed Markets excluding the U.S. ('DM ex-U.S.'), and Emerging Markets excluding China ('EM ex-China'). Underneath the Mean, we report in parenthesis the $p$-value (pval) for the null hypothesis that the average conditional asymmetry (Mean) equals the unconditional robust asymmetry $R A$ of the corresponding return series. For DM ex-U.S. and EM ex-China, the $p$-value is the average across all countries within each group.

\begin{tabular}{|c|c|c|c|c|c|c|c|c|c|c|c|c|c|c|c|}
\hline \multicolumn{16}{|c|}{ Panel A: Monthly horizon $(n=22)$} \\
\hline & \multicolumn{5}{|c|}{$C A_{I N T, t-1}\left(r_{t, 22}\right)$} & \multicolumn{5}{|c|}{$C A_{0.95, t-1}\left(r_{t, 22}\right)$} & \multicolumn{5}{|c|}{$C A_{0.75, t-1}\left(r_{t, 22}\right)$} \\
\hline & U.S. & China & World & DM ex-U.S. & EM ex-China & U.S. & China & World & DM ex-U.S. & EM ex-China & U.S. & China & World & DM ex-U.S. & EM ex-China \\
\hline Mean & -0.159 & 0.063 & -0.142 & -0.098 & -0.028 & -0.145 & 0.038 & -0.131 & -0.084 & -0.029 & -0.124 & 0.023 & -0.098 & -0.039 & -0.003 \\
\hline pval & $(0.39)$ & $(0.36)$ & $(0.40)$ & $(0.21)$ & $(0.16)$ & $(0.75)$ & $(0.63)$ & $(0.44)$ & $(0.19)$ & $(0.16)$ & $(0.00)$ & $(0.81)$ & $(0.20)$ & $(0.28)$ & $(0.21)$ \\
\hline Std & 0.048 & 0.084 & 0.041 & 0.055 & 0.079 & 0.071 & 0.095 & 0.062 & 0.063 & 0.083 & 0.064 & 0.098 & 0.017 & 0.089 & 0.107 \\
\hline Min & -0.320 & -0.191 & -0.310 & -0.346 & -0.306 & -0.370 & -0.303 & -0.362 & -0.330 & -0.305 & -0.401 & -0.445 & -0.175 & -0.372 & -0.347 \\
\hline Max & -0.052 & 0.275 & -0.055 & 0.069 & 0.195 & 0.204 & 0.268 & -0.009 & 0.120 & 0.206 & 0.063 & 0.288 & -0.061 & 0.205 & 0.307 \\
\hline \multicolumn{16}{|c|}{ Panel B: Quarterly horizon $(n=66)$} \\
\hline & \multicolumn{5}{|c|}{$C A_{I N T, t-1}\left(r_{t, 66}\right)$} & \multicolumn{5}{|c|}{$C A_{0.95, t-1}\left(r_{t, 66}\right)$} & \multicolumn{5}{|c|}{$C A_{0.75, t-1}\left(r_{t, 66}\right)$} \\
\hline & U.S. & China & World & DM ex-U.S. & EM ex-China & U.S. & China & World & DM ex-U.S. & EM ex-China & U.S. & China & World & DM ex-U.S. & EM ex-China \\
\hline Mean & -0.168 & 0.128 & -0.125 & -0.120 & -0.055 & -0.163 & 0.147 & -0.140 & -0.102 & -0.035 & -0.013 & 0.117 & -0.028 & -0.035 & -0.020 \\
\hline pval & $(0.40)$ & $(0.10)$ & $(0.58)$ & $(0.23)$ & $(0.20)$ & $(0.25)$ & $(0.10)$ & $(0.30)$ & $(0.18)$ & $(0.25)$ & $(0.83)$ & $(0.00)$ & $(0.89)$ & $(0.21)$ & $(0.23)$ \\
\hline Std & 0.083 & 0.120 & 0.127 & 0.062 & 0.087 & 0.061 & 0.136 & 0.108 & 0.077 & 0.099 & 0.088 & 0.097 & 0.041 & 0.095 & 0.163 \\
\hline Min & -0.436 & -0.253 & -0.526 & -0.325 & -0.320 & -0.444 & -0.269 & -0.496 & -0.324 & -0.335 & -0.312 & -0.303 & -0.143 & -0.325 & -0.471 \\
\hline Max & 0.002 & 0.426 & 0.155 & 0.069 & 0.196 & 0.007 & 0.466 & 0.199 & 0.144 & 0.245 & 0.165 & 0.476 & 0.079 & 0.239 & 0.456 \\
\hline
\end{tabular}


Table 4: Conditional Asymmetry, Volatility, and U.S. Recessions

Estimates of the monthly regression:

$$
C A_{t-1}\left(r_{t, n, i}\right)=a+b_{1} \sigma_{t-1, n, i}+b_{2} N B E R_{t-1}+\epsilon_{t, n, i}
$$

where the left-hand-side variable is either $C A_{I N T, t-1}\left(r_{t, n, i}\right)$ (left block), $C A_{0.95, t-1}\left(r_{t, n, i}\right)$ (middle block), or $C A_{0.75, t-1}\left(r_{t, n, i}\right)$ (right block). The horizon $n$ is either monthly (22-day) in Panel A or quarterly (66-day) in Panel B. $\sigma_{t-1, n, i}$ is the $n$-day conditional volatility of country $i$ stock return for month $t$ and $N B E R_{t-1}$ is a dummy variable that takes value 1 if month $t-1$ is marked as a recession by the National Bureau of Economic Research. For the U.S., China, and World index the regressions are time-series, and the $p$-values (in parenthesis) are Newey and West (1987) with 12 lags. For developed markets ex-U.S. and emerging markets ex-China, the estimates are from pooled regressions and the $p$-values (in parenthesis) are clustered by country.

Panel A: Monthly horizon $(n=22)$

\begin{tabular}{|c|c|c|c|c|c|c|c|c|c|c|c|c|c|c|c|}
\hline & \multicolumn{5}{|c|}{$C A_{I N T, t-1}\left(r_{t, 22}\right)$} & \multicolumn{5}{|c|}{$C A_{0.95, t-1}\left(r_{t, 22}\right)$} & \multicolumn{5}{|c|}{$C A_{0.75, t-1}\left(r_{t, 22}\right)$} \\
\hline & U.S. & China & World & DM ex-U.S. & EM ex-China & U.S. & China & World & DM ex-U.S. & EM ex-China & U.S. & China & World & DM ex-U.S. & EM ex-China \\
\hline$\sigma_{t-1, n, i}$ & $\begin{array}{r}-6.077 \\
(0.00)\end{array}$ & $\begin{array}{l}-10.829 \\
-(0.00)\end{array}$ & $\begin{array}{l}-2.630 \\
(0.09)\end{array}$ & $\begin{array}{l}-3.694 \\
-(0.03)\end{array}$ & $\begin{array}{l}-5.361 \\
-(0.00)\end{array}$ & $\begin{array}{l}-2.744 \\
(0.17)\end{array}$ & $\begin{array}{c}-11.011 \\
000)\end{array}$ & $\begin{array}{l}0.431 \\
(0.81)\end{array}$ & $\begin{array}{c}-2.748 \\
0.06\end{array}$ & $\begin{array}{l}-5.516 \\
(0.00)\end{array}$ & $\begin{array}{l}1.352 \\
(0.38)\end{array}$ & $\begin{array}{l}-10.264 \\
\end{array}$ & $\begin{array}{l}-2.856 \\
\end{array}$ & $\begin{array}{l}-4.603 \\
-(001)\end{array}$ & -3.459 \\
\hline$N B E R_{t-1}$ & $\begin{array}{c}(0.00) \\
-0.022 \\
(0.03)\end{array}$ & $\begin{array}{l}(0.00) \\
0.003 \\
(0.94)\end{array}$ & $\begin{array}{c}(0.09) \\
-0.015 \\
(0.11)\end{array}$ & $\begin{array}{c}(0.03) \\
-0.004 \\
(0.45)\end{array}$ & $\begin{array}{c}(0.00) \\
-0.005 \\
(0.46)\end{array}$ & $\begin{array}{c}(0.019 \\
(0.14)\end{array}$ & $\begin{array}{l}(0.00) \\
0.002 \\
(0.96)\end{array}$ & $\begin{array}{c}(0.81) \\
-0.030 \\
(0.07)\end{array}$ & $\begin{array}{c}(0.06) \\
-0.006 \\
(0.21)\end{array}$ & $\begin{array}{c}(0.00) \\
-0.011 \\
(0.10)\end{array}$ & $\begin{array}{c}(0.38) \\
-0.018 \\
(0.23)\end{array}$ & $\begin{array}{l}(0.00) \\
0.020 \\
(0.50)\end{array}$ & $\begin{array}{l}(0.00) \\
0.001 \\
(0.83)\end{array}$ & $\begin{array}{c}(0.01) \\
-0.004 \\
(0.71)\end{array}$ & $\begin{array}{c}(0.00) \\
-0.003 \\
(0.71)\end{array}$ \\
\hline$R^{2}$ & 0.263 & 0.507 & 0.063 & 0.039 & 0.105 & 0.035 & 0.404 & 0.027 & 0.023 & 0.103 & 0.011 & 0.375 & 0.209 & 0.035 & 0.037 \\
\hline
\end{tabular}

Panel B: Quarterly horizon $(n=66)$

$C A_{I N T, t-1}\left(r_{t, 66}\right)$

$C A_{0.95, t-1}\left(r_{t, 66}\right)$

$C A_{0.75, t-1}\left(r_{t, 66}\right)$

\begin{tabular}{|c|c|c|c|c|c|c|c|c|c|c|c|c|c|c|c|}
\hline & U.S. & China & World & DM ex-U.S. & EM ex-China & U.S. & China & World & DM ex-U.S. & EM ex-China & U.S. & China & World & DM ex-U.S. & EM ex-China \\
\hline$\overline{\sigma_{t-1, n, i}}$ & -15.005 & -14.350 & -23.839 & $\begin{array}{r}-3.182 \\
(0.38)\end{array}$ & -5.070 & $\begin{array}{l}-5.976 \\
(0.92)\end{array}$ & -16.311 & -20.231 & $\begin{array}{l}-1.806 \\
(0.61)\end{array}$ & $\begin{array}{l}-5.743 \\
\end{array}$ & $\begin{array}{l}-21.783 \\
\end{array}$ & $\begin{array}{l}-1.206 \\
(0.30)\end{array}$ & -11.636 & $\begin{array}{l}0.684 \\
(0.78)\end{array}$ & -3.432 \\
\hline$N B E R_{t-1}$ & $\begin{array}{c}-0.032 \\
(0.06)\end{array}$ & $\begin{array}{c}-0.018 \\
(0.69)\end{array}$ & $\begin{array}{c}-0.038 \\
(0.16)\end{array}$ & $\begin{array}{l}0.002 \\
(0.83)\end{array}$ & $\begin{array}{c}-0.006 \\
(0.45) \\
(0.006\end{array}$ & $\begin{array}{c}-0.023 \\
(0.03)\end{array}$ & $\begin{array}{c}-0.030 \\
(0.56)\end{array}$ & $\begin{array}{c}-0.033 \\
(0.15)\end{array}$ & $\begin{array}{l}0.002 \\
(0.82)\end{array}$ & $\begin{array}{c}-0.007 \\
(0.42)\end{array}$ & $\begin{array}{c}-0.034 \\
(0.03)\end{array}$ & $\begin{array}{l}0.018 \\
(0.39)\end{array}$ & $\begin{array}{c}-0.013 \\
(0.09)\end{array}$ & $\begin{array}{l}0.013 \\
(0.44)\end{array}$ & $\begin{array}{l}0.014 \\
(0.33)\end{array}$ \\
\hline$R^{2}$ & 0.309 & 0.625 & 0.183 & 0.009 & 0.059 & 0.112 & 0.635 & 0.182 & 0.003 & 0.067 & 0.550 & 0.010 & 0.398 & 0.002 & 0.014 \\
\hline
\end{tabular}




\section{Table 5: International Dynamic Portfolio Allocation, Loadings}

Estimates of the loadings on the conditioning variables in the international dynamic portfolio allocation problem, expression (11), based on either monthly (Panel A) or quarterly (Panel B) rebalancing. Specifications (1) to (8) include different combinations of the following conditioning variables: the conditional asymmetry $C A$ measures based on integrated $\theta, \theta=0.95$, and $\theta=0.75$; the interaction between $C A_{I N T}$ and the NBER recession dummy; conditional volatility, $\sigma$; expected skewness, $E\left[S\left(r_{t, n}\right)\right]$; and co-skewness, CoSkew. All variables are constructed using information up to and including time $t-1, I_{t-1}$ Below the coefficients, $p$-values are reported in parenthesis. The last row reports the $p$-value for the joint likelihood ratio test (LR) that all coefficients are zero.

\begin{tabular}{|c|c|c|c|c|c|c|c|c|}
\hline \multicolumn{9}{|c|}{ Panel A: Monthly horizon $(n=22)$} \\
\hline Conditioning variable & $(1)$ & $(2)$ & (3) & (4) & (5) & (6) & (7) & $(8)$ \\
\hline$C A_{I N T, t-1}\left(r_{t, 22}\right)$ & $\begin{array}{l}3.273 \\
(0.00)\end{array}$ & & & $\begin{array}{l}3.162 \\
(0.00)\end{array}$ & & & $\begin{array}{l}2.988 \\
(0.00)\end{array}$ & \\
\hline$C A_{0.95, t-1}\left(r_{t, 22}\right)$ & & $\begin{array}{l}3.562 \\
(0.00)\end{array}$ & & & $\begin{array}{l}3.452 \\
(0.00)\end{array}$ & & & $\begin{array}{l}4.721 \\
(0.00)\end{array}$ \\
\hline$C A_{0.75, t-1}\left(r_{t, 22}\right)$ & & & $\begin{array}{l}0.823 \\
(0.29)\end{array}$ & & & $\begin{array}{l}0.544 \\
(0.49)\end{array}$ & & $\begin{array}{l}-2.566 \\
(0.02)\end{array}$ \\
\hline$C A_{I N T, t-1}\left(r_{t, 22}\right) \times N B E R_{t-1}$ & & & & & & & $\begin{array}{l}0.892 \\
(0.62)\end{array}$ & $\begin{array}{l}0.986 \\
(0.61)\end{array}$ \\
\hline$\sigma_{t-1,22}$ & & & & $\begin{array}{r}-0.212 \\
(0.64)\end{array}$ & $\begin{array}{r}-0.219 \\
(0.62)\end{array}$ & $\begin{array}{r}-0.780 \\
(0.07)\end{array}$ & $\begin{array}{r}-0.217 \\
(0.63)\end{array}$ & $\begin{array}{l}-0.189 \\
(0.68)\end{array}$ \\
\hline$E_{t-1}\left[S\left(r_{t, 22}\right)\right]$ & & & & $\begin{array}{l}1.001 \\
(0.27)\end{array}$ & $\begin{array}{l}0.998 \\
(0.28)\end{array}$ & $\begin{array}{l}1.589 \\
(0.08)\end{array}$ & $\begin{array}{l}0.984 \\
(0.28)\end{array}$ & $\begin{array}{l}0.821 \\
(0.37)\end{array}$ \\
\hline CoSkew $_{t-1}$ & & & & $\begin{array}{r}-0.402 \\
(0.48)\end{array}$ & $\begin{array}{r}-0.370 \\
(0.51)\end{array}$ & $\begin{array}{r}-0.141 \\
(0.80)\end{array}$ & $\begin{array}{r}-0.423 \\
(0.46)\end{array}$ & $\begin{array}{l}-0.645 \\
(0.27)\end{array}$ \\
\hline pval LR & 0.00 & 0.00 & 0.30 & 0.00 & 0.00 & 0.07 & 0.00 & 0.00 \\
\hline \multicolumn{9}{|c|}{ Panel B: Quarterly horizon $(n=66)$} \\
\hline Conditioning variable & $(1)$ & $(2)$ & $(3)$ & $(4)$ & $(5)$ & $(6)$ & $(7)$ & $(8)$ \\
\hline$C A_{I N T, t-1}\left(r_{t, 66}\right)$ & $\begin{array}{l}2.391 \\
(0.00)\end{array}$ & & & $\begin{array}{l}1.935 \\
(0.01)\end{array}$ & & & $\begin{array}{l}2.161 \\
(0.01)\end{array}$ & \\
\hline$C A_{0.95, t-1}\left(r_{t, 66}\right)$ & & $\begin{array}{l}2.626 \\
(0.00)\end{array}$ & & & $\begin{array}{l}2.342 \\
(0.00)\end{array}$ & & & $\begin{array}{l}4.407 \\
(0.00)\end{array}$ \\
\hline$C A_{0.75, t-1}\left(r_{t, 66}\right)$ & & & $\begin{array}{l}0.185 \\
(0.79)\end{array}$ & & & $\begin{array}{l}0.111 \\
(0.89)\end{array}$ & & $\begin{array}{l}-3.069 \\
(0.01)\end{array}$ \\
\hline$C A_{I N T, t-1}\left(r_{t, 66}\right) \times N B E R$ & & & & & & & $\begin{array}{r}-1.055 \\
(0.54)\end{array}$ & $\begin{array}{c}-2.193 \\
(0.22)\end{array}$ \\
\hline$V O L_{t}\left(r_{t, 66}\right)$ & & & & $\begin{array}{c}-0.656 \\
(0.17)\end{array}$ & $\begin{array}{c}-0.455 \\
(0.35)\end{array}$ & $\begin{array}{c}-1.334 \\
(0.00)\end{array}$ & $\begin{array}{c}-0.631 \\
(0.19)\end{array}$ & $\begin{array}{r}-0.410 \\
(0.41)\end{array}$ \\
\hline$E\left[S\left(r_{t, 66}\right)\right]$ & & & & $\begin{array}{l}1.481 \\
(0.04)\end{array}$ & $\begin{array}{l}1.662 \\
(0.02)\end{array}$ & $\begin{array}{l}1.670 \\
(0.02)\end{array}$ & $\begin{array}{l}1.591 \\
(0.03)\end{array}$ & $\begin{array}{c}0.830 \\
(0.31)\end{array}$ \\
\hline CoSkew & & & & $\begin{array}{r}-0.307 \\
(0.59)\end{array}$ & $\begin{array}{c}-0.292 \\
(0.61)\end{array}$ & $\begin{array}{c}-0.193 \\
(0.74)\end{array}$ & $\begin{array}{c}-0.219 \\
(0.71)\end{array}$ & $\begin{array}{c}-0.055 \\
(0.93)\end{array}$ \\
\hline pval LR & 0.00 & 0.00 & 0.78 & 0.00 & 0.00 & 0.00 & 0.00 & 0.00 \\
\hline
\end{tabular}




\section{Table 6: International Conditional Portfolio Allocation, Optimal Portfolio}

Properties of optimal portfolio in the international dynamic portfolio allocation, based on either monthly (Panel A) or quarterly (Panel B) rebalancing. For the value-weighted portfolio (column 'VW') and for each of the (1)-(8) specifications from Table 5 , the first line shows the average weight to $\operatorname{EM}\left(\bar{w}_{E M}\right)$, while $\bar{w}_{E M}^{C A}$ is the fraction attributable to the actively managed portfolio based on conditional asymmetry. $\bar{r}_{p}$ is the average annualized optimal portfolio return. $\bar{r}_{D M}$ and $\bar{r}_{E M}$ denote the average annualized return to the group of DM and EM, respectively, and $\rho\left(r_{E M}^{C A}, r_{D M}^{C A}\right)$ is their correlation. $\bar{r}_{D M}^{C A}$ and $\bar{r}_{E M}^{C A}$ denote the average annualized return to the group of DM and EM, respectively, from the actively managed portfolio based on conditional asymmetry, and $\rho\left(r_{E M}^{C A}, r_{D M}^{C A}\right)$ is their correlation. For the optimal portfolio, the last four rows report the annualized volatility, moment-based skewness, annualized certainty equivalent, and annualized alpha with respect to the VW portfolio.

\begin{tabular}{|c|c|c|c|c|c|c|c|c|c|}
\hline \multicolumn{10}{|c|}{ Panel A: Monthly returns $(n=22)$} \\
\hline & VW & (1) & (2) & (3) & (4) & (5) & (6) & (7) & (8) \\
\hline $\bar{w}_{E M}(\%)$ & 9.290 & 47.000 & 40.102 & 12.968 & 48.335 & 41.621 & 9.846 & 47.750 & 42.636 \\
\hline $\bar{w}_{E M}^{C A}(\%)$ & & 37.710 & 30.812 & 3.678 & 36.433 & 29.862 & 2.432 & 34.425 & 40.838 \\
\hline $\bar{r}_{p}$ & 0.077 & 0.146 & 0.165 & 0.076 & 0.152 & 0.170 & 0.085 & 0.151 & 0.210 \\
\hline $\bar{r}_{E M}$ & 0.000 & 0.072 & 0.082 & -0.001 & 0.086 & 0.095 & 0.011 & 0.080 & 0.128 \\
\hline $\bar{r}_{D M}$ & 0.077 & 0.074 & 0.083 & 0.077 & 0.066 & 0.075 & 0.074 & 0.070 & 0.081 \\
\hline$\rho\left(r_{E M}, r_{D M}\right)$ & 0.563 & -0.072 & -0.152 & 0.378 & -0.046 & -0.155 & -0.192 & -0.064 & -0.172 \\
\hline & & 0.072 & 0.082 & -0.001 & 0.070 & 0.080 & -0.001 & 0.066 & 0.109 \\
\hline $\bar{r}_{D M}^{C A}$ & & -0.003 & 0.006 & 0.000 & -0.003 & 0.006 & 0.000 & -0.003 & 0.008 \\
\hline$\rho\left(r_{E M}^{C A}, r_{D M}^{C A}\right)$ & & 0.014 & 0.101 & -0.058 & 0.014 & 0.101 & -0.058 & 0.014 & 0.101 \\
\hline$\sigma\left(r_{p}\right)$ & 0.163 & 0.160 & 0.170 & 0.160 & 0.160 & 0.168 & 0.146 & 0.158 & 0.196 \\
\hline$S\left(r_{p}\right)$ & -1.038 & 0.501 & 0.568 & -0.825 & 0.469 & 0.510 & -0.138 & 0.499 & 1.278 \\
\hline $\mathrm{CE}\left(r_{p}\right)$ & 0.001 & 0.084 & 0.097 & 0.005 & 0.090 & 0.103 & 0.031 & 0.091 & 0.124 \\
\hline$\alpha$ & & 0.115 & 0.138 & 0.003 & 0.125 & 0.147 & 0.032 & 0.126 & 0.193 \\
\hline
\end{tabular}

Panel B: Quarterly returns $(n=66)$

\begin{tabular}{lccccccccc} 
& $\mathrm{VW}$ & $(1)$ & $(2)$ & $(3)$ & $(4)$ & $(5)$ & $(6)$ & $(7)$ & $(8)$ \\
\hline $\bar{w}_{E M}(\%)$ & 9.161 & 28.212 & 26.884 & 8.914 & 23.214 & 27.387 & -1.166 & 24.460 & 38.657 \\
$\bar{w}_{E M}^{C A}(\%)$ & & 19.051 & 17.723 & -0.248 & 15.419 & 15.805 & -0.148 & 17.214 & 29.743 \\
$\bar{r}_{p}$ & & & & & & & & & \\
$\bar{r}_{E M}$ & 0.065 & 0.083 & 0.100 & 0.064 & 0.098 & 0.118 & 0.082 & 0.103 & 0.156 \\
$\bar{r}_{D M}$ & 0.002 & 0.025 & 0.035 & 0.000 & 0.032 & 0.047 & 0.004 & 0.036 & 0.083 \\
$\rho\left(r_{E M}, r_{D M}\right)$ & 0.063 & 0.058 & 0.065 & 0.063 & 0.066 & 0.071 & 0.078 & 0.067 & 0.073 \\
$\bar{r}_{E A}^{C A}$ & 0.564 & -0.134 & -0.175 & 0.494 & -0.208 & -0.157 & -0.392 & -0.191 & -0.043 \\
$\bar{r}_{D M}^{C A}$ & & 0.024 & 0.033 & -0.001 & 0.019 & 0.030 & -0.001 & 0.022 & 0.056 \\
$\rho\left(r_{E M}^{C A}, r_{D M}^{C A}\right)$ & & -0.006 & 0.002 & 0.000 & -0.005 & 0.002 & 0.000 & -0.005 & 0.003 \\
& & 0.023 & 0.006 & -0.232 & 0.023 & 0.006 & -0.232 & 0.023 & 0.006 \\
$\sigma\left(r_{p}\right)$ & & & & & & & & \\
$S\left(r_{p}\right)$ & 0.159 & 0.149 & 0.161 & 0.158 & 0.145 & 0.160 & 0.142 & 0.151 & 0.180 \\
$C E\left(r_{p}\right)$ & -0.743 & 0.747 & 0.840 & -0.692 & 0.430 & 0.677 & -0.002 & 0.462 & 0.973 \\
$\alpha$ & -0.009 & 0.033 & 0.044 & -0.009 & 0.050 & 0.062 & 0.031 & 0.051 & 0.088 \\
& & 0.042 & 0.062 & -0.001 & 0.065 & 0.087 & 0.042 & 0.070 & 0.130 \\
\hline \hline
\end{tabular}




\section{Table 7: International Conditional Portfolio Allocation, Robustness Analysis}

Robustness analysis of the international dynamic portfolio allocation problem corresponding to specification (7) in Table 5 . Columns (1)-(4) report the estimates for a power utility investor with relative risk aversion $\gamma$ respectively of 3,5 (same as in Table 5), 10, and 20. Column (5) replaces the conditional asymmetry of returns with that of de-TARCHed returns. Column (6) uses the investable indices dataset described in Section 5.3. The first row reports the loading on conditional asymmetry $(\phi$ in equation (12)), with underneath its $p$-value. The remaining rows report the properties of the optimal portfolio based on the format of Table 6 .

\begin{tabular}{lcccccc}
\hline \hline & $\gamma=3$ & $\gamma=5$ & $\gamma=10$ & $\gamma=20$ & de-TARCHed & Investable \\
& $(1)$ & $(2)$ & $(3)$ & $(4)$ & $(5)$ & $(6)$ \\
\hline$C A_{I N T, t-1}\left(r_{t, 22}\right)$ & 4.252 & 2.988 & 2.065 & 1.627 & 2.567 & 4.050 \\
& $(0.00)$ & $(0.00)$ & $(0.00)$ & $(0.00)$ & $(0.00)$ & $(0.00)$ \\
& & & & & & \\
$\bar{w}_{E M}(\%)$ & 63.627 & 47.750 & 35.855 & 29.406 & 26.286 & 13.231 \\
$\bar{w}_{E M}^{C A}(\%)$ & 48.992 & 34.425 & 23.796 & 18.744 & 21.158 & 47.372 \\
$\bar{r}_{p}$ & & & & & & \\
$\bar{r}_{E M}$ & 0.182 & 0.151 & 0.129 & 0.118 & 0.155 & 0.190 \\
$\bar{r}_{D M}$ & 0.118 & 0.080 & 0.053 & 0.039 & 0.055 & 0.073 \\
$\rho\left(r_{E M}, r_{D M}\right)$ & 0.064 & 0.070 & 0.076 & 0.079 & 0.100 & 0.117 \\
$\bar{r}_{E A}^{C A}$ & -0.033 & -0.064 & -0.106 & -0.142 & -0.207 & -0.349 \\
$\bar{r}_{D M}^{C A}$ & 0.094 & 0.066 & 0.046 & 0.036 & 0.046 & 0.057 \\
$\rho\left(r_{E M}^{C A}, r_{D M}^{C A}\right)$ & -0.004 & -0.003 & -0.002 & -0.002 & 0.007 & 0.025 \\
& 0.014 & 0.014 & 0.014 & 0.014 & -0.016 & -0.104 \\
$\sigma\left(r_{p}\right)$ & & & & & & \\
$S\left(r_{p}\right)$ & 0.207 & 0.158 & 0.133 & 0.126 & 0.175 & 0.198 \\
$C E\left(r_{p}\right)$ & 0.620 & 0.499 & 0.369 & 0.317 & 0.461 & 0.821 \\
$\alpha$ & 0.121 & 0.091 & 0.044 & -0.035 & 0.082 & 0.099 \\
& 0.168 & 0.126 & 0.095 & 0.081 & 0.118 & 0.184 \\
\hline \hline
\end{tabular}


Figure 1: Realized Measures of Skewness, U.S. and China

Realized moment-based skewness $S\left(r_{t}\right)$ in Panel A, truncated skewness $S^{T}\left(r_{t}\right)$ at the top and bottom $0.50 \%$ in Panel B, and integrated robust asymmetry $R A_{I N T}\left(r_{t}\right)$ from expression $(2)$ using $\theta=[0.99 ; 0.975 ; 0.95 ; 0.90 ; 0.85 ; 0.80 ; 0.75]$ in Panel C for stock returns to the U.S. (solid line) and China (dashed line), based on 250-day backward-looking rolling windows. The sample period is 01Jan1980 to 31Dec2011 for the U.S., and 04Apr1991 to 31Dec2011 for China.

Panel A: Skewness $S\left(r_{t}\right)$

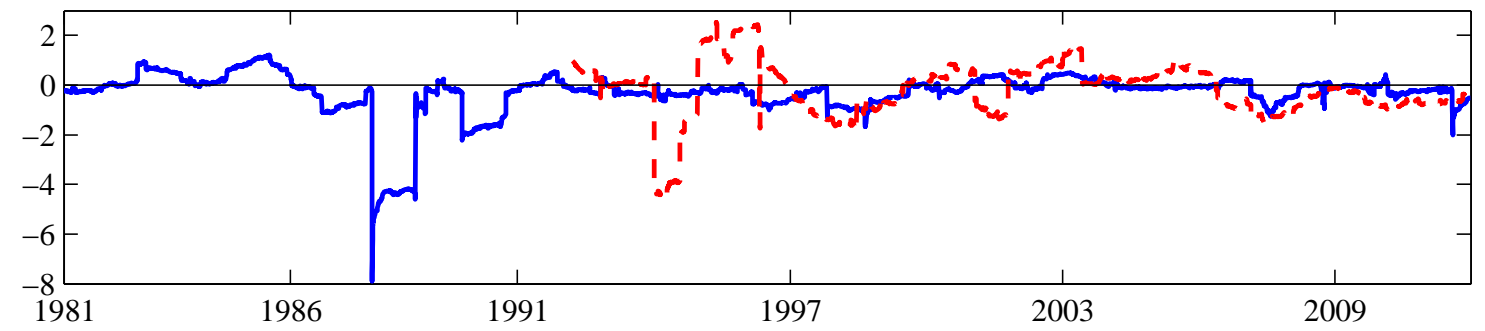

Panel B: Truncated Skewness $S^{T}\left(r_{t}\right)$

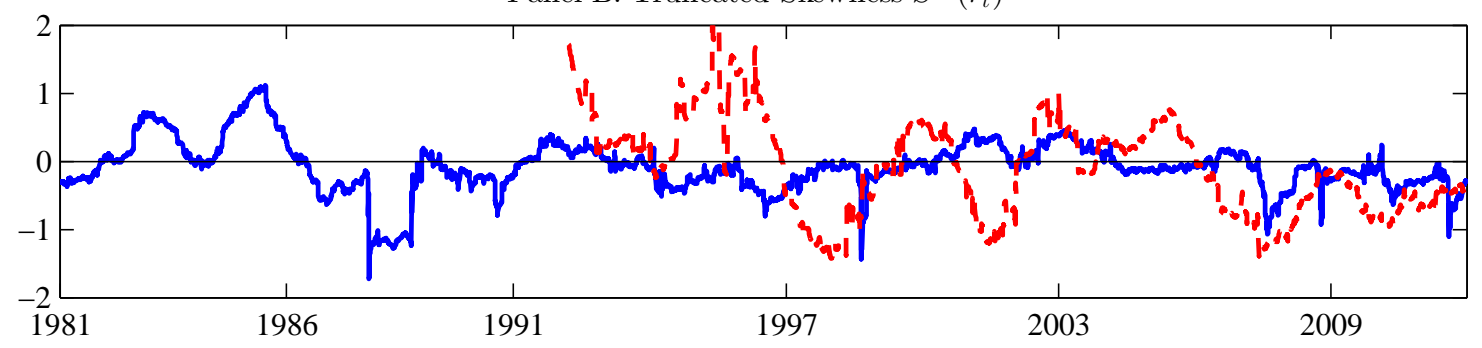

Panel C: Robust Asymmetry $R A_{I N T}\left(r_{t}\right)$

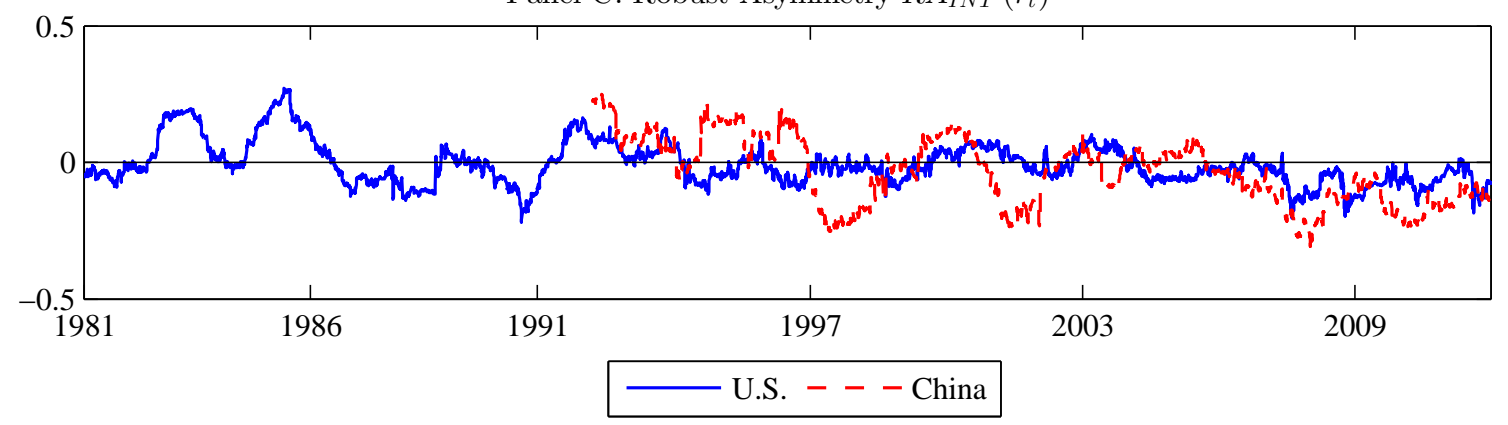


Figure 2: MIDAS Conditional quantiles estimates of U.S. and China Portfolio Returns

The figure displays the monthly series of the 5th, 25th, 75th, and 95th conditional quantiles of returns to the U.S. (left plots) and China (right plots). The top plots refer to monthly (22-day) returns, the bottom plots are for quarterly (66-day) returns. The quantiles are obtained from the estimates in Table 2 . The gray areas highlight months that are marked as recessions by the National Bureau of Economic Research.

Panel A: Monthly horizon

U.S

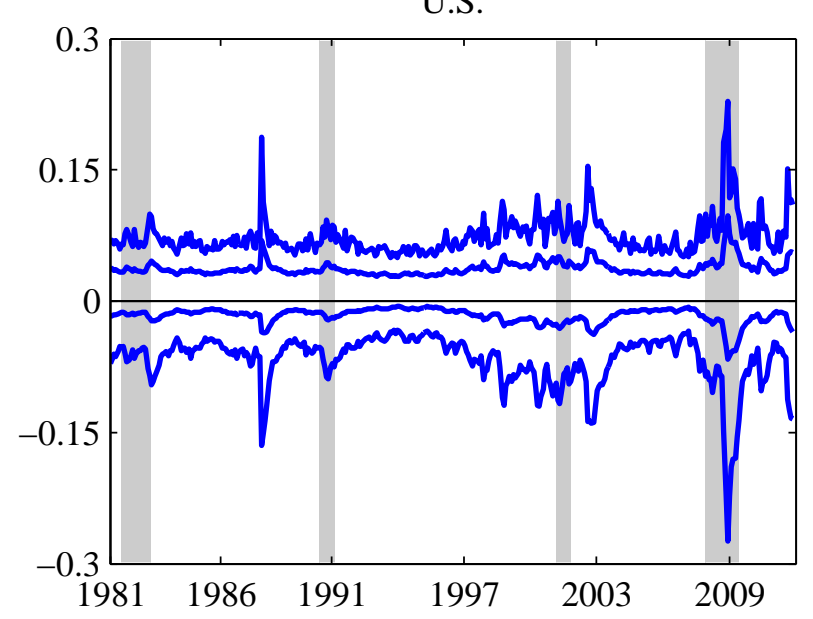

China

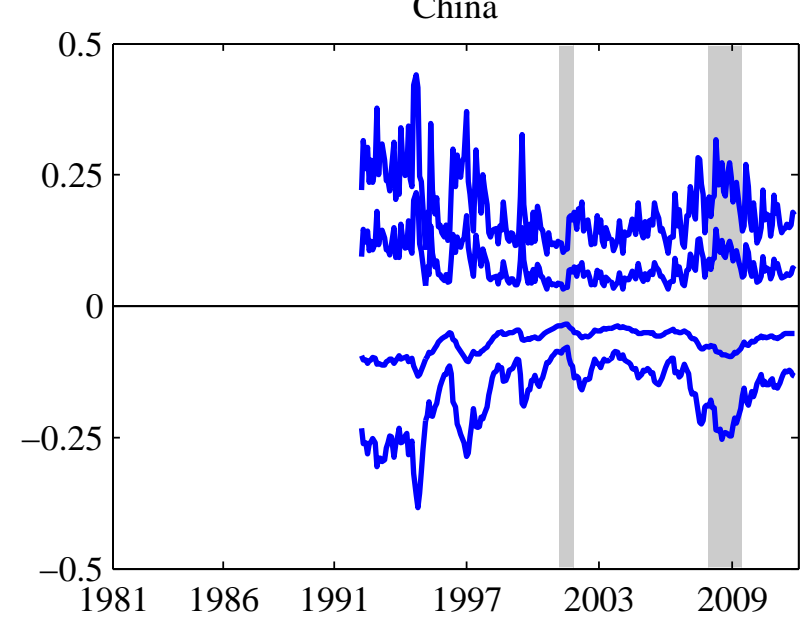

Panel B: Quarterly horizon

U.S

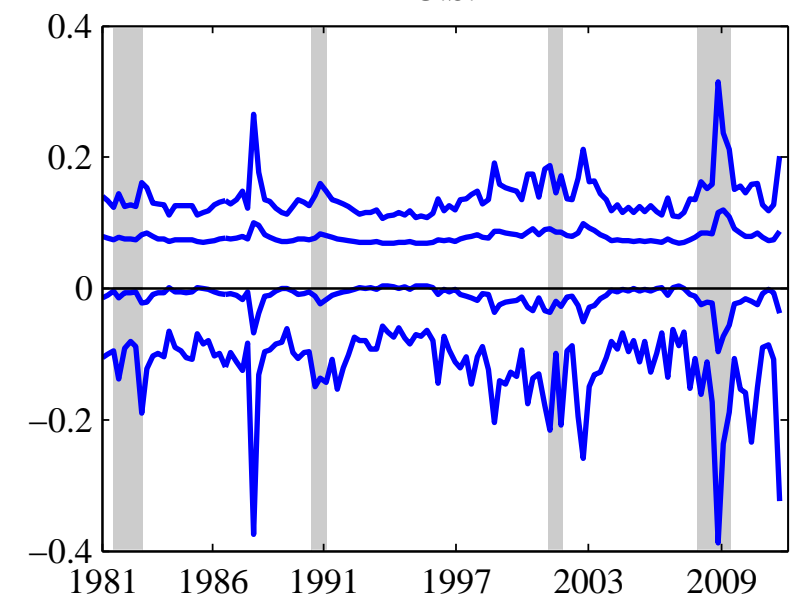

China

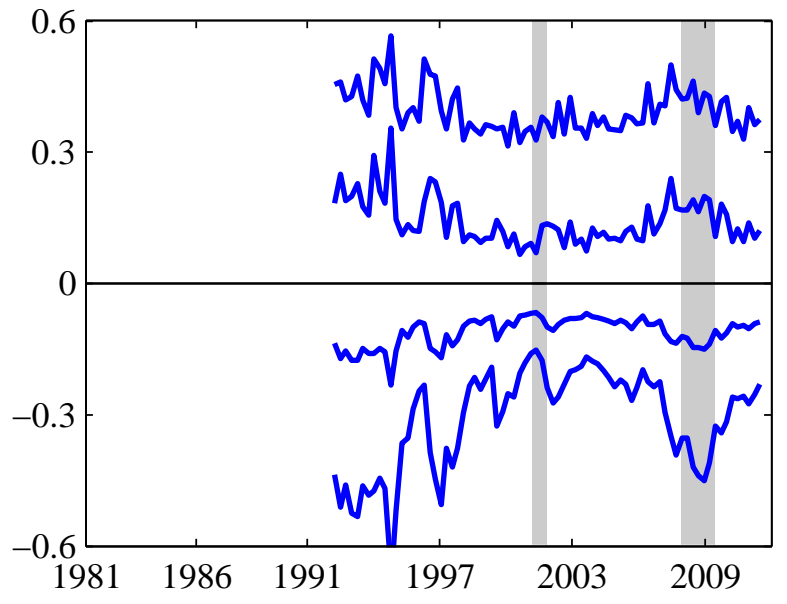


Figure 3.a: Time-series of $C A_{\theta, t-1}\left(r_{t, 22}\right)$

The graphs plot the monthly series of the estimated 22-day conditional asymmetry $\left(C A_{\theta, t-1}\left(r_{t, 22}\right)\right)$ for stock returns to the U.S. (solid line) and China (dashdot line) based on integrated $\theta$ (top plot), $\theta=0.95$ (middle plot), and $\theta=0.75$ (bottom plot). The gray areas highlight months that are marked as recessions by the National Bureau of Economic Research. In the plots, 'corr' denotes the correlation coefficient between the two series.
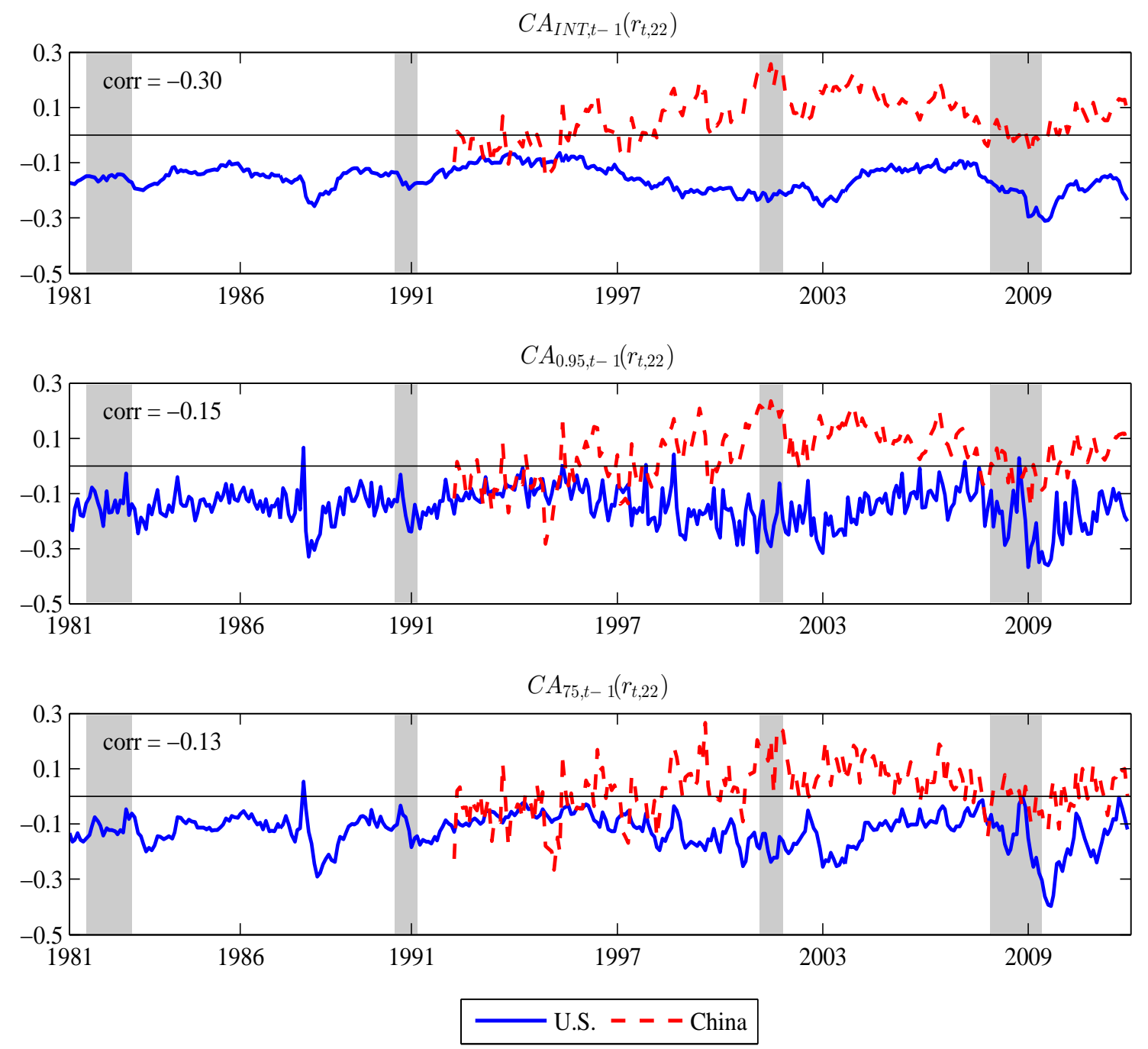
Figure 3.b: Time-series of $C A_{\theta, t-1}\left(r_{t, 66}\right)$

The graphs plot the monthly time-series of the estimated 66-day conditional asymmetry $\left(C A_{\theta, t-1}\left(r_{t, 66}\right)\right)$ for stock returns to the U.S. (solid line) and China (dashdot line) based on integrated $\theta$ (top plot), $\theta=0.95$ (middle plot), and $\theta=0.75$ (bottom plot). The gray areas highlight months that are marked as recessions by the National Bureau of Economic Research. In the plots, 'corr' denotes the correlation coefficient between the two series.
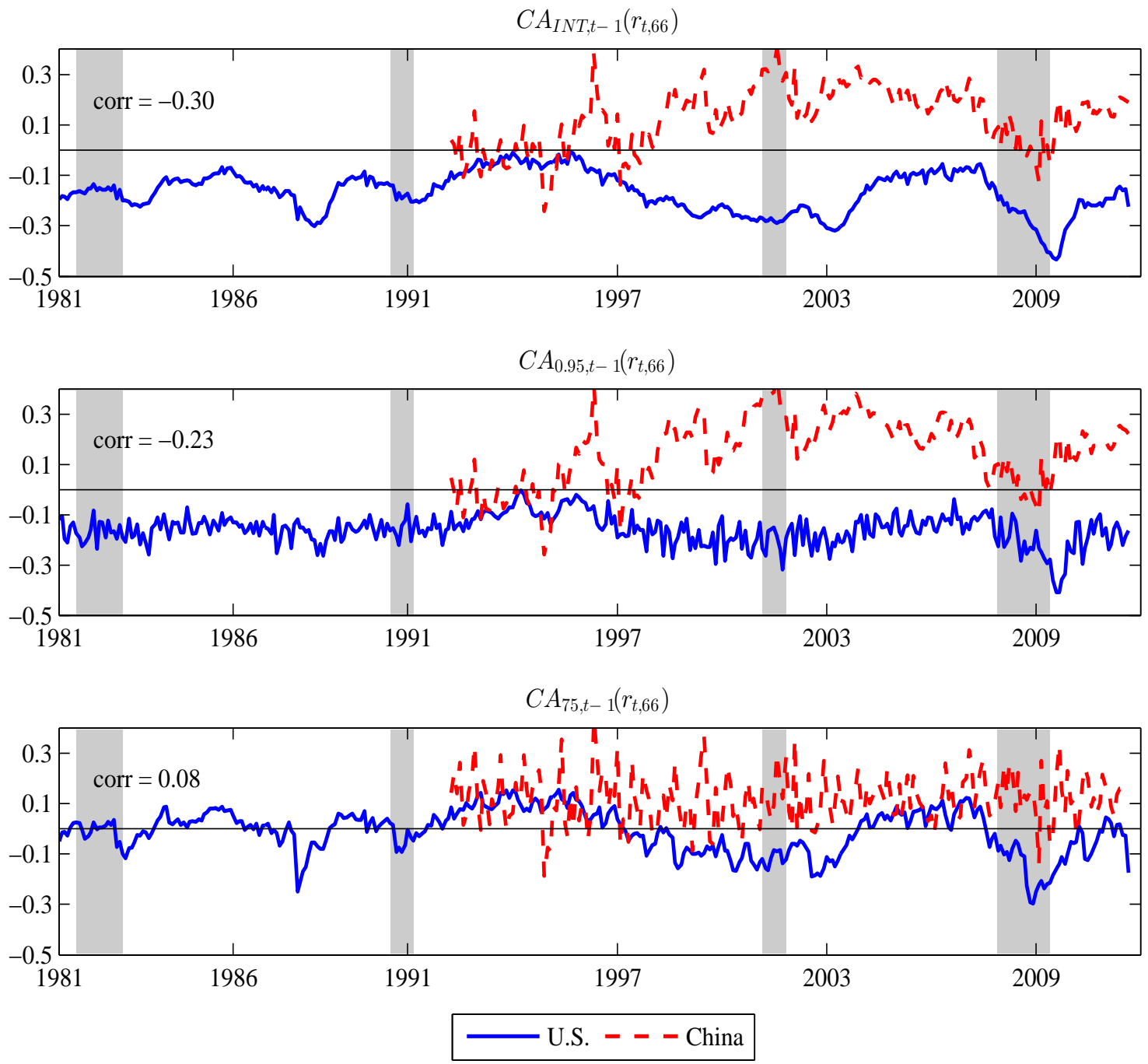


\section{Figure 4: Principal Component Analysis of Conditional Moments}

Cumulative overall variance explained by the first two principal components of conditional asymmetry measures $C A_{I N T}$ (1st column), $C A_{0.95}$ (2nd column), $C A_{0.75}$ (3rd column), and conditional volatility (4th column) at the quarterly (66-day) horizon. The top plots display the results for all countries, the middle plots results are for only Developed Markets, and the bottom plots are for only Emerging Markets.

Panel A: All countries
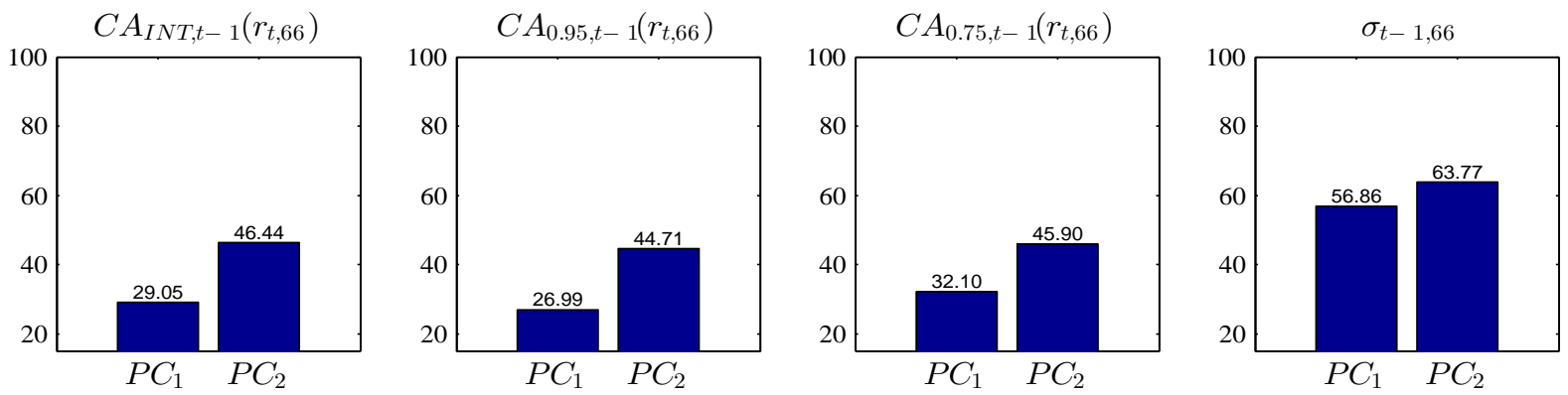

Panel B: Developed markets
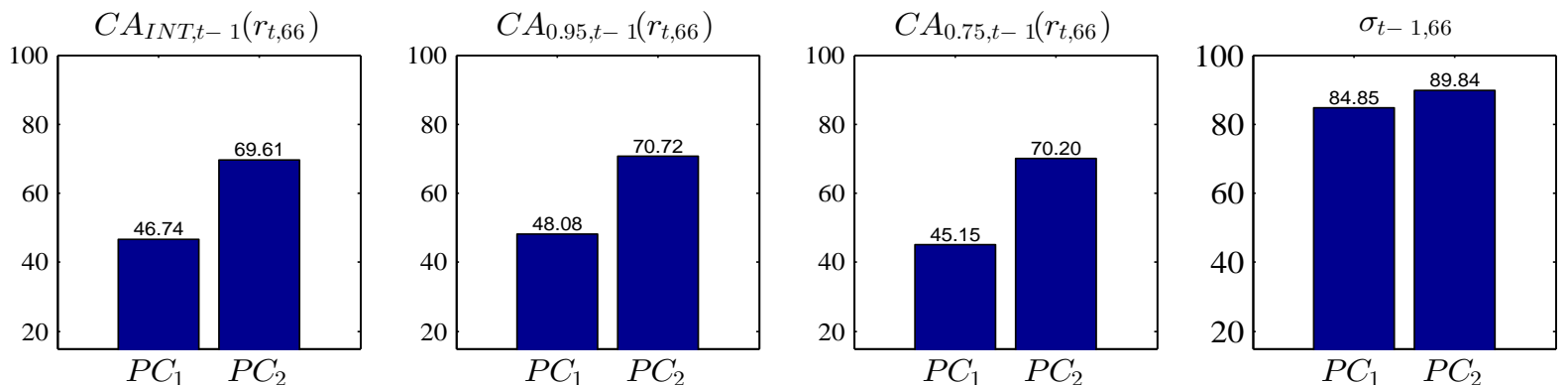

Panel C: Emerging markets
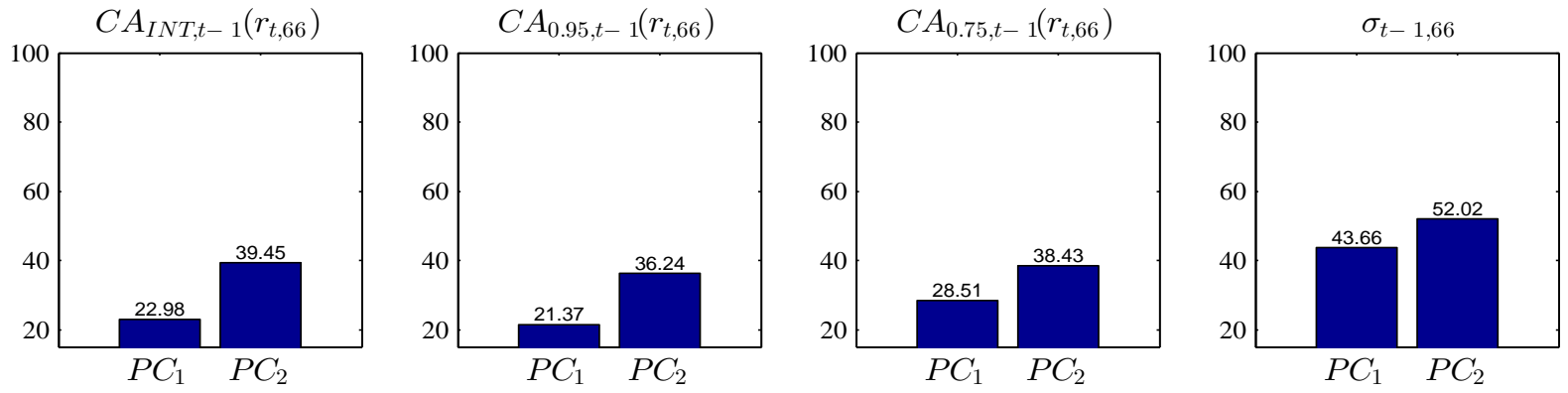


\section{Figure 5: Return and Conditional Asymmetry Correlation Over Time}

Average correlation in monthly returns (Panel A) and monthly integrated conditional asymmetry (Panel B) based on 24-month rolling windows. The average is taken among Developed Markets (dotted line), among Emerging Markets (dash-dot line), and between Developed and Emerging Markets (solid line).
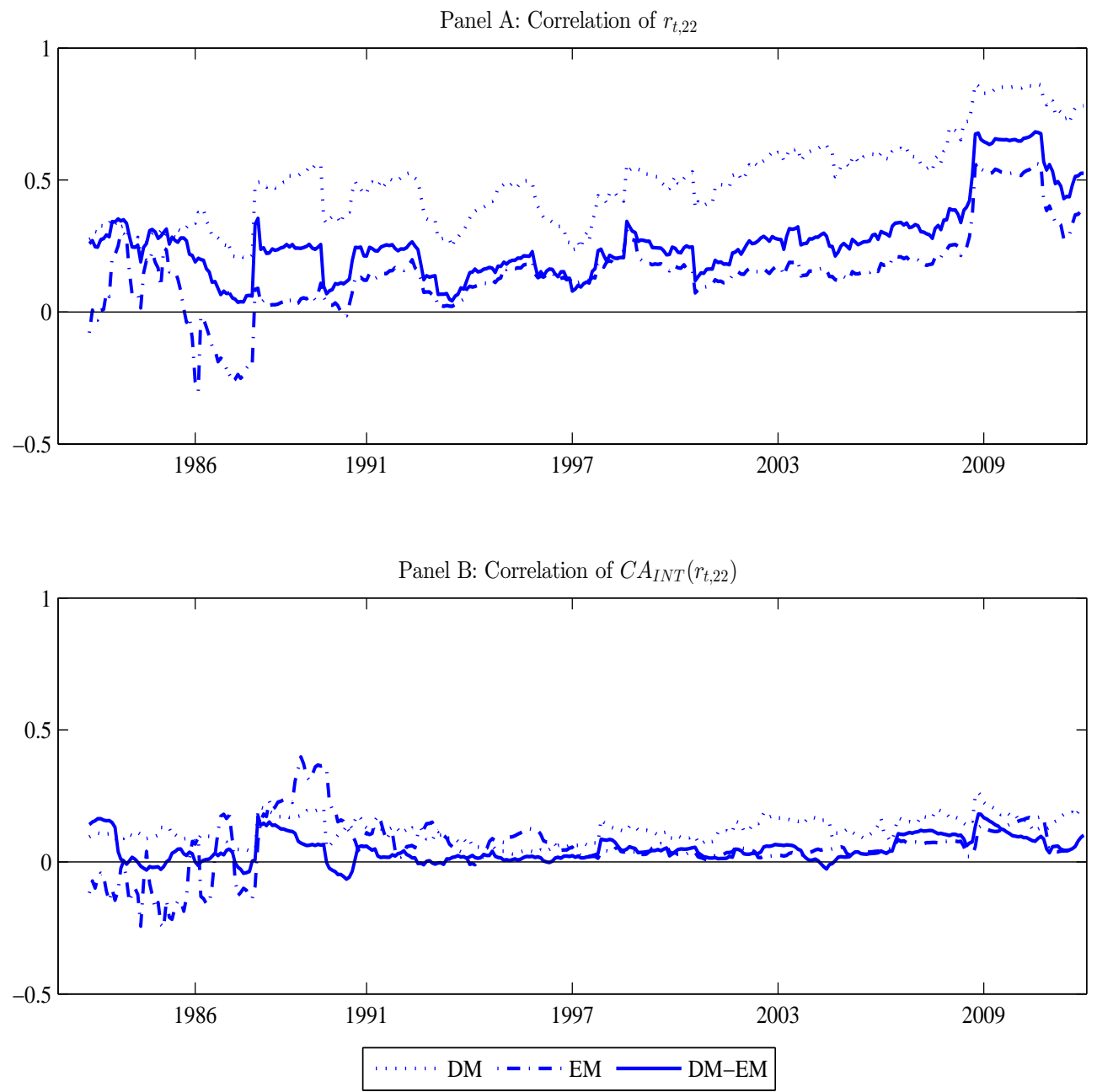
Figure 6: International Portfolio Allocation

Optimal fraction invested in Emerging Markets from the quarterly dynamic portfolio allocation policy estimates of Table 5, specification (4). The top plot displays the sum (solid line, $\bar{w}_{E M, t-1}$ ) and the cross-sectional minimum (dotted line) and maximum (dash-dot line) for the weights to EM. The bottom plot graphs the sum (solid line, $\bar{w}_{E M, t-1}^{C A}$ ) and the cross-sectional minimum (dotted line) and maximum (dash-dot line) for the weights to EM from conditioning on the integrated conditional asymmetry measure $C A_{I N T, t-1}\left(r_{t, 66}\right)$. The gray areas highlight months that are marked as recessions by the National Bureau of Economic Research.
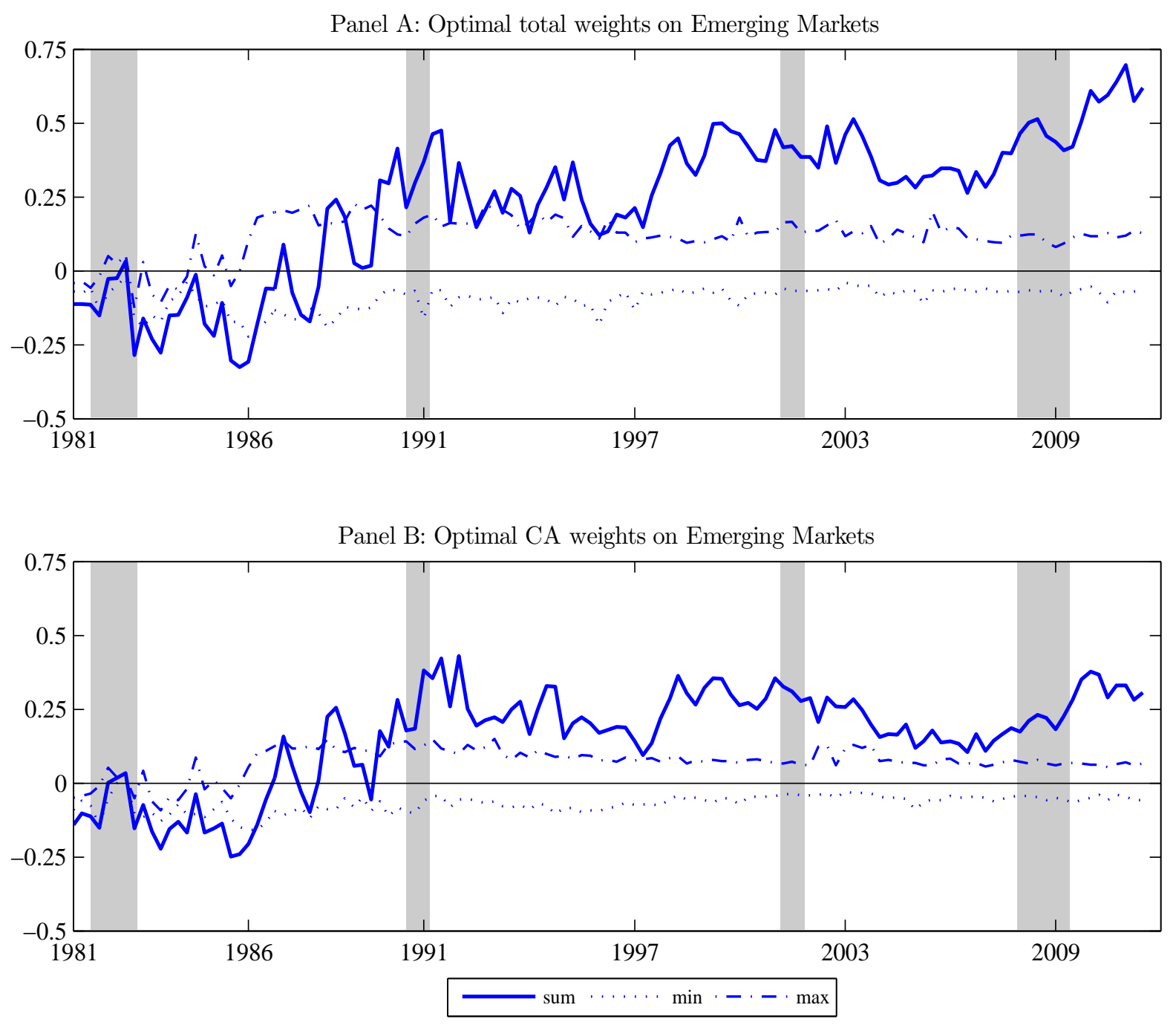


\section{Technical Appendix}

\section{A Specification, Estimation and Testing of Quantiles}

We follow Ghysels, Santa-Clara, and Valkanov (2006) and specify the weighting scheme $w_{d}\left(\kappa_{\theta, n}\right)$ in quantile regression (9) as:

$$
\lambda_{d}\left(\kappa_{\theta, n}\right)=\frac{f\left(\frac{d}{D}, \kappa_{1, \theta, n} ; \kappa_{2, \theta, n}\right)}{\sum_{d=1}^{D} f\left(\frac{d}{D}, \kappa_{1, \theta, n} ; \kappa_{2, \theta, n}\right)}
$$

where: $f(z, a, b)=z^{a-1}(1-z)^{b-1} / \beta(a, b)$ and $\beta(a, b)$ is based on the Gamma function, or $\beta(a, b)$ $=\Gamma(a) \Gamma(b) / \Gamma(a+b) .{ }^{24} \mathrm{~A}$ main advantage of this "Beta" function is its well-known flexibility. It can take many shapes, including flat weights, gradually declining weights as well as hump-shaped patterns. For instance, equal weights obtain when $\kappa_{1}=\kappa_{2}=1$, whereas for $\kappa_{1}=1$ and $\kappa_{2}>1$ the $\lambda_{d}\left(\kappa_{\theta, n}\right)$ exhibit a slowly decaying pattern that is typical for many time-series filters. The weights are normalized to add up to one which allows us to identify a scale parameter $\beta_{\theta, n}$.

We estimate the parameters $\delta_{\theta, n}$ in (8) and (9) with non-linear least squares. More specifically, for a given quantile $\theta$ and horizon $h$ we define

$$
\hat{\delta}_{\theta, n}:=\underset{\delta_{\theta, n}}{\arg \min } T^{-1} \sum_{t=1}^{T} \rho_{\theta, n}\left(e_{\theta, n, t}\right)
$$

where $e_{\theta, n, t}=r_{t, n}-q_{\theta, t-1}\left(r_{t, n} ; \delta_{\theta, n}\right), \rho_{\theta, n}\left(e_{\theta, n, t}\right)=\left(\theta-1\left\{e_{\theta, n, t}<0\right\}\right) e_{\theta, n, t}$ is the usual "check" function used in quantile regressions. The novelty here is the MIDAS structure in the nonlinear quantile estimation. Under suitable regularity conditions, $\hat{\delta}_{\theta, n}$ is consistent and asymptotically normally distributed with a variance-covariance matrix that can be consistently estimated. ${ }^{25}$ Once we have estimates of $q_{1-\theta, t-1}\left(r_{t, n} ; \delta_{1-\theta, n}\right), q_{0.50, t-1}\left(r_{t, n} ; \delta_{0.50, n}\right)$ and $q_{\theta, t-1}\left(r_{t, n} ; \delta_{\theta, n}\right)$, we substitute them into expression (3) and obtain an estimate of the conditional skewness measure $C A_{\theta, t-1}\left(r_{t, n}\right) .{ }^{26}$ The unrestricted estimation of equation (A.2) turned out to be quite challenging, especially for those countries with short time series. Therefore, to facilitate estimation we impose a downward-sloping weighting scheme for the MIDAS polynomial by restricting $\kappa_{1, \theta, n}=1$ and $\kappa_{2, \theta, n} \geq 1$. Relaxing this assumption does not however alter the main message and findings of the paper.

\footnotetext{
${ }^{24}$ Ghysels, Sinko, and Valkanov (2006) and Ghysels (2013) discuss the properties of (A.1) and other lag specifications in detail. ${ }^{25}$ See Koenker and Bassett (1978), White (1996), Weiss (1991), Engle and Manganelli (2004), Koenker and Xiao (2006), among others.

${ }^{26}$ We estimate the quantiles separately. A joint estimating, while theoretically more efficient, has proven difficult to implement in practice.
} 
Table A.1: CAViaR Conditional Quantile Estimates of U.S., China, and the World Portfolio Returns

Estimates of the asymmetric absolute value CAViaR model for the 5th, 25th, 50th, 75th, and 95th conditional quantiles of stock returns to the U.S., China, and World index. $p$-values based on HAC standard errors appear in parenthesis below the estimates. The row 'Coverage' reports the unconditional coverage associated to each quantile, with underneath the $p$-value of the Kupiec (1995) test of the null that Coverage equals $\theta$. The row 'Correl. MIDAS-CAViaR' displays the correlation between the monthly series of quantiles estimates using MIDAS and CAViaR.

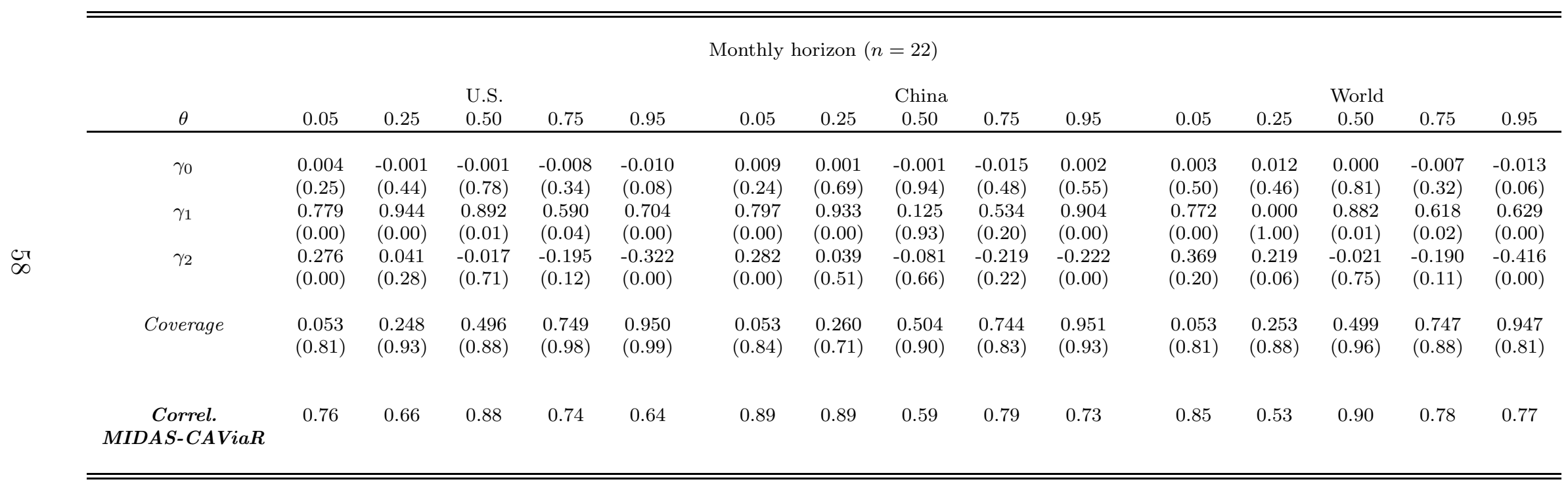


Table A.2: MIDAS Conditional Quantile Estimates of U.S., China, and the World Portfolio de-TACHED Returns

Estimates of the MIDAS model (equations (8) - (9)) for the 5th, 25th, 50th, 75th, and 95th conditional quantiles of de-TARCHed monthly stock returns to the U.S., China, and World index. de-TARCHed monthly returns are obtained by fitting a Glosten, Jagannathan, and Runkle (1993) TARCH(1,1,1) model to monthly (22-day) non-overlapping returns. $p$-values appear in parenthesis below the estimates. For $\kappa_{2}$, the null hypothesis is $\kappa_{2}=1$. The row 'Coverage' reports the unconditional coverage associated to each quantile, with underneath the $p$-value of the Kupiec (1995) test of the null that Coverage equals $\theta$. The row 'Correl. simple-deTARCHed' displays the correlation between the monthly series of MIDAS quantiles estimates of simple versus deTARCHed returns.

\begin{tabular}{|c|c|c|c|c|c|c|c|c|c|c|c|c|c|c|c|}
\hline$\theta$ & 0.05 & 0.25 & $\begin{array}{l}\text { U.S. } \\
0.50\end{array}$ & 0.75 & 0.95 & 0.05 & 0.25 & $\begin{array}{l}\text { China } \\
0.50\end{array}$ & 0.75 & 0.95 & 0.05 & 0.25 & $\begin{array}{c}\text { World } \\
0.50\end{array}$ & 0.75 & 0.95 \\
\hline$\alpha$ & $\begin{array}{r}-0.002 \\
(0.71)\end{array}$ & $\begin{array}{l}0.000 \\
(0.98)\end{array}$ & $\begin{array}{l}0.004 \\
(0.00)\end{array}$ & $\begin{array}{l}0.007 \\
(0.00)\end{array}$ & $\begin{array}{l}0.007 \\
(0.00)\end{array}$ & $\begin{array}{c}-0.013 \\
(0.05)\end{array}$ & $\begin{array}{r}-0.005 \\
(0.01)\end{array}$ & $\begin{array}{l}0.000 \\
(0.79)\end{array}$ & $\begin{array}{l}0.004 \\
(0.04)\end{array}$ & $\begin{array}{l}0.012 \\
(0.00)\end{array}$ & $\begin{array}{c}-0.006 \\
(0.64)\end{array}$ & $\begin{array}{r}-0.002 \\
(0.51)\end{array}$ & $\begin{array}{c}0.001 \\
(0.57)\end{array}$ & $\begin{array}{l}0.006 \\
(0.01)\end{array}$ & $\begin{array}{l}0.002 \\
(0.40)\end{array}$ \\
\hline$\beta$ & $\begin{array}{r}-1.775 \\
(0.02)\end{array}$ & $\begin{array}{r}-0.510 \\
(0.16)\end{array}$ & $\begin{array}{c}-0.176 \\
(0.22)\end{array}$ & $\begin{array}{l}0.244 \\
(0.32)\end{array}$ & $\begin{array}{l}1.041 \\
(0.00)\end{array}$ & $\begin{array}{r}-0.190 \\
(0.57)\end{array}$ & $\begin{array}{c}-0.041 \\
(0.75)\end{array}$ & $\begin{array}{l}0.066 \\
(0.41)\end{array}$ & $\begin{array}{l}0.164 \\
(0.17)\end{array}$ & $\begin{array}{l}0.408 \\
(0.00)\end{array}$ & $\begin{array}{r}-1.519 \\
(0.50)\end{array}$ & $\begin{array}{r}-0.498 \\
(0.26)\end{array}$ & $\begin{array}{l}0.214 \\
(0.46)\end{array}$ & $\begin{array}{l}0.384 \\
(0.24)\end{array}$ & $\begin{array}{l}2.323 \\
(0.00)\end{array}$ \\
\hline$\kappa_{2}$ & $\begin{array}{l}4.185 \\
(0.45)\end{array}$ & $\begin{array}{l}2.772 \\
(0.60)\end{array}$ & $\begin{array}{l}41.494 \\
(0.78)\end{array}$ & $\begin{array}{l}1.076 \\
(0.97)\end{array}$ & $\begin{array}{l}2.211 \\
(0.36)\end{array}$ & $\begin{array}{l}3.189 \\
(0.96)\end{array}$ & $\begin{array}{l}1.291 \\
(0.99)\end{array}$ & $\begin{array}{c}75.000 \\
(0.81)\end{array}$ & $\begin{array}{l}75.000 \\
(0.64)\end{array}$ & $\begin{array}{c}38.744 \\
(0.20)\end{array}$ & $\begin{array}{l}1.099 \\
(0.98)\end{array}$ & $\begin{array}{l}2.452 \\
(0.72)\end{array}$ & $\begin{array}{l}1.000 \\
(1.00)\end{array}$ & $\begin{array}{l}1.000 \\
(1.00)\end{array}$ & $\begin{array}{l}4.027 \\
(0.16)\end{array}$ \\
\hline Coverage & $\begin{array}{l}0.051 \\
(0.92)\end{array}$ & $\begin{array}{l}0.253 \\
(0.90)\end{array}$ & $\begin{array}{l}0.495 \\
(0.84)\end{array}$ & $\begin{array}{l}0.755 \\
(0.81)\end{array}$ & $\begin{array}{l}0.944 \\
(0.58)\end{array}$ & $\begin{array}{l}0.055 \\
(0.74)\end{array}$ & $\begin{array}{l}0.236 \\
(0.62)\end{array}$ & $\begin{array}{l}0.502 \\
(0.95)\end{array}$ & $\begin{array}{l}0.747 \\
(0.91)\end{array}$ & $\begin{array}{l}0.945 \\
(0.74)\end{array}$ & $\begin{array}{l}0.048 \\
(0.89)\end{array}$ & $\begin{array}{l}0.253 \\
(0.90)\end{array}$ & $\begin{array}{l}0.503 \\
(0.92)\end{array}$ & $\begin{array}{l}0.750 \\
(1.00)\end{array}$ & $\begin{array}{l}0.938 \\
(0.31)\end{array}$ \\
\hline $\begin{array}{c}\text { Correl. } \\
\text { simple-deTARCHed }\end{array}$ & 0.99 & 1.00 & -0.56 & 0.75 & 0.74 & 1.00 & 0.99 & 1.00 & 0.88 & 0.97 & 0.96 & 0.96 & 1.00 & 0.87 & 0.99 \\
\hline
\end{tabular}


Figure A.1: Conditional quantiles estimates of U.S. and China Portfolio Returns, MIDAS and CAViaR

The figure displays the 5th, 25th, 75th, and 95th conditional quantiles of monthly (22-day) returns to the U.S. (top plot) and China. The solid series refer to MIDAS estimates, while dashed lines denote CAViaR estimates. The gray areas highlight months that are marked as recessions by the National Bureau of Economic Research.

U.S.

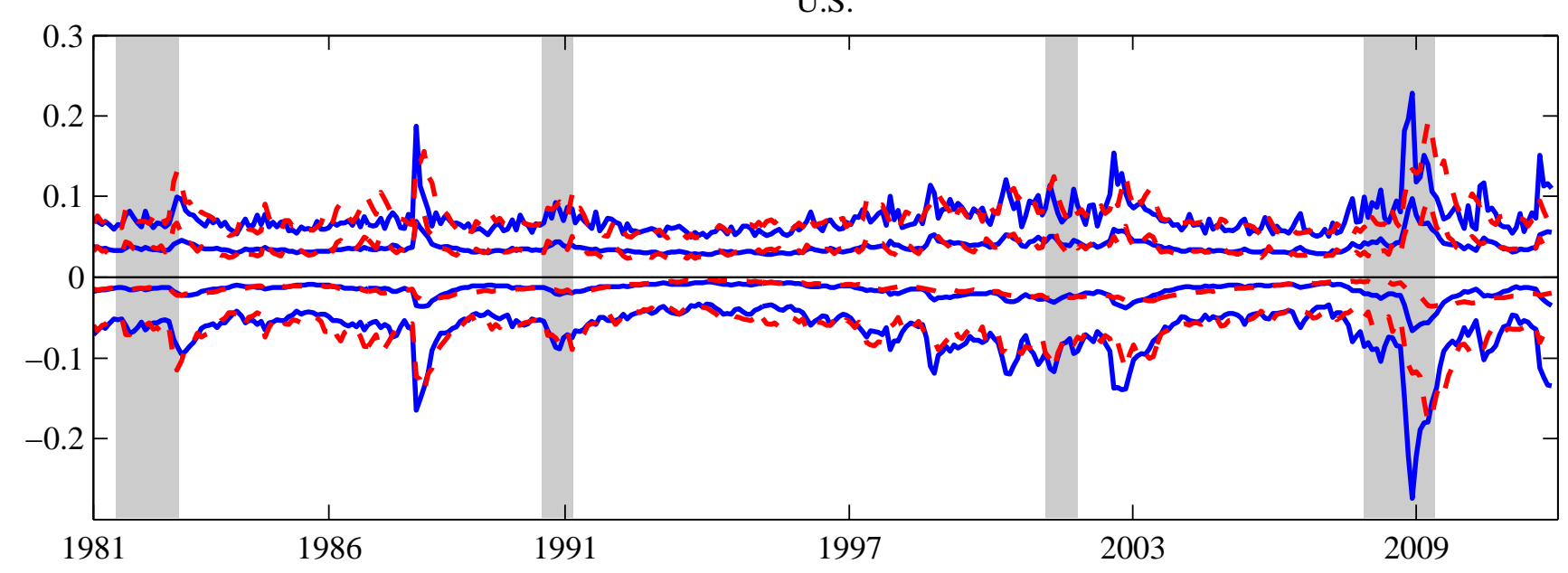

China

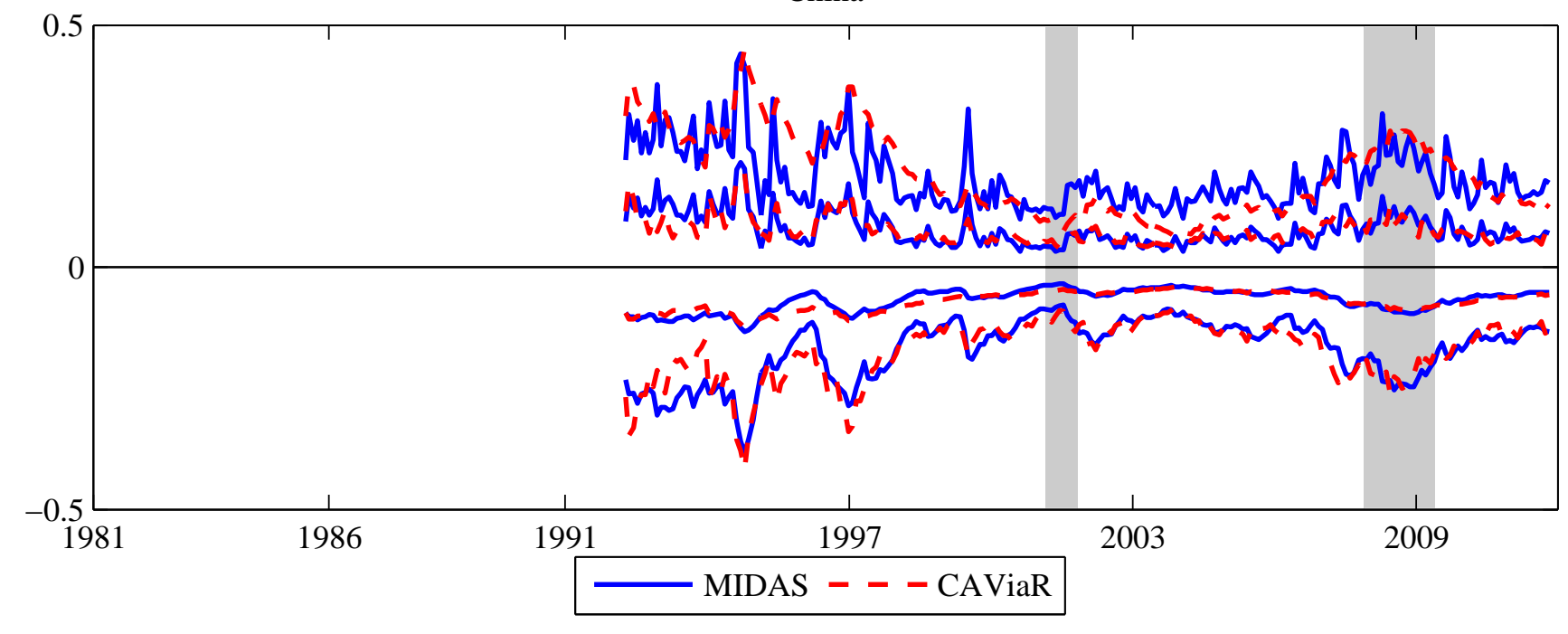


Figure A.2: MIDAS Conditional quantiles estimates of U.S. and China Portfolio deTARCHed Returns

The figure displays the monthly series of the 5th, 25th, 75th, and 95th MIDAS conditional quantiles of deTARCHed returns to the U.S. (left plot) and China (right plot). deTARCHed monthly returns are obtained by fitting a Glosten, Jagannathan, and Runkle (1993) TARCH(1,1,1) model to monthly (22-day) non-overlapping returns. The quantiles are obtained from the estimates in Table A.2. The gray areas highlight months that are marked as recessions by the National Bureau of Economic Research.
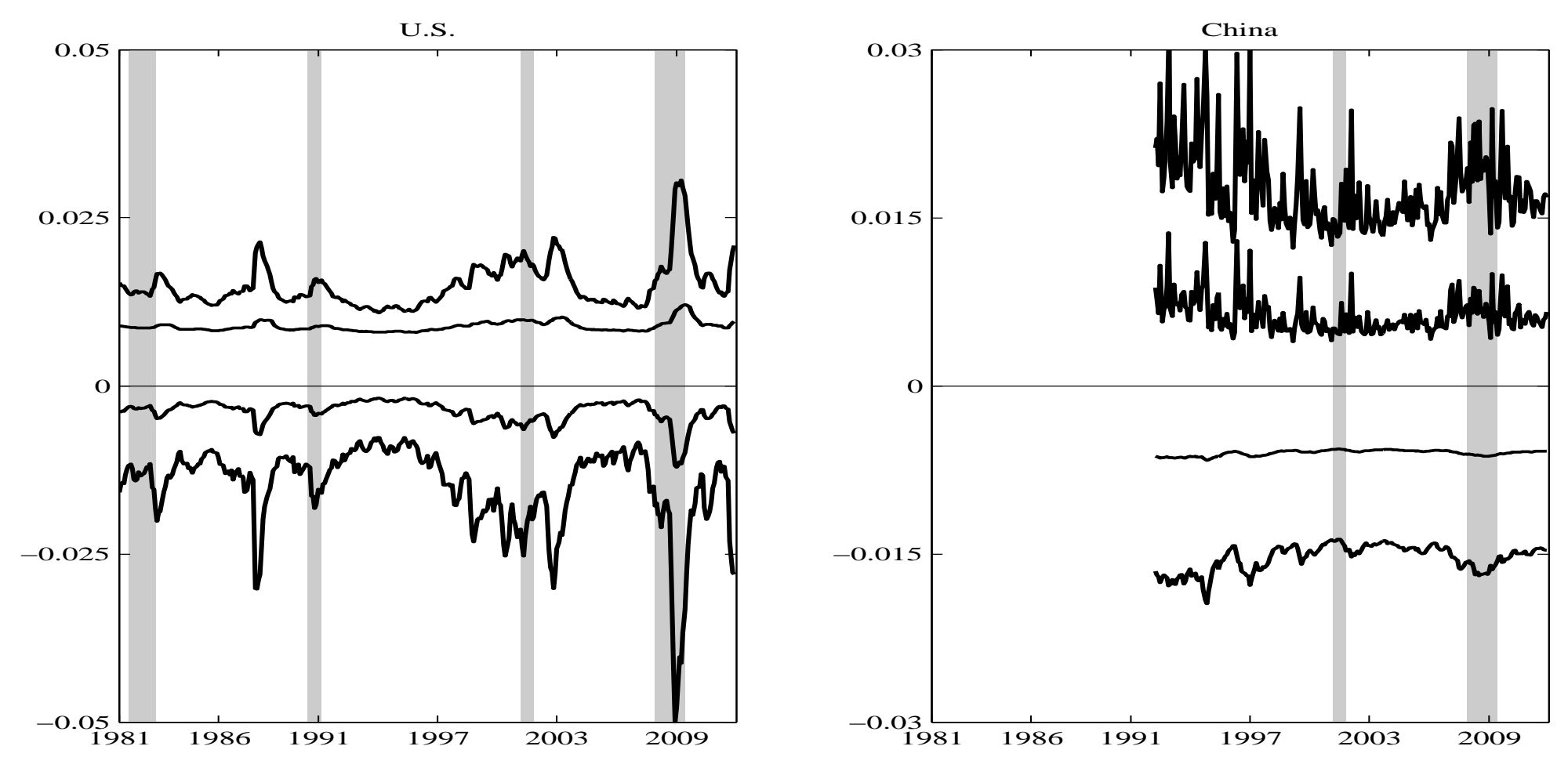